Aus der Poliklinik für Zahnärztliche Prothetik

(Prof. Dr. Ralf Bürgers)

im Zentrum Zahn-, Mund- und Kieferheilkunde

der Medizinischen Fakultät der Universität Göttingen

\title{
Zusammensetzung der mikrobiellen \\ Flora auf der Zunge und im Speichel bei frühkindlicher Karies
}

\author{
INAUGURAL-DISSERTATION \\ zur Erlangung des Doktorgrades \\ (für Zahnheilkunde) \\ der Medizinischen Fakultät der \\ Georg-August-Universität zu Göttingen
}

vorgelegt von

Christiana Hanhus, geb. Landrath

aus

Braunschweig

Göttingen 2019 
Dekan:

Prof. Dr. rer. nat. H.K. Kroemer

\section{Betreuungsausschuss}

Betreuer/in

Prof. Dr. med. N. Miosge

Ko-Betreuer/in:

Prof. Dr. med. dent. A. Wiegand

\section{Prüfungskommission}

Referent/in:

Prof. Dr. med. N. Miosge

Ko-Referent/in:

Prof. Dr. med. dent. A. Wiegand

Drittreferent/in:

Prof. Dr. med. U. Groß

Datum der mündlichen Prüfung: 15.10.2020 
Hiermit erkläre ich, die Dissertation mit dem Titel "Zusammensetzung der mikrobiellen Flora auf der Zunge und im Speichel bei frühkindlicher Karies" eigenständig angefertigt und keine anderen als die von mir angegebenen Quellen und Hilfsmittel verwendet zu haben.

Göttingen, den 


\section{Inhaltsverzeichnis}

Abbildungsverzeichnis.................................................................................. III

Tabellenverzeichnis ......................................................................................... III

Abkürzungsverzeichnis......................................................................................

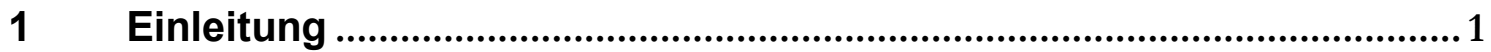

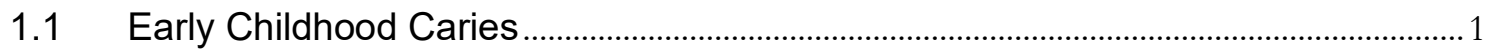

1.1.1 Definition: ECC-Typen .........................................................................................................2

1.1.2 Epidemiologie der frühkindlichen Karies ...........................................................................

1.1.3 Pathogenese von Karies............................................................................................

1.1.4 Ätiologie der frühkindlichen Karies..............................................................................

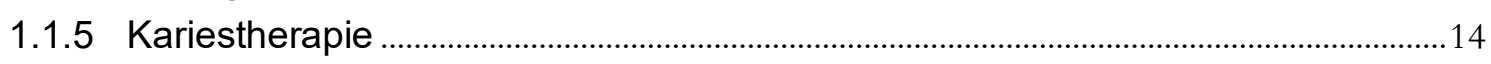

1.2 Mikrobiom der Mundhöhle.......................................................................................................16

1.2.1 Orales Mikrobiom bei Erwachsenen.................................................................................16

1.2.2 Orales Mikrobiom bei Kindern..................................................................................................21

1.3 Ziele der Arbeit ...................................................................................................................................24

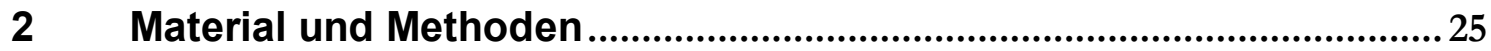

2.1 Mitwirkende und Ethikvotum...................................................................................................25

2.2 Standardisierung der klinischen Untersuchung und Probenentnahme...................26

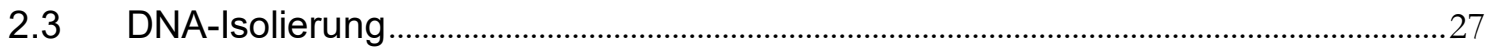

2.4 Herstellung von 16S rRNA-Amplikons..............................................................................28

2.4.1 PCR (Polymerase-Ketten-Reaktion) ………………………………………………......28

2.4.2 Gelelektrophorese und Aufreinigung des PCR-Produktes...........................................31

2.4.3 DNA-Konzentrationsmessung.........................................................................................

2.5 Sequenzierung und Datenauswertung …………………………………………………....36

2.6 Statistische Analyse ................................................................................................................

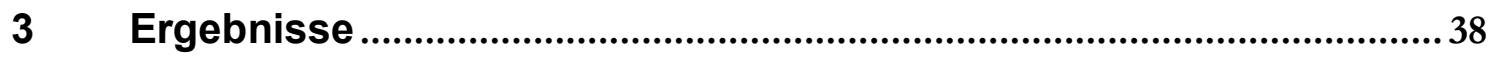

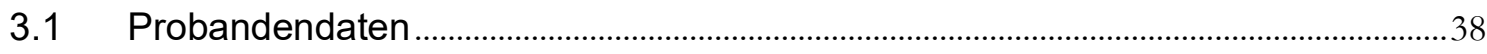

3.2 Mikrobiologische Daten ..................................................................................................3

3.2.1 Qualität der Proben ..................................................................................................................39

3.2.2 Taxonomie .............................................................................................................................

3.2.3 Vergleichende Analyse der Proben ……………………..................................................42

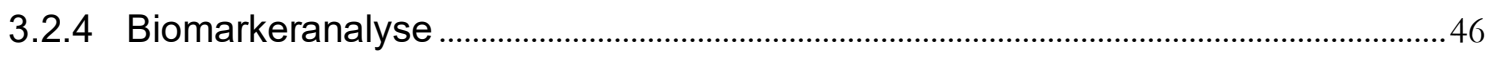

3.2.5 Shannon-Diversität.....................................................................................................................4 


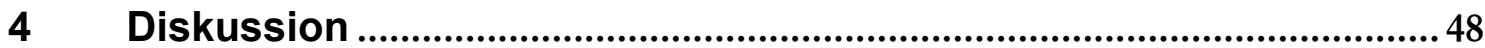

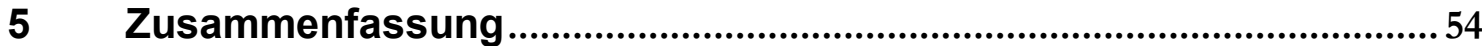

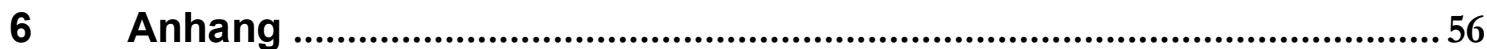

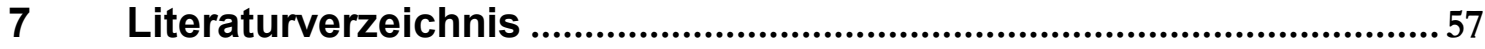




\section{Abbildungsverzeichnis}

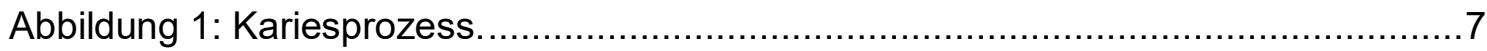

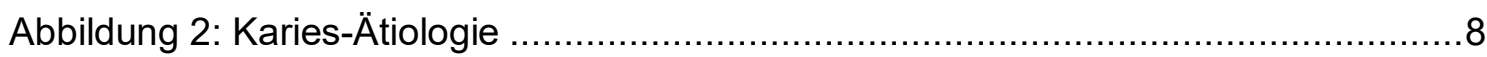

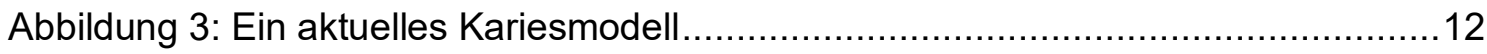

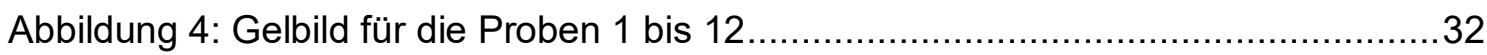

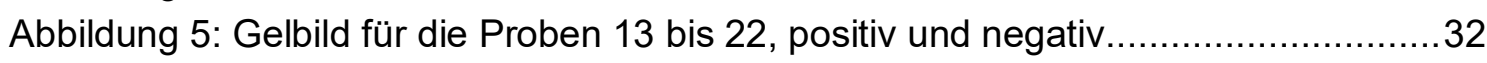

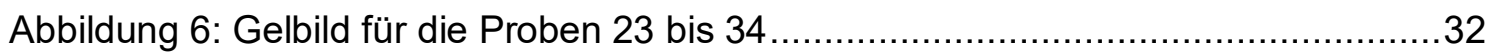

Abbildung 7: Gelbild für die Proben 35 bis 44 , positiv und negativ............................ 33

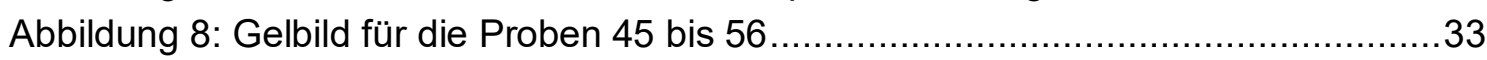

Abbildung 9: Gelbild für die Proben 57 bis 60 , positiv und negativ.............................33

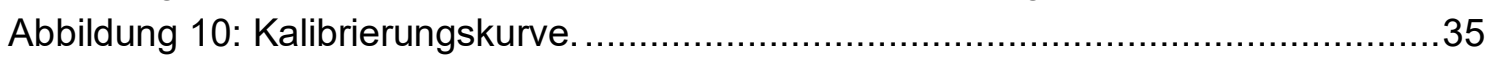

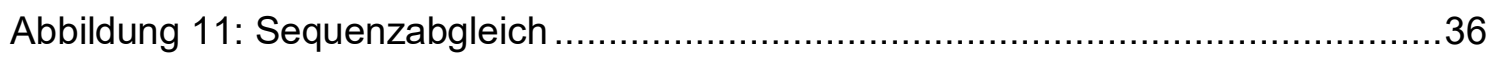

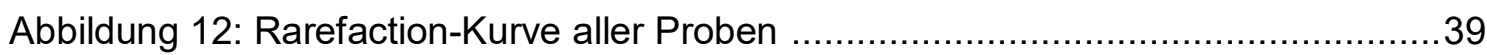

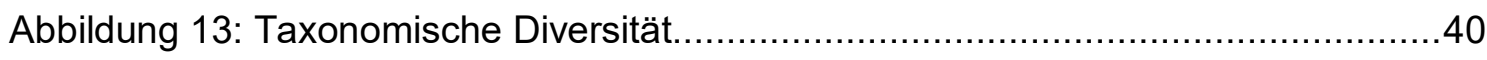

Abbildung 14: Taxonomische Zuordnung der OTUs ............................................41

Abbildung 15: Hauptkomponentenanalyse der verschiedenen ECC-Typen.................42

Abbildung 16: Hauptkomponentenanalyse der Proben nach Alter ................................43

Abbildung 17: Hauptkomponentenanalyse der Proben nach Geschlecht.....................44

Abbildung 18: Hauptkomponentenanalyse der Zungen- und Speichelproben...............45

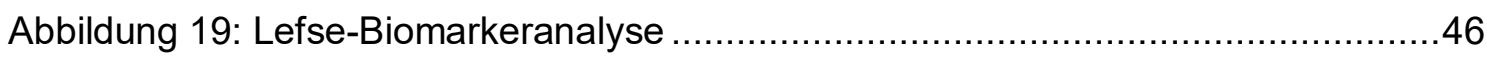

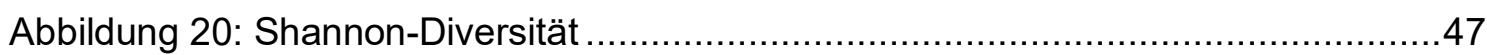

\section{Tabellenverzeichnis}

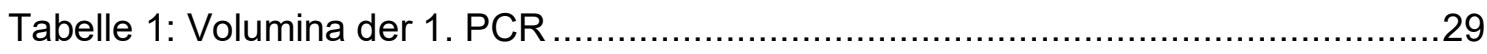

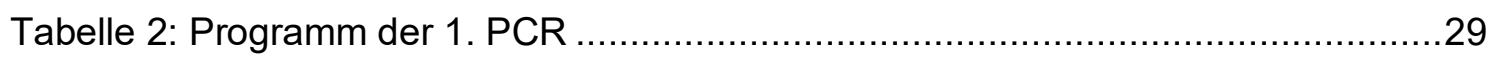

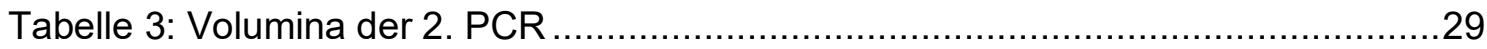

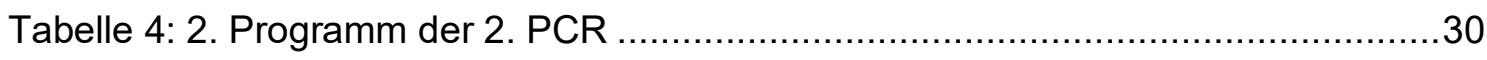

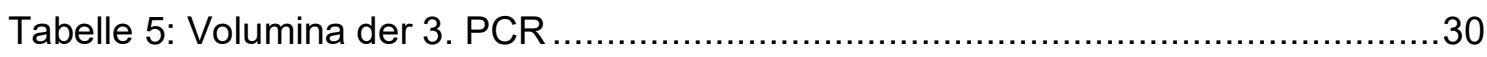

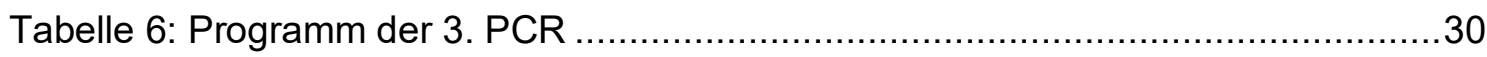

Tabelle 7: Sequenzen der verwendeten Primer..................................................... 31

Tabelle 8: Top 5 Arten, Top 5 Gattungen, Top 5 Stämme ..........................................41 


\section{Abkürzungsverzeichnis}

$\begin{array}{ll}\text { bp } & \text { Basenpaare } \\ \text { DGZMK } & \text { Deutsche Gesellschaft für Zahn-, Mund- und Kieferheilkunde } \\ \text { dmft } & \text { decayed missed filled teeth } \\ \text { EAPD } & \text { European Academy of Paediatric Dentistry } \\ \text { ECC } & \text { Early Childhood Caries (frühkindliche Karies) } \\ \text { FDI } & \text { Fédération Dentaire Internationale/World Dental Federation } \\ \text { HIV } & \text { Humanes Immundefizienz-Virus } \\ \text { HOMD } & \text { Human Oral Microbiome Database } \\ \text { HPV } & \text { Humane Papillomviren } \\ \text { MS } & \text { Mutans Streptococci } \\ \text { OTU } & \text { Operational Taxonomic Unit } \\ \text { PCR } & \text { Polymerase-Chain-Reaction (Polymerase-Kettenreaktion) } \\ \text { pufa } & \text { pulpal involvement, ulceration, fistula, abscess } \\ \text { RKI } & \text { Robert Koch-Institut } \\ \text { S-ECC } & \text { Severe Early Childhood Caries (schwerwiegende frühkindliche } \\ & \text { Karies) }\end{array}$




\section{$1 \quad$ Einleitung}

Frühkindliche Karies oder auch Milchzahnkaries (Early Childhood Caries/ECC) ist laut FDI (World Dental Federation) ein weltweites Problem (FDI 2015). Alleine in Deutschland leiden laut RKI (Robert Koch-Institut) ca. 15\% der sechs Jahre alten Kinder an ECC (RKI 2008). ECC ist eine multifaktorielle Erkrankung. Dabei sind vor allem die Mund- und Zahnhygiene sowie die Ernährung von Bedeutung. Eine wichtige Rolle spielen auch bestimmte Komponenten des Speichels sowie seine mikrobielle Flora, da diese die De- und Remineralisation der Zähne beeinflussen (Borutta et al. 2010). Bisher ist nicht bekannt, ob bei verschiedenen ECC-Typen die Zungen- und Speichelflora eine signifikante Veränderung aufweist und als Reservoir für Pathogene der Zahnplaque dienen kann.

\subsection{Early Childhood Caries}

Orale Gesundheit gehört zu der allgemeinen Gesundheit und ist ein wichtiger Faktor für die normale Entwicklung eines Kindes. So können orale Krankheiten die allgemeine Entwicklung und Gesundheit eines Kindes beeinflussen und somit die Lebensqualität beeinträchtigen (Petersen 2009). Frühkindliche Karies ist die häufigste chronische Erkrankung im Kindesalter (Colak et al. 2013). Sowohl in Entwicklungsländern als auch in Industrienationen stellt ECC ein ernsthaftes Problem dar (Livny et al. 2007). Normalerweise sind Fissuren, Grübchen und Approximalräume zwischen den Zähnen die Stellen mit dem höchsten Kariesrisiko, da dort die Plaque schwerer entfernt werden kann und somit kariöse Läsionen problemlos fortschreiten können. Bei ECC sind schon im frühen Stadium die glatten Flächen der Oberkieferschneidezähne betroffen, wohingegen bei allen anderen Kariesformen diese erst im späten Stadium befallen werden (Borutta et al. 2010). Untere Schneidezähne sind seltener betroffen, da sie durch die Zunge geschützt sind und die naheliegenden großen Speicheldrüsen durch die Speichelproduktion die Plaquebildung hemmen können. Bei den oberen Schneidezähnen fällt dieser Schutz weg, da der Speichel aus den kleinen Speicheldrüsen des Gaumens und der Lippen in geringeren Mengen produziert wird und die oberen Zähne nicht derart umspülen kann, wie es bei den Zähnen des Unterkiefers der Fall ist (Borutta et al. 2010). 


\subsubsection{Definition: ECC-Typen}

Es wurde oft versucht, eine passende Definition und Unterteilung für frühkindliche Karies zu finden. Eine einzige Definition, bei welcher sowohl die Anzahl der Läsionen, als auch die Zahl der involvierten Zähne und das Alter des Kindes berücksichtigt werden, ist schwer zu realisieren. Wyne unterteilt ECC im Jahr 1999 in drei noch immer geläufige Basisformen (Wyne 1999):

Typ 1 (mild bis moderat)-ECC

Bei dieser milden bis moderaten Form sind einzelne kariöse Läsionen vorhanden, wobei Molaren und/oder Inzisiven betroffen sein können. Die Ursache ist in der Regel eine Kombination aus kariogenen Nahrungsmitteln und mangelnder Mundhygiene. Das typische Alter der Kinder bei dieser Form beträgt 2 bis 5 Jahre.

Typ 2 (moderat bis schwerwiegend)-ECC

Bei dieser Form sind die labiolingualen Flächen der oberen Inzisiven von Karies betroffen. Molaren können ebenfalls betroffen sein, in Abhängigkeit vom Alter des Kindes und dem Fortschritt der Krankheit. Nicht betroffen sind hierbei die unteren Inzisiven. Als Ursachen gelten das Trinken aus Nuckelflaschen (zumeist zuckerhaltige Getränke) oder auch Stillen in Kombination mit schlechter Mundhygiene (Ripa, 1988). Dieser Typ tritt kurz nach dem Durchbruch des ersten Milchzahns auf und kann sich bei fehlendem Einschreiten zum Typ 3-ECC weiterentwickeln.

\section{Typ 3 (schwerwiegend)-ECC}

Bei dieser schwerwiegenden Form der ECC sind fast alle Zähne betroffen, wozu auch die unteren Inzisiven zählen. Die Ursache liegt wiederum in der Kombination aus kariogener Nahrung und mangelhafter Mundhygiene. Dieser Zustand findet sich bei Kindern im Alter von drei bis fünf Jahren wieder. Der Zustand ist rasch fortschreitend und greift Zahnflächen an, die normalerweise nicht von Karies betroffen sind. 


\subsubsection{Epidemiologie der frühkindlichen Karies}

Trotz steigender Prophylaxemaßnahmen in den westlichen Ländern bleibt die frühkindliche Karies ein Problem sowohl in Industriestaaten als auch in Entwicklungsländern (Vadiakas 2008). Laut verschiedener Studien aus Europa, Afrika, Asien, dem Mittleren Osten und Nordamerika wurde die höchste Kariesprävalenz in Afrika und Südostasien festgestellt (Milnes 1996). Nach einer aktuellen Studie aus Südostasien liegt die Kariesprävalenz bei fünf- bis sechsjährigen Kindern in den verschiedenen Ländern zwischen 25\% und 95\%, wobei im Durchschnitt 79\% an ECC erkrankt sind (Duangthip et al. 2016).

Studien aus Ostasien zeigen eine hohe ECC-Prävalenz bei dreijährigen Kindern, die bei 36-85\% liegt (Tsai et al. 2006). In Indien sind 44\% der 8-48 Monate alten Kinder von ECC betroffen (Jose und King 2003). In China kam bei einer Studie aus dem Jahr 2005 heraus, dass $60 \%$ der drei bis fünf Jahre alten Kinder an ECC erkrankt sind (Zeng et al. 2005). Studien zeigen, dass die ECC-Prävalenz bei Dreijährigen im Mittleren Osten zwischen $22 \%$ und $61 \%$ liegt (Rajab und Hamdan 2002) und in Afrika zwischen $38 \%$ und $45 \%$ (Kiwanuka et al. 2004).

In manchen europäischen Ländern (England, Schweden, Finnland) ist die ECCPrävalenz seltener, wobei die Zahlen zwischen $1 \%$ und $32 \%$ variieren (Douglass et al. 2001). In einigen osteuropäischen Ländern steigt der Anteil der Kinder mit ECC auf bis zu $56 \%$ an (Szatko et al. 2004).

Eine Studie aus den USA beschäftigt sich mit der Kariesprävalenz bei zwei bis fünf Jahre alten Kindern, welche in den Jahren 1988-1994 bei $24 \%$ lag und in den Jahren 1999-2004 auf $28 \%$ angestiegen ist (Tang et al. 1997). In Kanada leiden unter $5 \%$ der Kinder an ECC, wobei der Anteil bei Risikogruppen auf 50$80 \%$ ansteigt. Eine besondere Risikogruppe bilden die Kinder kanadischer Ureinwohner, bei welchen $65 \%$ der Dreijährigen an ECC leiden (Peressini et al. 2004). Ebenfalls stark von ECC betroffen ist mit $46 \%$ die Gruppe der 25-36 Monate alten Kinder in Kanada (Rosenblatt und Zarzar 2002).

Aktuellere Studien zeigen eine ECC-Prävalenz von $23 \%$ in den USA (Dye et al. 2015) und über $60 \%$ in China (Hu et al. 2011). Tinanoff und Kollegen haben 72 Studien zur ECC-Prävalenz aus den Jahren 1998 bis 2018 weltweit zusammengefasst. Dabei schwankte die ECC-Prävalenz bei vierjährigen Kindern zwischen 12 \% (Studie von 2009 aus Frankreich) und 98 \% (Studie von 2014 aus Australien). Die mittlere ECC-Prävalenz betrug bei einjährigen Kindern $17 \%$ und stieg bei den Zweijährigen schon auf $36 \%$ an. Die Werte stiegen bei drei-, vierund fünfjährigen Kindern auf $43 \%, 55 \%$ und $63 \%$ an (Tinanoff et al. 2019). 
In Deutschland wurde in den 1980er Jahren ein Anstieg der Kariesprävalenz bei sehr jungen Kindern beobachtet (Wetzel 1981), woraufhin in Gießen eine Prävalenzstudie durchgeführt wurde. Dabei kam heraus, dass bereits $5 \%$ der einjährigen Kinder an Karies erkrankt waren. Bei den drei- bis vierjährigen Kindern stieg der Anteil der Kinder mit ECC auf $23 \%$ an (Buhl et al. 1989). Neuere Studien aus dem Jahr 2008 zeigen eine ECC-Prävalenz an verschiedenen Orten in Deutschland zwischen 7,3 \% in Dresden und 20,3 \% in Emden (Borutta et al. 2010). Laut einer Gesundheitsstudie des RKI (Robert KochInstitut) aus dem Jahr 2008 hat Karies in Deutschland allgemein in den vergangenen Jahrzehnten deutlich abgenommen (RKI 2008). Dies wurde erzielt durch verbesserte Mundhygiene, wirksame Anwendung von Fluoriden und Inanspruchnahme prophylaktischer Leistungen. Allerdings werden zahnärztliche Kontrolluntersuchungen zu selten wahrgenommen, was laut RKI vor allem Kinder im Alter von drei bis sechs Jahren betrifft (RKI 2008).

Die DAJ-Studie, welche sich mit der Entwicklung der Karieserfahrung in Deutschland beschäftigt, zeigt einen Rückgang der dmft-Mittelwerte bei sechsbis siebenjährigen Kindern von 2,89 dmft in den Jahren 1994/95 auf 1,73 dmft im Jahr 2016. Seit dem Jahr 2000 ist jedoch nur eine geringe Reduktion der Karieserfahrung von 2,21 auf 1,73 dmft festzustellen. Die Kariesprävalenz lag bei den sechs bis sieben Jahre alten Kindern im Jahr 2016 bei 26,9 \%. Nur 56,4 \% der Kinder hatten einen dmft von 0. Im Durchschnitt waren bei Kindern mit Karies 3,96 Milchzähne betroffen. Insgesamt war nur ca. die Hälfte aller kariösen Läsionen versorgt (57,5 \%). Im Jahr 2016 wurde erstmals auch der dmft bei dreijährigen Kindern mitaufgenommen, welcher bei 0,48 lag. Die ECC-Prävalenz lag bei den Dreijährigen bei 13,7 \%, wobei $73 \%$ der kariösen Läsionen unbehandelt waren (DAJ 2016).

Klinische Konsequenzen von unbehandelter Karies in Deutschland bei fünf- bis achtjährigen Kindern wurden von Grund und Kollegen untersucht. Die Prävalenz und Erfahrung von odontogenen Infektionen, sowie die unbehandelte Kariespufa-Rate (Pulpabeteiligung, Ulzerationen, Fisteln, Abszesse) stiegen von den jüngeren zu den älteren Kindern. Die dmft- und pufa-Werte in Milchzähnen sagen somit ein höheres Kariesrisiko in bleibenden Zähnen voraus (Grund et al. 2015).

Bissar und Kollegen untersuchten Faktoren in Südwestdeutschland, die zu schwerwiegender ECC (S-ECC) beitragen. Dazu füllten Eltern von drei- bis fünfjährigen Kindergartenkindern einen Fragebogen aus. Dieser enthielt fünf Variablen: Stillen mehr als zwölf Monate, Nuckelflasche im Bett, Zähneputzen nach dem ersten Geburtstag, regelmäßige Kontrollen beim Zahnarzt und Mutter mit Migrationshintergrund. Zusätzlich fand eine Munduntersuchung der Kinder 
statt, bei der sich eine S-ECC-Prävalenz von 9,5 \% ergab. Als Ergebnis kam heraus, dass das Auftreten von S-ECC eine komplexe Interaktion zwischen sozioökonomischen, psychologischen und verhaltensbezogenen Faktoren der Eltern ist (Bissar et al. 2014).

Ob räumliche Ungleichheiten in ECC durch soziodemografische Merkmale erklärt werden können, wurde von Meyer et al. in der Stadt Braunschweig analysiert. Dazu wurde zwischen 2009 und 2014 der dmft bei drei- bis sechsjährigen Kindern in Kindertagesstätten in verschiedenen Stadtbezirken aufgenommen. Hohe dmftWerte konnten in der Innenstadt festgestellt werden, was mit der Arbeitslosenquote und dem Anteil an Personen mit Migrationshintergrund korrelierte. Als Schlussfolgerung konnte festgehalten werden, dass regionale Cluster mit schlechter Zahngesundheit durch soziodemografische Merkmale erklärt werden können (Meyer et al. 2017).

Um ECC besser vorbeugen zu können, haben Winter und Kollegen ein interdisziplinäres Präventionskonzept entwickelt. Das Programm beinhaltet sieben Informationsimpulse eines interdisziplinären Teams aus Gynäkologen, Hebammen, Kinderärzten, Zahnärzten, städtischen Sozialeinrichtungen und dem Gesundheitsamt. Verglichen wurde dabei die Kariesprävalenz und Karieserfahrung bei drei- und vierjährigen Kindern, die an dem Präventionsprogramm teilgenommen hatten, mit einer gleichaltrigen Kontrollgruppe ohne Teilnahme am Präventionsprogramm. Sowohl der dmft, als auch der Anteil an Kindern mit S-ECC waren bei der Kontrollgruppe deutlich höher als bei der Testgruppe. Dies hat gezeigt, dass ein interdisziplinäres Präventionsprogramm ein effektives Konzept darstellt, um ECC vorzubeugen (Winter et al. 2019). 


\subsubsection{Pathogenese von Karies}

Dentale Karies resultiert aus Interaktionen über einen Zeitraum zwischen säureproduzierenden Bakterien, einem Substrat, das die Bakterien metabolisieren können und verschiedenen Wirtsfaktoren einschließlich Zahn und Speichel. Dentale Karies entsteht aus einem ökologischen Ungleichgewicht im physiologischen Gleichgewicht zwischen Zahnhartsubstanz und oralen mikrobiellen Biofilmen (Fejerskov 2004). Die Bakterien leben auf den Zähnen in Mikrokolonien, eingekapselt in eine organische Matrix aus Polysacchariden, Proteinen und DNA, welche von den Zellen abgegeben wird und als Schutz gegen antimikrobielle Faktoren dient und die Resistenz erhöht (Scheie und Petersen 2004).

Der Mechanismus des Kariesprozesses ist bei allen Kariestypen gleich. Endogene Bakterienarten im Biofilm produzieren organische Säuren als Nebenprodukt in ihrem Kohlenhydratstoffwechsel (Caufield und Griffen 2000). Diese Säuren verursachen lokale niedrige $\mathrm{pH}$-Werte, die unter die kritische Grenze sinken und zur Demineralisierung der Zahnhartsubstanz führen (Featherstone 2000). Wenn die Diffusion von Kalzium, Phosphat und Karbonat aus dem Zahn heraus weiter fortschreitet, kann dies zur Kavitation führen (Featherstone 2004). In frühen Stadien ist die Demineralisation reversibel durch Einnahme von Kalzium, Phosphat und Fluorid. Fluoride dienen dabei als Katalysatoren für die Diffusion von Kalzium und Phosphat in den Zahn, wodurch die kristallinen Strukturen remineralisiert werden. Die remineralisierten Schmelzoberflächen, welche aus fluoridiertem Hydroxylapatit und Fluorapatit bestehen, sind resistenter gegen Säureangriffe als die Originalstruktur (Axelsson 2000). Ob der Kariesprozess stoppt oder fortschreitet, hängt von dem Gleichgewicht zwischen Demineralisation und Remineralisation ab. Diese Prozesse finden bei den meisten Menschen frequenzartig während eines Tages statt. Mit der Zeit führt dieser Prozess entweder zur Kavitation oder zur Reparatur der Läsion oder zur Beibehaltung des momentanen Zustandes (Featherstone 2004). Der Speichel dient dabei als Puffer, um den pH-Wert im Biofilm wiederherzustellen. Die remineralisierten Bereiche haben eine höhere Fluoridkonzentration und weniger Mikroporen in der Schmelzstruktur als die Originalzahnoberfläche aufgrund der Aufnahme von Kalzium und Phosphat aus dem Speichel (Abbildung 1). 


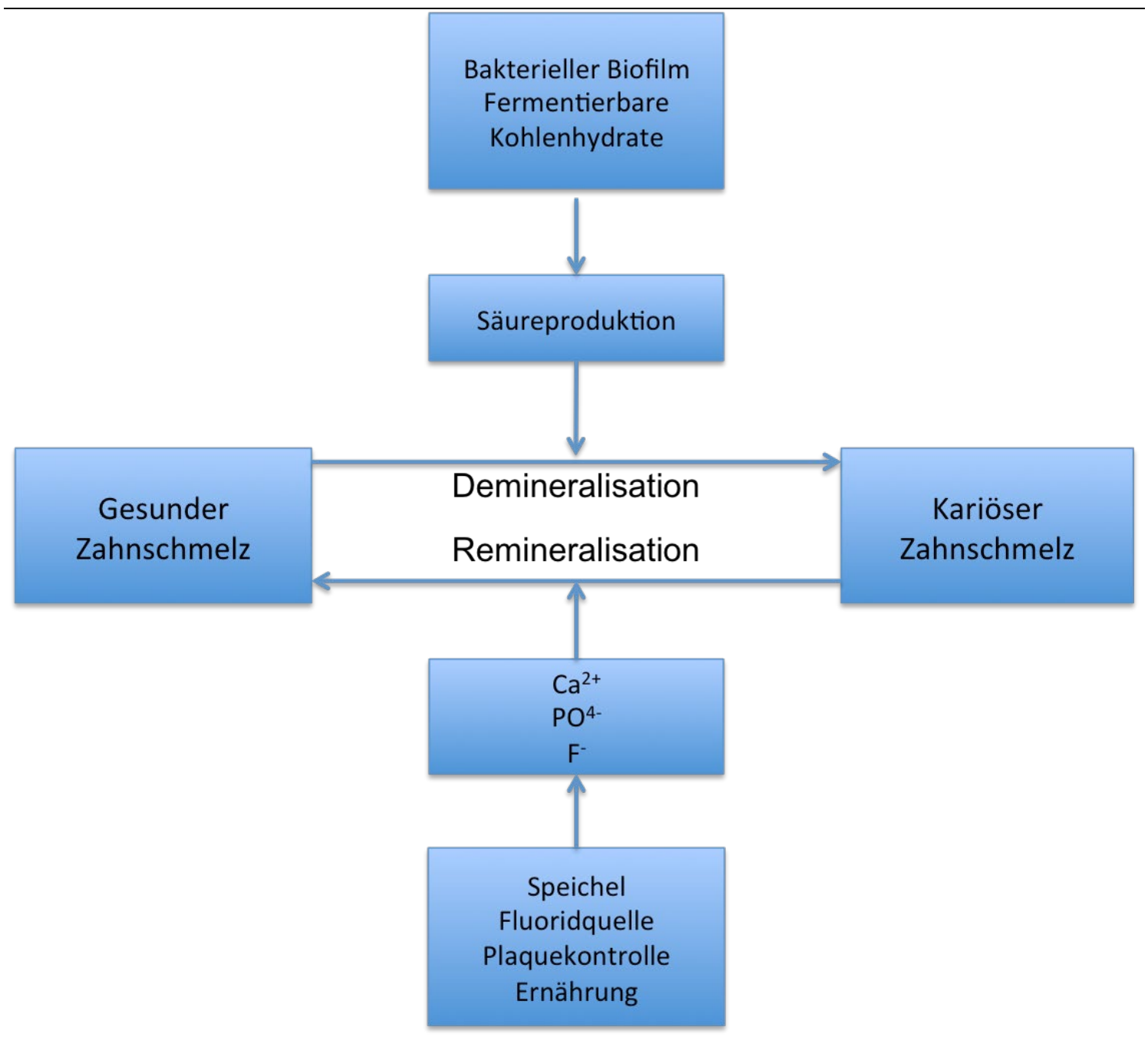

Abbildung 1: Kariesprozess. Der Zahnschmelz ist dauerhaft im Gleichgewicht zwischen Demineralisation durch Säuren und Remineralisation durch Kalzium-und Phosphationen, die mit der Unterstützung von Fluoridionen in den angegriffenen Zahnschmelz eingebaut werden können. Quelle: eigene Darstellung, bearbeitet nach Kidd und Joyston-Bechal

Kariöse Läsionen entwickeln sich dort, wo orale Biofilme für einen langen Zeitraum auf der Zahnoberfläche bestehen können. Wenn sich eine Kavität entwickeln kann, bildet sich eine ökologische Nische, in der sich Plaquebakterien allmählich an einen niedrigen pH-Wert anpassen (Fejerskov 2004). Solange der Patient nicht in der Lage ist, diesen Bereich zu reinigen, kann der kariöse Prozess fortschreiten (Kidd und Fejerskov 2004). 


\subsection{4 Ätiologie der frühkindlichen Karies}

ECC ist eine multifaktorielle Erkrankung. Die Leitlinie der EAPD (European Academy of Paediatric Dentistry) stellt ECC als allgemeines Gesundheitsproblem mit biologischen und sozialen Faktoren sowie Komponenten des individuellen Verhaltens dar (EAPD 2008). Es wurden zunächst drei Hauptfaktoren für die Entstehung von Karies festgelegt: Substrat, Wirt und Mikroorganismen (Keyes 1962). Im Jahr 1971 fügte König noch den Faktor Zeit als vierten Faktor hinzu (König 1971) (Abbildung 2).

\section{Wirts-}

faktoren

\section{Substrat

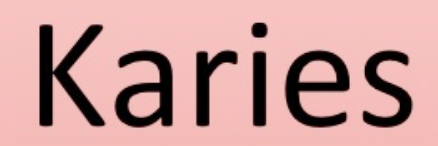 \\ Mikroor- ganismen}

Zeit

Abbildung 2: Karies-Ätiologie. Quelle: Eigene Darstellung, bearbeitet nach „Dental Caries“ (Selwitz et al. 2007)

\subsubsection{Substrat}

Zum Faktor Substrat gehören Kohlenhydrate, welche in der Nahrung vorkommen, von Mikroorganismen verwertet werden und zu Säuren umgesetzt werden können. Dazu zählen Glukose, Fruktose, Maltose, Laktose und Saccharose. Stärkehaltige Produkte werden von dem im Speichel enthaltenen Enzym Amylase an den alpha-1,4-glykosidische Bindungen in Oligo- und 
Disaccharide (Maltose) aufgespalten, welche wiederum von Bakterien metabolisiert werden können (Jensen 1999). Es handelt sich hierbei um sogenannte versteckte Zucker, die z. B. in Brot und anderen Getreideprodukten vorkommen. Bei der Fermentation von Kohlenhydraten produzieren die Bakterien Säuren, was wiederum zum Abfall des pH-Wertes und somit zur Demineralisation des Zahnschmelzes führt (Harel-Raviv et al. 1996). Bei den entstehenden Säuren handelt es sich vor allem um Laktat (Milchsäure).

Das Trinken aus Nuckelflaschen spielt eine zentrale Rolle bei der Entstehung von ECC. Vor allem das Trinken von süßen, zuckerhaltigen Getränken zum Einschlafen fördert die Entstehung von ECC, da kein erneutes Zähneputzen mehr stattfindet und die Zucker über einen langen Zeitraum in der Mundhöhle verbleiben. Es findet somit eine anhaltende Säureproduktion durch die oralen Mikroorganismen statt, wodurch es zur Demineralisation des Zahnschmelzes kommt. Als weiterer Faktor kommt hinzu, dass die Speichelproduktion nachts herabgesetzt ist und somit auch die Remineralisation durch den Speichel schwächer ausfällt (Colak et al. 2013). Dabei sind nicht nur Fruktose-haltige Säfte und Saccharose-haltige Softdrinks schädlich, sondern auch Milch, die Laktose, also Milchzucker, enthält (Hallett und O'Rourke 2002). Durch das Stillen erlangen Säuglinge viele Vorteile, wie z.B. ein gestärktes Immunsystem und ein geringeres Risiko für Magen-Darm- und Atemwegsinfektionen (Kramer und Kakuma 2012). Trotzdem hat eine Reihe von Studien gezeigt, dass auch das Stillen mit einem erhöhten Risiko für ECC verbunden ist, vor allem, wenn die Kinder älter als 12 Monate sind. Durch den in regelmäßigen Abständen stattfindenden und für längere Zeit anhaltenden Kontakt von Zahnschmelz und Muttermilch kommt es zum Abfall des pH-Wertes im Mund und somit zur Demineralisation des Schmelzes (Ramos-Gomez et al. 2010). Entscheidend ist vor allem der Zeitraum über einen Tag gesehen, in dem fermentierbare Kohlenhydrate im Mund verfügbar sind. Steigt dieser Zeitraum an, verschiebt sich das Gleichgewicht zwischen Re- und Demineralisation des Schmelzes auf die Seite der Demineralisation (Ramos-Gomez et al. 2010).

Die Länge des Zeitraums, in welchem der Zucker mit den Zähnen in Kontakt steht, ist dabei der entscheidende Faktor. Es wurde herausgefunden, dass die bakterielle Säureproduktion nach Zuckerzufuhr für 20-40 min anhält. Luke et al. haben in einer Studie die Clearence verschiedener Zucker und Nahrungsmittel in der Mundhöhle untersucht (Luke et al. 1999). Als Zucker verwendeten sie Glukose, Fruktose, Saccharose, Maltose und Sorbitol, als Nahrungsmittel wurden Schokoladenriegel, Weißbrot und Bananen untersucht. Es stellte sich heraus, dass Saccharose am schnellsten verarbeitet wurde, wohingegen Sorbitol und die Nahrungsmittel am längsten im Mund blieben. 
Die Schlussfolgerung hiervon ist, dass die Kariesprävalenz in Ländern am niedrigsten ist, wo der Konsum freier Zucker unter 40-55 g pro Tag liegt (WHO 2003). Am höchsten ist das Kariesrisiko, wenn Zucker in hoher Frequenz konsumiert werden und in Formen, die lange Zeit im Mund verweilen (Misra et al. 2007).

\subsubsection{Wirt}

Es gibt viele Studien über den Zusammenhang zwischen dem sozioökonomischen Status (SES) und ECC. Es stellt sich dabei heraus, dass ECC verstärkt auftritt bei Kindern aus wirtschaftlich schlechter gestellten Familien. Des Weiteren sind vor allem Kinder betroffen, die zu einer ethnischen Minderheit gehören, die allein bei der Mutter leben oder wo die Eltern, vor allem die Mutter, einen niedrigen Bildungsstand aufweisen (Rajab und Hamdan 2002). Diese Kinder haben ein erhöhtes Kariesrisiko aufgrund von erhöhtem Konsum von Zuckern und mangelnder Zufuhr von kariesprophylaktisch wirksamen Fluoriden durch Zahnpasta (Sheiham und Watt 2000). Darüber hinaus wird ein Zusammenhang zwischen ECC und Rauchen während der Schwangerschaft diskutiert (Kellesarian et al. 2017). Weinstein und Kollegen heben in ihrer Studie die deutliche Diskrepanz der ECC Prävalenz zwischen Industrienationen und Entwicklungsländern hervor. Diese beträgt in hoch entwickelten Ländern 1-12 \%, wohingegen in Entwicklungsländern bis zu 70 \% der Kinder an ECC leiden (Weinstein et al. 1994). Andere Studien belegen, dass Kinder von Eltern aus der niedrigsten Einkommensgruppe viermal so hohe dmft-Werte (decayed, missing, filled teeth) haben wie Kinder mit Eltern aus der höchsten Einkommensgruppe (Tang et al. 1997). Auch genetische Faktoren werden diskutiert (Hassell und Harris 1995). Diese können Einfluss auf die Speichelfunktion, Schmelzbildung und Immunantwort nehmen (Vieira 2012). In einer aktuellen Studie wurden die bakterielle Mundflora und die Zahngesundheit von 485 zweieiigen und eineiigen Zwillingen im Alter von fünf bis elf Jahren verglichen. Im Ergebnis zeigte sich, dass eineiige Zwillinge öfter eine ähnliche mikrobielle Zusammensetzung besitzen, dies bezieht sich jedoch vorwiegend auf Bakterienarten, die nicht mit Karies assoziiert werden. Daraus lässt sich schlussfolgern, dass potenziell kariogene Bakterien nicht durch genetische Faktoren, sondern durch Faktoren wie Zahnpflege und Ernährung kontrolliert werden (Gomez et al. 2017).

\subsubsection{Mikroorganismen}

Obwohl Karies häufig als Infektionserkrankung beschrieben wird, ist sie keine echte Infektionserkrankung nach klassischem Verständnis, da sie nicht Kochs Postulate befolgt. Die kariogenen Bakterien gehören zur normalen 
physiologischen Mundflora und besitzen bei kariesfreien Personen ein geringes kariogenes Potential (Takahashi und Nyvad 2008). Als kariogene Mikroorganismen bekannt sind vor allem Streptococcus mutans und Streptococcus sobrinus (Nurelhuda et al. 2010). Diese und auch andere Bakterien sind in der Lage, aus Kohlenhydraten wie Saccharose, Fruktose und Glukose in ihrem Stoffwechsel Säuren zu produzieren (Schafer und Adair 2000). Neuere Studien zeigen, dass S. mutans in der Plaqueflora sowohl bei Kindern mit ECC, als auch bei gesunden Kindern gefunden wird (Ma et al. 2015). Es ist bekannt, dass die initiale Besiedlung mit $S$. mutans bei Kindern in einem ganz bestimmten Altersbereich stattfindet, welcher als Infektionszeitraum (window of infectivity) bezeichnet wird. Caufield und Kollegen fanden heraus, dass diese initiale Besiedlung mit S. mutans im durchschnittlichen Alter von 26 Monaten stattfindet (Caufield et al. 1993). Viele Langzeitstudien zeigen, dass Kinder mit geringem Infektionsgrad in diesem Zeitraum seltener an einer Infektion mit $S$. mutans erkranken und ein geringes Risiko für die Entstehung von Karies haben (Ercan et al. 2007).

Vertikale Transmission, welche auch als Mutter-Kind-Transmission bezeichnet wird, ist die Weitergabe einer Infektion von einem Elternteil auf das Kind. Die meisten Kinder bekommen S. mutans von ihren Müttern. Nachgewiesen wurde dies in Bakteriocin-Typing-Studien (bacteriocin typing studies), bei denen $S$. mutans von Müttern und ihren Kindern isoliert wurde und die gleichen Bakteriocin-Typing-Muster (bacteriocin typing patterns) entdeckt wurden (Davey und Rogers 1984). Das Konzept der vertikalen Transmission wird ebenfalls bestätigt durch weiter fortgeschrittene Technologien, wie die Analyse der chromosomalen DNA-Muster oder die Analyse identischer Plasmide (Caufield et al. 1985).

Neben der Produktion von Laktat sind kariogene Bakterien in der Lage, in ihrem Stoffwechsel aus Glukose extrazelluläre Polysaccharide zu produzieren, welche das Plaquewachstum beschleunigen. Dabei handelt es sich um Polyglukane, welche die Adhäsion und Aggregation von Plaque erleichtern. Außerdem können diese Bakterien intrazellulär Polysaccharide produzieren, wodurch auch in Perioden ohne Substratzufuhr die Säureproduktion anhalten kann (Borutta et al. 2010).

Die Besiedlung mit $S$. mutans und anderen kariogenen Bakterien im jungen Alter könnte ein Schlüsselfaktor für die Kariesentstehung sein (Berkowitz 2003). Jedoch konnte die Rolle von $S$. mutans als Hauptursache für Karies nicht nachgewiesen werden. Aufgrund der Komplexität der oralen Mikroflora, welche 
mehrere hundert Bakterienarten enthält, kann nicht eine einzelne Bakterienart die Kariesentstehung in einer Person verursachen (Hausen 1997).

\subsubsection{Weitere Risikofaktoren}

Neben den Hauptfaktoren, die direkt mit der Entstehung von Karies im Zusammenhang stehen, existieren eine Reihe weiterer Risikofaktoren, zu denen persönliche Faktoren und orale Umweltfaktoren gehören. Physikalische und biologische Risikofaktoren für Karies sind inadäquater Speichelfluss, eine hohe Anzahl an kariogenen Bakterien, eine insuffiziente Fluoridzufuhr, gingivale Rezessionen, immunologische Komponenten und genetische Faktoren (Hassell und Harris 1995; Anderson 2002). Die Entstehung von Karies ist ebenfalls abhängig vom Lebensstil und von Verhaltenskomponenten einer Person. Zu diesen persönlichen Risikofaktoren gehören die schlechte Mundhygiene, schlechte Essgewohnheiten, wie der häufige und in kurzen Abständen stattfindende Konsum niedermolekularer Kohlenhydrate, die Einnahme oraler Medikamente mit Zuckerzusatz und schlechte Ernährungsmethoden bei Kindern (Krol 2003; Winn 2001). Ein weiterer wichtiger Faktor ist das fehlende Zähneputzen ab dem ersten Geburtstag durch die Eltern (Bissar et al. 2014). Zudem sind die fehlende Überwachung des Zähneputzens und das fehlende Nachputzen durch die Eltern Risikofaktoren für die Entstehung von ECC (Mangla et al. 2017). Hinzu kommt das Fehlen zahnärztlicher Untersuchungen, welche vor allem bei Kindern zwischen drei und sechs Jahren zu selten wahrgenommen werden (RKI 2008).

\subsubsection{Aktuelles Kariesmodell}

Ein aktuelles Kariesmodell wurde von Paris und Meyer-Lückel erstellt (MeyerLückel et al. 2012) (Abbildung 3). Demnach nimmt eine zuckerreiche Ernährung als primär pathogener Faktor eine zentrale Rolle in der Kariesentstehung ein (Zero 2004). Dies lässt sich damit begründen, dass Karies eine Erkrankung in Zivilisationen ist, in denen vermehrt Zucker konsumiert wird. Das war in dem überwiegenden Anteil der Menschheitsgeschichte nicht der Fall (Moore 1983). Der übermäßig hohe Zuckerkonsum ist somit als unphysiologisch zu sehen und führt zu einer pathologischen Veränderung der oralen Flora, wobei azidogene und azidurische Spezies (pathogene Flora) begünstigt werden (Marsh 1994). Durch die erhöhte metabolische Aktivität dieser potenziell kariogenen Bakterien, kommt es zur vermehrten Bildung organischer Säuren, welche eine Demineralisation der Zahnhartsubstanzen begünstigen. Dies führt zu den klinischen Symptomen der Karies. Dem entgegen wirken protektive Faktoren, bei denen die Wirtsabwehr und die Mundhygiene des Patienten das Wachstum und 
die Stoffwechselaktivität des oralen Biofilms und somit die Säureproduktion hemmen. Die puffernden Eigenschaften und der Mineralgehalt des Speichels begünstigt die Remineralisation der Zahnhartsubstanzen. Dabei kann zudem durch eine äußere Zufuhr von Fluoriden und Kalziumverbindungen die remineralisierende Wirkung des Speichels noch verstärkt werden (ten Cate und Featherstone 1991). Abgesehen von diesen lokal und direkt wirkenden Faktoren gibt es weitere Faktoren, die indirekt über die lokalen Faktoren mit dem Kariesprozess verbunden sind. Dazu gehören verhaltensbedingte und sozioökonomische Faktoren (Harris et al. 2004) wie die Bildung, der sozioökonomische Status, das Einkommen, die Genetik, das Alter und der behandelnde Zahnarzt (Meyer-Lückel et al. 2012). Der Konsum fermentierbarer Kohlenhydrate steht als einziger pathogener Faktor den protektiven Faktoren gegenüber. Jedoch kann auch der Wegfall eines protektiven Faktors schwerwiegende Auswirkungen auf den Kariesprozess haben. Bei Hyposalivation und somit dem Wegfall des protektiven Faktors Speichel kann Karies sehr viel schneller voranschreiten, bei keiner Veränderung der restlichen Faktoren (Fox 2004). Risikofaktoren für Karies sind somit sowohl die Steigerung des pathogenen Faktors als auch der Wegfall oder die Minderung protektiver Faktoren (Meyer-Lückel et al. 2012).

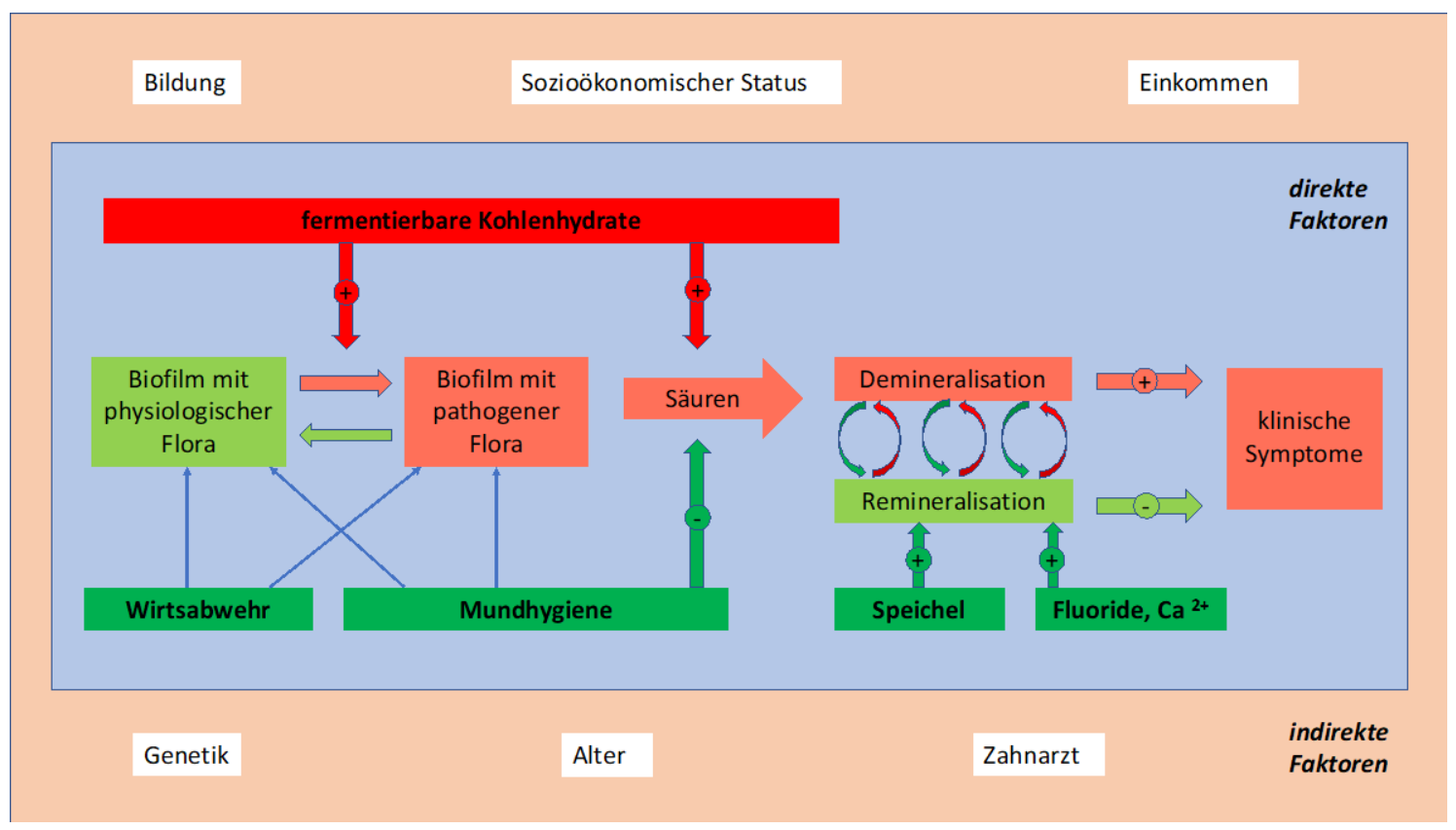

Abbildung 3: Ein aktuelles Kariesmodell. Der primäre pathogene Faktor (dunkelrot) für Karies ist der häufige Konsum fermentierbarer Kohlenhydrate. Dem gegenüber stehen protektive Faktoren (dunkelgrün), zu denen die Wirtsabwehr, die Mundhygiene, der Speichel, Fluoride und Kalziumverbindungen gehören. Abgesehen von diesen direkten Faktoren sind einige indirekte Faktoren teilweise stark mit dem Kariesprozess assoziiert. Quelle: eigene Darstellung, bearbeitet nach Meyer-Lückel et al. (2012) 


\subsubsection{Kariestherapie}

Die Art der Therapie hängt vom Fortschritt der Krankheit, dem Alter des Kindes sowie von sozialen Faktoren ab (Colak et al. 2013). Anzustreben ist, die Krankheit gar nicht erst ausbrechen zu lassen und durch präventive Maßnahmen das Kariesrisiko zu senken. Dazu zählen vor allem die lokale und systemische Anwendung von Fluoriden, wobei die lokale (topische) Wirkung eine übergeordnete Rolle spielt (Section on Pediatric Dentistry and Oral Health, 2008). Zur systemischen Anwendung kommt es durch fluoridhaltiges Speisesalz und Fluoridtabletten, wobei jedoch gewisse Grenzdosen nicht überschritten werden dürfen. Die Deutsche Gesellschaft für Zahn-, Mund- und Kieferheilkunde (DGZMK) empfiehlt daher, möglichst nur eine Form der systemischen Fluoridzufuhr (Tablette oder Speisesalz) in relevanter Menge zu verwenden (DGZMK 2013). Laut europäischer Lebensmittelbehörde EFSA liegt die tolerable obere Zufuhrmenge für Kinder im Alter von ein bis acht Jahren bei $0,1 \mathrm{mg} / \mathrm{kg}$ Körpergewicht (EFSA, 2005). Bei der Verwendung fluoridhaltiger Zahnpasten stimmen die pädiatrischen und zahnärztlichen Empfehlungen nicht überein. Die Deutsche Gesellschaft für Kinder- und Jugendmedizin empfiehlt, fluoridhaltige Zahnpasten erst ab dem fünften Lebensjahr einzusetzen, da das Kind ab diesem Alter die Zahnpasta beim Zähneputzen regelmäßig ausspucken kann. Die DGZMK hingegen spricht sich für die Anwendung von geringen Mengen fluoridhaltiger Kinderzahnpasta (500 ppm F-) aus, ab dem Durchbruch der ersten Milchzähne einmal am Tag sowie ab einem Alter von zwei Jahren zweimal täglich. Die lokale Fluoridierung, vor allem bei Kindern mit erhöhtem Kariesrisiko, sollte zusätzlich zweimal im Jahr durch die Applikation hochfluoridhaltiger Lacke oder Gele durch den Zahnarzt ergänzt werden (DGZMK 2013).

Bei Initialkaries (white spots) steht die präventive Behandlung durch Fluoride im Vordergrund, wodurch demineralisierte Schmelzareale wieder remineralisiert werden können (Tinanoff und Douglass 2001). Kariöse Läsionen, die bis in die Schichten des Dentins reichen, müssen invasiv behandelt werden. Dazu gehört die vollständige Entfernung des kariösen Gewebes durch rotierende Instrumente (Rosenbohrer) oder alternativ durch Handinstrumente (Tinanoff und Douglass 2001). Die Behandlung erfolgt in der Regel in lokaler Betäubung, um potentielle Schmerzen zu minimieren und die Kooperation der Kinder zu steigern. Die atraumatische Behandlung mit Handinstrumenten kann auch ohne Lokalanästhesie erfolgen und ist somit für Kinder geeignet, die Angst vor der Betäubungsspritze und dem Bohren haben (Dulgergil et al. 2005). Als Restaurationsmaterial für Milchmolaren wird Glasionomerzement (GIZ) verwendet, welcher sich einfach und schnell verarbeiten lässt und keine absolute 
Trockenlegung durch Kofferdam erfordert. Bei Milchinzisiven werden in der Regel zahnfarbene Kompomere oder Komposite verwendet (Colak et al. 2013).

Bei größeren Defekten sind konfektionierte Stahlkronen das Mittel der Wahl. Diese sind in verschiedenen Größen erhältlich und können direkt im Mund an den entsprechenden Milchzahn angepasst und einzementiert werden. Eine Indikation ist gegeben bei stark kariösen Milchmolaren (mehr als zwei Flächen betroffen), bei lokalisierten oder generalisierten Entwicklungsstörungen (zum Beispiel Molaren-Inzisiven-Hypomineralisation, Amelogenesis imperfecta), nach Pulpotomie oder Pulpektomie, bei Frakturen und bei Milchmolaren, die als Platzhalter dienen und aus kieferorthopädischen Gründen bis zum Durchbruch des bleibenden Zahnes erhalten werden sollen (Kindelan et al. 2008).

Kinder, die große Angst vor der zahnmedizinischen Behandlung haben und bei denen viele Zähne stark kariös zerstört sind, können in Vollnarkose behandelt werden. Milchzähne, die nicht mehr restaurativ versorgt werden können, müssen extrahiert werden. Jede Vollnarkose bringt jedoch ein gewisses Risiko mit sich. Eine Alternative dazu bietet die Hypnose, welche nachweislich das Schmerzempfinden herabsetzen kann, jedoch nicht unter Garantie bei jedem Patienten anwendbar ist (Peretz et al. 2013). 


\subsection{Mikrobiom der Mundhöhle}

\subsubsection{Orales Mikrobiom bei Erwachsenen}

\subsubsection{Bakterien}

Mehr als 700 verschiedene Bakterienarten wurden von Aas et al. 2005 in der Mundhöhle beschrieben (Aas et al. 2005). In dieser Studie wurden den fünf gesunden erwachsenen Probanden an neun verschiedenen Stellen der Mundhöhle Proben entnommen: Zungenrücken, laterale Zunge, Wangenschleimhaut, harter Gaumen, weicher Gaumen, supragingivale Zahnflächen, subgingivale Plaque, Vestibulum und Tonsillen. Es konnten dabei 141 vorherrschende Arten identifiziert werden, welche bei allen Individuen vorkamen und von denen $60 \%$ nicht kultivierbar waren. Es wurden sechs verschiedene Stämme entdeckt: Firmicutes, Actinobacteria, Proteobacteria, Bacteroidetes, Fusobacteria und der TM7-Stamm (nicht kultivierbare Spezies). Arten, die in allen Proben gefunden wurden, gehörten zu den Gattungen Gemella, Granulicatella, Streptococcus und Veillonella.

Es ist bekannt, dass orale Bakterienarten bevorzugt verschiedene Oberflächen in der Mundhöhle besiedeln. Spezifische Adhäsine auf der bakteriellen Oberfläche sorgen für eine Anheftung an komplementären spezifischen Rezeptoren an einer bestimmten Oberfläche (Zunge, Zahn, Wange, Gaumen, Vestibulum, Tonsillen) (Gibbons 1989). Dementsprechend wurden manche Bakterienarten wie Streptococcus mitis und Granulicatella adiacens im gesamten Mundraum gefunden, wohingegen diverse Arten sehr ortsspezifisch waren. Beispielsweise wurde Streptococcus salivarius fast ausschließlich auf dem Zungenrücken gefunden, wohingegen Rothia dentocariosa, Actinomyces spp., Streptococcus sanguinis, Streptococcus gordonii und Abiotrophia defectiva hauptsächlich auf den Zähnen erschienen. Andere Arten wie Gemella sanguinis und Streptococcus australis kamen bevorzugt auf weichen Oberflächen vor und nicht auf supra- und subgingivalen Zahnflächen. Darüber hinaus war zu sehen, dass sich die bakterielle Flora der gesunden Mundhöhle von der Mikroflora bei oralen Krankheiten unterscheidet. Es wurden keine Spezies identifiziert, welche mit parodontalen Erkrankungen assoziiert werden, wie z. B. Porphyromonas gingivalis, Tannerella forsythia und Treponema denticola. Ebenfalls wurden keine Bakterien gefunden, die mit dentaler Karies assoziiert sind, wie z. B. S. mutans. Die gesunde Mundhöhle besitzt somit eine charakteristische vorherrschende bakterielle Flora, welche sehr vielfältig sowie orts- und subjektspezifisch ist (Aas et al. 2005). 


\subsubsection{Viren, Protozoen, Pilze und Archaeen}

Neben Bakterien können eine Reihe von Viren in der Mundhöhle gefunden werden, welche in erster Linie mit anderen Krankheiten als Karies in Verbindung gebracht werden. Mumpsviren und Rabiesviren (Tollwutvirus) infizieren die Speicheldrüsen und werden dementsprechend im Speichel infizierter Individuen gefunden. Durch Blut übertragene Viren wie Hepatitisviren und HIV (Humanes Immundefizienz-Virus) können durch die gingivale Sulkusflüssigkeit in die Mundhöhle eintreten. Herpes-simplex-Viren verursachen Gingivostomatitis und können in ein inaktives Stadium im Ganglion Trigeminale eintreten. Durch äußere Einflüsse wie zum Beispiel Stress, kaltes Wetter oder andere Virusinfektionen kann der Virus reaktiviert werden und Herpes labiales kann entstehen (Scott et al. 1997). HPV (Humane Papillomviren) verursachen eine Reihe von oralen Veränderungen, wie Papillome, Kondylome und fokale epitheliale Hyperplasie (Kumaraswamy und Vidhya 2011) und werden darüber hinaus mit Plattenepithelkarzinomen im Kopf- und Halsbereich in Verbindung gebracht (Loning et al. 1985).

Neben Viren können auch zwei Protozoenarten in der physiologischen Mundflora gefunden werden: eine Amöbe, Entamoeba gingivalis, und Trichomonas tenax. Die Anzahl dieser Organismen steigt mit zunehmend schlecher Mundhygiene und gingivalen Krankheiten. Sie werden als harmlose Saprophyten betrachtet (Wantland et al., 1958).

Auch Pilze, wie etwa verschiedene Candida-Arten, kommen symptomlos bei ca. der Hälfte der Bevölkerung vor, wobei die Prävalenz mit zunehmendem Alter steigt und eine Reihe von akuten und chronischen Infektionen verursacht werden können (Arendorf und Walker 1979). Bei einer kultur-unabhängigen Studie wurden die oralen Mikrobiome von 20 gesunden Probanden untersucht (Ghannoum et al. 2010). Es wurden 85 verschiedene Pilzgattungen gefunden, wobei die vorherrschenden Gattungen Candida, Cladosporium, Aureobasidium, Saccharomycetales, Aspergillus, Fusarium und Cryptococcus waren. Eine Infektion mit Candida kann im Zusammenhang mit erhöhtem Kariesbefall stehen (Thomas et al. 2016). Ebenso kann durch Candida albicans die Aktivität von säureproduzierenden Bakterien wie S. mutans erhöht werden (Kim et al., 2017).

Die Archaeen bilden gelegentlich eine nebensächliche Komponente des oralen Mikrobioms und sind auf eine kleine Anzahl an Arten begrenzt, wovon alle Methanogene sind. Man kann sie bei Gesunden finden, jedoch steigt die Prävalenz und Anzahl in Individuen mit Parodontitis. Zu den gefundenen Spezies gehören Methanobrevibacter oralis und zwei nicht benannte 
Methanobrevibacter-Phylotypen, Methanobacterium curvum/congolense und Methanosarcina mazeii (Lepp et al. 2004), (Matarazzo et al. 2011).

\subsubsection{Zusammensetzung der Zahnplaque}

Die dentale Plaque bildet ein eigenes Mikro-Ökosystem, welches verschiedene Bakterien enthält. Diese Bakterien produzieren in ihrem Zuckerstoffwechsel Säuren, wodurch es in der Umgebung zum Abfall des pH-Wertes kommt und somit zur Demineralisation des Zahnschmelzes beiträgt und zur Entstehung von Karies führen kann.

Viele Studien stellen Mutans Streptokokken (MS) als Hauptpathogene für die Kariesentstehung heraus. Als MS werden sieben Arten zusammengefasst, die in acht Serotypen eingeteilt werden können: Streptococcus mutans (serotypes c, e and f), Streptococcus sobrinus (Serotyp d und g), Streptococcus criceti (Serotyp a), Streptococcus downei (Serotyp h), Streptococcus ferus (Serotyp c), Streptococcus macacae (serotype c) und Streptococcus ratti (serotyp b) (Hung et al. 2005). Die Assoziation mit Karies hat verschiedene Gründe und Ursachen. Zum einen wurden MS aus kavitierten Läsionen isoliert, zum anderen hat man in Tierversuchen herausgefunden, dass MS bei Saccharosezufuhr Karies verursachen können. Des Weiteren haben MS eine hohe Säureproduktion sowie Säureausscheidung und sind in der Lage, wasserunlösliche Glukane zu bilden, welche die Adhäsion an der Zahnoberfläche und an anderen Bakterien ermöglichen (Hamada und Slade 1980). Neuere Untersuchungen zeigen jedoch, dass es keine absolute Beziehung zwischen MS und Karies gibt: trotz hoher Menge an MS auf der Zahnoberfläche kann eine Läsion ausbleiben und auch ohne MS kann es zur Kariesentstehung kommen (Nyvad 1993).

Es gibt daher Überlegungen, dass auch andere säurebildende und säureausscheidende Bakterien, wie z.B. Nicht-Mutans-Streptokokken und Aktinomyzeten für die Kariesentstehung verantwortlich sein können (Sansone et al. 1993). Aktuelle mikrobielle Untersuchungen zeigen, dass die Mikroflora bei White Spot Läsionen vielfältiger ist und neue Phylotypen und Spezies wie Actinomyces gernesceriae, Actinomyces naes/undii und Actinomyces israelii, sowie eine Reihe von Nicht-Mutans-Streptokokken und Veillonela spp. (Aas et al. 2008) involviert sind. Da alle diese kariesassoziierten Bakterien zur physiologischen Mikroflora der Mundhöhle gehören, wurde Karies als endogene Infektion beschrieben (Nyvad et al. 2003). Endogene Infektionen entstehen, wenn Mitglieder der vorhandenen Flora einen Selektionsvorteil gegenüber anderen Spezies erlangen, wodurch das homöostatische Gleichgewicht des Biofilms zerstört wird (Marsh 1999). Hieraus hat Marsh 1994 eine „ökologische Plaque-Hypothese" beschrieben (Marsh 1994), welche 2008 von Takahashi und 
Nyvad ausgeweitet wurde (Takahashi und Nyvad 2008). In dieser Hypothese ist die dentale Plaque ein dynamisches mikrobielles Ökosystem, worin NichtMutans-Bakterien (Nicht-Mutans-Streptokokken und Aktinomyzeten) eine Schlüsselrolle spielen für anhaltende dynamische Stabilität. Mikrobielle säureinduzierte Adaptation und somit säureinduzierte Selektion von "niedrig-pH“ Nicht-Mutans-Bakterien spielen eine kritische Rolle bei der Destabilisierung der Plaquehomöostase (acidogenic stage). Sobald sich eine saure Umwelt gebildet hat, können sich MS und andere säureausscheidende Bakterien vermehren und damit die Entstehung von Läsionen begünstigen (aciduric stage) (Takahashi und Nyvad 2008).

Studien haben gezeigt, dass die initialen Besiedler von frisch gereinigten Zahnoberflächen aus einem stark selektierten Teil der oralen Mikroflora besteht, hauptsächlich S. sanguinis, S. oralis und S. mitis (Nyvad und Kilian 1987). Jedoch sind andere Gattungen wie Aktinomyzeten ebenfalls präsent (Dige et al. 2009). Der Anteil von MS beträgt nur $2 \%$ oder weniger der initialen Streptokokkenpopulation, unabhängig von der Kariesaktivität der Person (Nyvad und Kilian 1990). Diese Beobachtungen heben hervor, dass die große Mehrheit der initialen Besiedler von Zahnoberflächen zu der Mitis-Gruppe gehören. Diese Bakterien sowie andere Viridans-Streptokokken werden oft als Nicht-MutansStreptokokken bezeichnet, welche genetisch zu unterscheiden sind von MS (Kawamura et al. 1995). Wenn die Mikroflora älter wird, wechselt die Zusammensetzung von Streptokokken-Dominanz zu Aktinomyzeten-Dominanz (Syed und Loesche 1978). Die vorherrschenden Gattungen in ausgereifter Plaque stellen Aktinomyzeten und Streptokokken dar, wovon die meisten NichtMutans-Streptokokken sind (Ximenez-Fyvie et al. 2000). MS kommt in sehr geringer Menge vor (Bowden et al. 1975). Der Anteil von MS in Plaque auf White Spot Läsionen ist oft höher als auf klinisch gesunden Flächen. Trotzdem bleiben Nicht-Mutans-Streptokokken die Hauptbakteriengruppe in White Spots (Sansone et al. 1993). In kavitierten Läsionen, die bis ins Dentin reichen, stellen MS einen Anteil von ca. 30\% der gesamten Flora dar (Loesche et al. 1984), womit MS mit Karies in fortgeschrittenem Stadium in Verbindung gebracht werden kann. Im Gegensatz dazu werden MS weniger häufig an der fortschreitenden Seite von Dentinkaries gefunden, wo Lactobacilli, Prevotella und Bifidobacterium vorherrschend sind (Mantzourani et al. 2009). All diese Studien zeigen, dass sich die Mikroflora auf Zahnoberflächen mit der Entwicklung von kariösen Läsionen verändert, von einer Dominanz der Nicht-Mutans-Streptokokken und Aktinomyzeten zu einer Dominanz von MS und anderen Bakterien, wie Lactobacilli und Bifidobacterium. Durch aktuelle molekulare Identifikationsmethoden wurde herausgefunden, dass die Mikroflora auf klinisch 
gesunden und kariösen Zahnflächen sehr viel vielfältiger ist und hunderte vorherrschende Arten enthält, wovon 50-60\% noch nicht kultivierbar sind (Aas et al. 2008). Aber auch diese Studien verdeutlichen, dass andere Bakterienarten als S. mutans, wie z.B. Lactobacillus, Bifidobakterium, Propionibakterium, NichtMutans-Streptokokken und Aktinomyzeten, wichtige Rollen beim Kariesprozess spielen.

\subsubsection{Mikrobiom im Speichel und auf der Zunge}

Sowohl Zunge als auch Speichel besitzen ein eigenes Mikrobiom mit verschiedener mikrobieller Zusammensetzung. Häufig wird diskutiert, ob sich die mikrobielle Zusammensetzung bei oralen Krankheiten signifikant verändert.

Simon-Soro und ihre Mitarbeiter fanden 2013 in einer Studie mit zwei gesunden erwachsenen Probanden heraus, dass Speichel- und Zungenproben eine erheblich höhere Anzahl an OTUs (operational taxonomic units) enthielten als Zahn- und Gingivasulkusproben. Des Weiteren enthielten die Speichelproben eine höhere Diversität im Vergleich zu Zahn- und Gingivaproben. Daraus lässt sich schließen, dass der Speichel Bakterien aus anderen oralen Nischen enthält. Eine weitere Beobachtung war, dass es eine beachtliche Ähnlichkeit zwischen den Zungenproben und Proben mit stimuliertem Speichel gab. Es ist allerdings zu beachten, dass bei dieser Studie nur zwei Individuen betrachtet wurden und sicherlich eine größere Probandenzahl für eine höhere Validität nötig ist (SimonSoro et al. 2013).

In der Studie von Yang wurde der Speichel von 19 kariesaktiven und 26 kariesfreien erwachsenen Probanden untersucht. Yang et al. fanden heraus, dass das Speichelmikrobiom in beiden Gruppen eine hohe Diversität aufwies und nur einen minimalen Kern an übereinstimmenden OTUs auf Artebene. Des Weiteren waren die Mikrobiome mit Karies variabler in ihrer Struktur, wohingegen die gesunden Mikrobiome mehr Ähnlichkeit zueinander aufwiesen. Es wurden in allen Proben sechs verschiedene Stämme identifiziert: Bacteroidetes, Firmicutes, Proteobacteria, Fusobacteria, Actinobacteria und Spirochaetes. Ein weiterer Unterschied zwischen kariesaktiven und kariesfreien Mikrobiomen konnte bei der Gattung Prevotella entdeckt werden, welche in kariesaktiven Mikrobiomen in erhöhtem Anteil vorkam (Yang et al. 2012). 


\subsubsection{Orales Mikrobiom bei Kindern}

Betrachtet man die mikrobielle Zusammensetzung der Mundhöhle bei Kindern, so ist zu sehen, dass sich diese mit dem Alter verändert. Dazu wurde 2015 in einer Studie in Schweden von Holgerson et al. untersucht, wie sich das orale Mikrobiom bei drei Monate alten Kinder zusammensetzt und wie es sich später bei den gleichen Kindern im Alter von drei Jahren verändert hat. Es wurde herausgefunden, dass die Artenvielfalt in den ersten Lebensjahren deutlich zunimmt. Die meisten Bakterienarten, die bei drei Monate alten Kindern die Mundhöhle besiedeln, sind auch bei den dreijährigen Kindern zu finden, wenige verschwinden und eine große Anzahl neuer Arten kommt in dieser Zeit hinzu. Bei keinem der drei Monate alten Kinder wurde S. mutans entdeckt. Es wurden sechs verschiedene Stämme identifiziert, wozu Bacteroidetes, Firmicutes, Proteobacteria, Actinobacteria, Fusobacteria und TM7 gehören. Im Alter von drei Jahren wurde zusätzlich der Stamm SR1 gefunden. In der Studie wurden die Gattungen Actinomyces, Bergeyella, Camphylobacter, Granulicatella, Kingella, Leptrotrichia und Streptococcus bei gesunden dreijährigen Kindern identifiziert (Holgerson et al. 2015).

Auch Dzidic und Kollegen untersuchten die Entwicklung des oralen Mikrobioms während der Kindheit. Dazu nahmen sie Speichelproben im Alter von drei, sechs, zwölf und 24 Monaten, sowie sieben Jahren. Als frühe Besiedler konnten Streptococcus und Veillonella identifiziert werden. Andere Gattungen wie Neisseria kamen nach ein bis zwei Jahren dazu. Die Entwicklung von Karies konnte mit einer abweichenden mikrobiellen Zusammensetzung über die Zeit assoziiert werden. Streptococcus cristatus zeigte sich dabei im Zusammenhang mit einem erhöhten Risiko für die Entstehung von Karies und könnte eine Rolle als potenzieller Biomarker bekommen. Kinder, die per Kaiserschnitt geboren wurden, zeigten initial einen verzerrten bakteriellen Inhalt, was sich jedoch mit dem Alter regenerierte. Kürzeres Stillen und Antibiotikagabe während der ersten zwei Lebensjahre wurden mit einer verschiedenen bakteriellen Zusammensetzung zu späterem Alter assoziiert (Dzidic et al. 2018).

Santigli und Kollegen machten eine umfangreiche Mikrobiom-Analyse bei gesunden Kindern. Es wurden Proben aus dem subgingivalen Sulcus, von der Mukosa und aus dem Speichel entnommen. Zu den Stämmen, die dabei am häufigsten gefunden wurden, gehören Firmicutes, Proteobacteria, Actinobacteria, Bacteroidetes und Fusobacteria (Santigli et al. 2017).

In einer weiteren Studie wurden Plaque- und Speichelproben von Kindern zwischen drei und sechs Jahren mit und ohne Karies untersucht. Als kariesassoziierte Gattungen in den Plaqueproben konnten Streptococcus, 
Veillonella, Actinomyces, Granulicatella, Leptotrichia und Thiomonas identifiziert werden. Es wurde jedoch kein signifikanter Unterschied zwischen kariesaktiven und kariesfreien Speichel-Mikrobiomen gefunden (Ling et al. 2010).

Eine andere Studie beschäftigt sich mit der mikrobiellen Zusammensetzung von Zahnplaque bei Kindern, die jünger als 30 Monate alt sind. Es wurden fünf vorherrschende Stämme (Firmicutes, Fusobacteria, Proteobacteria, Bacteroidetes und Actinobacteria) und sieben vorherrschende Gattungen (Leptotrichia, Streptococcus, Actinomyces, Prevotella, Porphyromonas, Neisseria und Veillonella) gefunden, unabhängig von dem Vorhandensein von Karies. Als kariesassoziierte Gattungen konnten Streptococcus und Veillonella herausgestellt werden, wohingegen die Gattungen Leptotrichia, Selenomonas, Fusobacterium, Capnocytophaga und Porphyromonas vermehrt in den kariesfreien Proben gefunden wurden (Xu et al. 2014).

Die Analyse der Speichel- und Plaqueproben von drei- bis vierjährigen chinesischen Kindern zeigte deutliche Unterschiede in der bakteriellen Zusammensetzung bei Kindern mit S-ECC und Gesunden. Als Gattungen konnten Streptococcus, Porphyromonas und Actinomyces mit Karies assoziiert werden. Die Anzahl an S. mutans war sowohl in den Plaque- als auch in den Speichelproben bei Kindern mit S-ECC erhöht. Die Speichelproben wiesen eine höhere mikrobielle Diversität als die Plaqueproben auf (Ma et al. 2015).

Neves und Kollegen verglichen das Speichelmikrobiom von sieben Kindern mit ECC und sieben gesunden Kindern. Dabei kam heraus, dass die ECC-Gruppe eine höhere Anzahl an S. mutans und Lactobacillus spp. aufwies. Die beiden Gruppen unterschieden sich nicht in der Gesamtzahl der Mikroorganismen und der Anzahl an Candida spp. (Neves et al. 2015).

Auch in einer weiteren Studie wurde in Speichel- und Plaqueproben von Kindern mit S-ECC eine deutlich höhere Menge an Lactobacillus gefunden als bei gesunden Kindern. Die Anzahl an gramnegativen Anaerobiern war bei der SECC-Gruppe geringer als bei der gesunden Gruppe (Ledder et al. 2018).

In einer Übersichtsstudie von Hemadi und seinem Team wurden Mikroorganismen im Speichel (und Speichelproteine) herausgestellt, die als potentielle Biomarker für das ECC-Risikomanagement dienen können. Die Mehrzahl der Studien unterstützt eine positive Korrelation zwischen der Menge an Mutans Streptococci im Speichel und ECC. Zudem könnte die Anzahl an Lactobacilli im Speichel indirekt mit dem Fortschritt der Karies zusammenhängen. Viele Studien zeigten einen Zusammenhang zwischen Candida spp. und dem Fortschritt von ECC. C. albicans im Speichel könnte somit als Risikovorhersage für ECC dienen (Hemadi et al. 2017). 
Eine aktuelle Übersichtsstudie über das orale Mikrobiom bei ECC, bei der insgesamt 27 Studien mit Plaque- und Speichelproben miteinbezogen wurden, liefern Fakkruddin und Kollegen. Dabei wurden als neue Arten und Stämme Scardovia wiggsiae, Slackia exigua, Granulicatella elegans und Firmicutes im Plaquebiofilm bei Kindern mit ECC entdeckt. Im Gegensatz dazu waren Bakterien wie S. cristatus, S. gordonii, S. sanguinis, Corynebacterium matruchotii und Neisseria flavescens häufig verbreitet auf gesunden, nichtkariösen Zahnflächen bei Kindern mit ECC (Fakkruddin et al. 2018).

Das Vorhersagepotenzial von Speichelmikrobiomen für das Wiederauftreten von ECC wurde von Zhu und Kollegen untersucht. Dazu wurden von 28 Kindergartenkindern für ein Jahr lang alle sechs Monate Speichelproben entnommen, sodass insgesamt 84 Proben analysiert werden konnten. Bei sieben Kindern kam es zum Wiederauftreten von ECC, bei sechs Kindern trat ECC nicht erneut auf und 15 Kinder waren und blieben kariesfrei. Die relative Menge der Gattungen Fusobacterium, Prevotella, Leptotrichia und Capnocytophaga unterschied sich deutlich zwischen der Gruppe, bei der ECC erneut auftrat und der Gruppe ohne Wiederauftreten von ECC. Somit können diese Gattungen mit der Pathogenese und Progression von Wiederauftreten von ECC assoziiert werden (Zhu et al. 2018).

Einen Vergleich vom Speichel- und Zahnmikrobiom bei Kindern mit S-ECC und dem Speichelmikrobiom bei gesunden Kindern liefern Hurley und Kollegen. Sie fanden deutliche Unterschiede zwischen dem kariösen Dentinmikrobiom und den Speichelmikrobiomen bei Kindern mit und ohne S-ECC, wobei das Kariesmikrobiom eine geringere Diversität als die Speichelmikrobiome aufwies. Die Hauptstämme der kariesaktiven Dentinmikrobiome waren Firmicutes (33,5 $\%$ ) und Bacteroidetes (23,2 \%), wobei Neisseria (10,3\%) und Prevotella (10 \%) als Gattungen am häufigsten vertreten waren. Die kariesaktiven Speichelmikrobiome wurden von Proteobacteria $(38,2 \%)$ und Bacteroidetes $(27,8 \%)$ dominiert. Die häufigsten Gattungen waren Neisseria (16,3\%) und Porphyromonas (9,5\%). Kariesaktive Mikrobiome zeigten einen hohen relativen Reichtum an S. mutans, Prevotella spp., Bifidobacterium und Scardovia spp. (Hurley et al. 2019). 


\subsection{Ziele der Arbeit}

In der folgenden Arbeit wird die mikrobielle Zusammensetzung in Speichelproben und Zungenabstrichen bei ein- bis sechsjährigen Kindern untersucht, die an ECC erkrankt sind. Es werden potentielle Unterschiede zwischen den verschiedenen ECC-Typen in der mikrobiellen Zusammensetzung der Zungen- und Speichelflora gesucht. Darüber hinaus soll untersucht werden, ob es Unterschiede zwischen den mikrobiellen Gemeinschaften des Speichels und der Zunge gibt und worin genau sich diese unterscheiden. 


\section{Material und Methoden}

Insgesamt wurden von Prof. Dr. Jan Kühnisch, Ludwig-Maximilians-Universität München (Poliklinik für Zahnerhaltung und Parodontologie, Abteilung Kinderzahnheilkunde) 30 Zungenabstriche (Zungenoberseite) und 30 Speichelproben aus dem Sublingualraum von Kindern mit ECC im Alter zwischen ein und sechs Jahren mit sterilen Swabs (Floq Swab, Copan, Italien) entnommen, in RNAlater konserviert und bis zur weiteren Verarbeitung bei $-80^{\circ} \mathrm{C}$ gelagert. Zusätzlich wurden Abstriche von Zahn- und Füllungsflächen genommen, die in einer anderen Studie untersucht wurden. Die Kinder wurden anhand der Klassifikation nach Wyne den ECC-Typen 1 bis 3 zugeordnet. Aus den Proben wurde die DNA extrahiert und die variable Region 1-2 der ribosomalen 16S rRNA amplifiziert und sequenziert (MiSeq, Illumina). Mithilfe von Datenbanken (Human Oral Microbiome Database/HOMD und Ribosomal Database Project Classifier/RDP Classifier) wurde die taxonomische Zusammensetzung und Abundanz der Mikroorganismen bestimmt.

\subsection{Mitwirkende und Ethikvotum}

Die folgende Studie wurde in Kooperation mit Prof. Dr. Jan Kühnisch, LudwigMaximilians-Universität München (Poliklinik für Zahnerhaltung und Parodontologie, Abteilung Kinderzahnheilkunde) durchgeführt. Der Ethikantrag wurde von der Ethikkommision der LMU München wie gestellt genehmigt (siehe Anhang). Vor der Probenentnahme wurde eine Einverständniserklärung von den Eltern der Probanden unterschrieben.

Die Lagerung und Bearbeitung der Proben erfolgt im Helmholtz-Zentrum für Infektionsforschung in Braunschweig unter der Betreuung von Frau Prof. Dr. Irene Wagner-Döbler und Frederic Meyer. 


\subsection{Standardisierung der klinischen Untersuchung und Probenentnahme}

Von allen Kindern wurden der Zahnstatus und der dmft-Status (decayed missed filled teeth) aufgenommen, um eine Klassifizierung in ECC-Kategorien durchzuführen. Da der dmft nur eine Gesamtzahl an Zähnen angibt, wurde zusätzlich der Zahnstatus aufgenommen, um eine genaue Lokalisation der kariösen Stellen zu erhalten. Dies ist vor allem für die Unterscheidung von Typ 2- und Typ 3-ECC wichtig, da nur bei Typ 3 auch die unteren Inzisivi von Karies betroffen sind. Kariöse Läsionen wurden nach WHO-Kriterien beurteilt (WHO 1997). Keines der Kinder hatte zum Zeitpunkt der Probenentnahme durchgebrochene bleibende Molaren, Prämolaren oder Inzisiven. Die Anzahl der Milchmolaren betrug zwischen 4 und 8 Zähnen, die Anzahl der Milcheckzähne lag bei allen Kindern, mit einer Ausnahme von nur einem Milcheckzahn, vollständig bei 4 Zähnen. Auch die 8 Milchschneidezähne waren bei allen Kindern vorhanden. Des Weiteren wurde bei allen Kindern der Füllungs- und Restaurationsstatus, sowie die Anzahl der kariösen Läsionen aufgenommen. Dies wurde für eine andere Studie erfasst, bei der Abstriche von den Zahn- und Füllungsflächen der Kinder untersucht wurden. Für diese Studie hat es jedoch keine Relevanz und wurde nicht in die Auswertung miteingeschlossen. Die Anzahl der Milchzähne mit Füllungen betrug zwischen 3 und 18 Zähnen, die Anzahl der kariösen Läsionen lag zwischen 1 und 13. Die Entnahme der Proben erfolgte unter Vollnarkose nach einem standardisierten Prozedere. Die Zungenproben wurden von der Zungenoberseite und die Speichelproben aus dem Sublingualraum entnommen. Die Proben wurden mit sterilen Nylonswabs (Floq Swabs, Copan, Italien) entnommen, welche für wenige Sekunden an die Entnahmestelle gehalten wurden. Daraufhin wurden diese in RNAlater konserviert und bis zur weiteren Bearbeitung bei $-80^{\circ} \mathrm{C}$ gelagert. 


\subsection{DNA-Isolierung}

Aus den Proben wurde zunächst die DNA der Bakterien isoliert. Der mechanische Zellaufschluss und die weitere Aufreinigung der DNA erfolgte mithilfe des Fast DNA Spin Kit for Soil (MP Bioscience). Die DNA-Extraktion erfolgte wie im Protokoll des Herstellers beschrieben. Es wurden jeweils $450 \mu \mathrm{l}$ der Probe (in RNAlater) in eine Lysing Matrix E Tube (gefüllt mit Glasbeads unterschiedlicher Größe) gegeben und $978 \mu \mathrm{l}$ Na-Phosphat-Puffer hinzugefügt. Des Weiteren wurden $122 \mu \mathrm{l}$ MT-Puffer hinzugefügt, um den $\mathrm{pH}-$ Wert konstant zu halten und um die DNA beim Zellaufschluss nicht zu zerstören. Der mechanische Zellaufschluss erfolgte dann durch die FastPrep, welche dreimal 60s bei einer Stärke von $40 \mathrm{~m} / \mathrm{s}$ lief, mit jeweils 2 min Pause dazwischen, wobei die Proben auf Eis gelegt wurden. Daraufhin folgte ein Zentrifugationsschritt (10 min bei 14.000 U/min), um die Glasbeads von dem Proben-Puffer-Gemisch zu trennen. Der Überstand wurde in ein $2 \mathrm{~mL}$ Eppendorfgefäß gegeben und mit $250 \mu \mathrm{l}$ PPS (Protein Precipitation Solution) gemischt. Der PPS bewirkte die Fällung der noch vorhandenen Proteine (z.B. Zellwandbestandteile etc.). Nach weiterem Zentrifugieren ( $5 \mathrm{~min}$ bei $14.000 \mathrm{U} / \mathrm{min}$ ) wurde der Überstand in ein $15 \mathrm{ml}$ Falcon gegeben und mit $1 \mathrm{ml}$ Binding Matrix Lösung versetzt, sodass die negativ geladene DNA an der positiv geladenen Matrix binden kann. Nach zweiminütigem Schwenken mit der Hand wurde das Falcon auf Eis gestellt, damit sich die Matrix absetzen kann. Daraufhin wurden $1000 \mu \mathrm{l}$ des Überstandes abgenommen und verworfen. Nachdem die Binding Matrix wieder mit dem Rest des Überstandes gemischt wurde, wurden jeweils $730 \mu \mathrm{l}$ der Lösung auf einen Spin Filter gegeben und zentrifugiert ( $1 \mathrm{~min}$ bei $14.000 \mathrm{U} / \mathrm{min}$ ). Dies wurde solange wiederholt, bis das gesamte Volumen auf der Säule war, wobei in jedem Schritt der Durchfluss verworfen wurde. Im Folgenden wurde die an die Säule gebundene DNA mit $500 \mu$ I SEWS-M aufgereinigt, der Durchfluss verworfen und die Säule anschließend getrocknet und auf ein neues Auffanggefäß gesetzt. Schließlich wurde die Binding Matrix vorsichtig in $70 \mu \mathrm{L}$ DES (DNase/Pyrogen freies Wasser) resuspendiert und anschließend zentrifugiert ( 1 min bei 14.000 $\mathrm{U} / \mathrm{min}$ ). Die Lagerung der Proben erfolgte daraufhin bei $-20^{\circ} \mathrm{C}$. 


\subsection{Herstellung von 16S rRNA-Amplikons}

\subsubsection{PCR (Polymerase-Ketten-Reaktion)}

Ausgangsmaterial für die PCR und die Herstellung von Amplikons (durch PCR vervielfältigtes Fragment einer DNA) war die, wie in 2.3 beschrieben, extrahierte und aufgereinigte gesamte DNA. Das Ziel war die Vervielfältigung der V1/V2Region der 16S rRNA, mithilfe welcher eine große Anzahl verschiedener Bakterienarten voneinander differenziert werden können. Hierzu wurden drei PCRs hintereinander durchgeführt. Als Polymerase wurde in jedem Schritt die Takara PrimeSTAR HS DNA Polymerase (Takara Clonetech, USA) verwendet.

Die erste PCR diente zur Vervielfältigung der V1/V2-Region, wobei je $0.5 \mu \mathrm{l}$ der Primer 27F und 338R verwendet wurden (Tabelle 7). Außerdem kamen $4 \mu \mathrm{l}$ Puffer, $1.6 \mu$ dNTPs, $0.2 \mu$ Polymerase und $11.2 \mu$ DEPEC Wasser zu jeweils 2 $\mu l$ Probe (Tabelle 1). Das PCR Programm wurde auf 20 Zyklen eingestellt (Tabelle 2). Produkt der ersten PCR waren danach ca. 300 bp lange Amplikons.

Vom Produkt der ersten PCR dienten nun wieder $2 \mu \mathrm{l}$ als Ausgangsmaterial für die zweite PCR. Ziel dieser PCR war es Barcodes an die zuvor amplifizierte V1/V2-Region anzubauen. Hierzu wurde ein spezieller Forward Primer mit Überhang verwendet, welcher die Barcodes 1-60 enthielt. Als Reverse Primer wurde ein entsprechender Reverse Adapter mit Überhang verwendet. Die übrigen Mengenangaben und das PCR Programm waren identisch zur ersten PCR, es wurden jedoch nur 15 Zyklen für die DNA Synthese eingestellt (Tabelle 3 und Tabelle 4).

Für die dritte PCR diente $1 \mu \mathrm{l}$ vom Produkt der zweiten PCR als Ausgangsmaterial. Ziel war es nun, jeweils einen von 12 verschiedenen Indizes anzubauen. Der Forward Primer enthielt dementsprechend den Index, wobei es sich beim Reverse Primer um einen Multiplexing Primer handelte (Tabelle 5). Das PCR Programm wurde auf 10 Zyklen eingestellt (Tabelle 6). Die PCR basiert auf dem Protokoll von Camarinha-Silva et al. (Camarinha-Silva et al., 2014). 
Tabelle 1: Volumina der 1. PCR

\begin{tabular}{|c|c|}
\hline Angaben in $\boldsymbol{\mu l}$ & Volumen \\
\hline 4 & Puffer \\
\hline 1,6 & dNTPs \\
\hline 0,5 & Forward Primer (27F) \\
\hline 0,5 & Peverse Primer (338R) \\
\hline 0,2 & DNA Template \\
\hline 2,0 & DEPEC Wasser \\
\hline 11,2 & Gesamtes Volumen \\
\hline 20 &
\end{tabular}

Tabelle 2: Programm der 1. PCR

\begin{tabular}{|c|c|c|}
\hline Temperatur & Zeit & \\
\hline $95{ }^{\circ} \mathrm{C}$ & $3 \mathrm{~min}$ & \\
\hline $98{ }^{\circ} \mathrm{C}$ & 10 sek & \\
\hline $55^{\circ} \mathrm{C}$ & 10 sek & \\
\hline $72{ }^{\circ} \mathrm{C}$ & 45 sek & \\
\hline $72{ }^{\circ} \mathrm{C}$ & 2 min & \\
\hline $4{ }^{\circ} \mathrm{C}$ & Pausen & \\
\hline
\end{tabular}

Tabelle 3: Volumina der 2. PCR

\begin{tabular}{|c|c|}
\hline Angaben in $\boldsymbol{\mu l}$ & Volumen \\
\hline 4 & Puffer \\
\hline 1,6 & dNTPs \\
\hline 0,5 & Forward Primer (Barcode 1-60) \\
\hline 0,5 & Poverse Primer (Reverse Adapter) \\
\hline 0,2 & DNA Template \\
\hline 2,0 & DEPEC Wasser \\
\hline 11,2 & Gesamtes Volumen \\
\hline 20 & \\
\hline
\end{tabular}


Tabelle 4: 2. Programm der 2. PCR

\begin{tabular}{|c|c|c|}
\hline Temperatur & Zeit & \\
\hline $95{ }^{\circ} \mathrm{C}$ & $3 \mathrm{~min}$ & \\
\hline $98{ }^{\circ} \mathrm{C}$ & 10 sek & \\
\hline $55^{\circ} \mathrm{C}$ & 10 sek & $\mathbf{1 5}$ Zyklen \\
\hline $72{ }^{\circ} \mathrm{C}$ & 45 sek & \\
\hline $72{ }^{\circ} \mathrm{C}$ & $2 \mathrm{~min}$ & \\
\hline $4{ }^{\circ} \mathrm{C}$ & Pause & \\
\hline
\end{tabular}

Tabelle 5: Volumina der 3. PCR

\begin{tabular}{|c|c|}
\hline Angaben in $\boldsymbol{\mu l}$ & Volumen \\
\hline 10 & Puffer \\
\hline 4 & dNTPs \\
\hline 1,25 & Reverse Primer (Multiplexing) \\
\hline 1,25 & Polymerase \\
\hline 0,5 & DNA Template \\
\hline 1,0 & DEPEC Wasser \\
\hline 32 & Gesamtes Volumen \\
\hline 50 & \\
\hline
\end{tabular}

Tabelle 6: Programm der 3. PCR

\begin{tabular}{|c|c|c|}
\hline Temperatur & Zeit & \\
\hline $95{ }^{\circ} \mathrm{C}$ & 3 min & \\
\hline $98{ }^{\circ} \mathrm{C}$ & 10 sek & \\
\hline $55^{\circ} \mathrm{C}$ & 10 sek & 10 Zyklen \\
\hline $72{ }^{\circ} \mathrm{C}$ & 45 sek & \\
\hline $72{ }^{\circ} \mathrm{C}$ & 2 min & \\
\hline $4^{\circ} \mathrm{C}$ & Pause & \\
\hline
\end{tabular}




\begin{tabular}{|c|}
\hline 1. PCR: Vervielfältigung V1/V2-Region der 16S rRNA \\
\hline $\begin{array}{l}\text { Forward primer: 5'-27 Fw -3' } \\
\text { 5' - AGAGTTTGATCMTGGCTCAG -3' }\end{array}$ \\
\hline $\begin{array}{l}\text { Reverse primer: 5'-338 Rev -3' } \\
\text { 5' - TGCTGCCTCCCGTAGGAGT -3' }\end{array}$ \\
\hline 2. PCR: Anbau der Barcodes (Beispielhaft) \\
\hline $\begin{array}{l}\text { Forward primer: Barcode (Beispiel Barcode } 1 \text { von } 60 \text { möglichen) } \\
\text { 5'-ACACTCTTTCCCTACACGACGCTCTTCCGATCTTTATGCCAAGAGTTTGATCMTGGCTCAG -3' }\end{array}$ \\
\hline $\begin{array}{l}\text { Reverse primer: Reverse Adapter } \\
\text { 5' - GTGACTGGAGTTCAGACGTGTGCTCTTCCGATCTTGCTGCCTCCCGTAGGAGT -3' }\end{array}$ \\
\hline 3. PCR: Anbau der Indizes (Beispielhaft) \\
\hline $\begin{array}{l}\text { Forward primer: Index (Beispiel } 1 \text { von 12) } \\
\text { 5' -AATGATACGGCGACCACCGAGATCTACACTCTTTCCCTACACGACGCTCTTCCGATCT-3' }\end{array}$ \\
\hline $\begin{array}{l}\text { Reverse primer: Multiplexing } \\
\text { 5' -CAAGCAGAAGACGGCATACGAGATCGTGATGTGACTGGAGTTC-3' }\end{array}$ \\
\hline
\end{tabular}

\subsubsection{Gelelektrophorese und Aufreinigung des PCR-Produktes}

Um festzustellen ob die PCR erfolgreich war, wurden von jeder Probe nach der 3. PCR $5 \mu \mathrm{l}$ der Probe mit $1 \mu \mathrm{l}$ 6x Loading Dye in eine Kammer auf ein zweiprozentiges Agarosegel aufgetragen. In die erste Kammer wurden $2 \mu \mathrm{l} 100$ bp-Marker gegeben. Zusätzlich wurden eine Positivkontrolle mit DNA von Streptococcus mutans UA 159, sowie eine Negativkontrolle ohne DNA mit aufgetragen. Danach wurde das Gel mit 5x TE-Puffer überschwemmt und für 30 min bei $100 \mathrm{~V}$ angeschlossen. Nach einem 10-minütigen Ethidiumbromid-Bad konnten die Gele auf dem GelDoc XR betrachtet werden. Es ergaben sich folgende Gelbilder: 


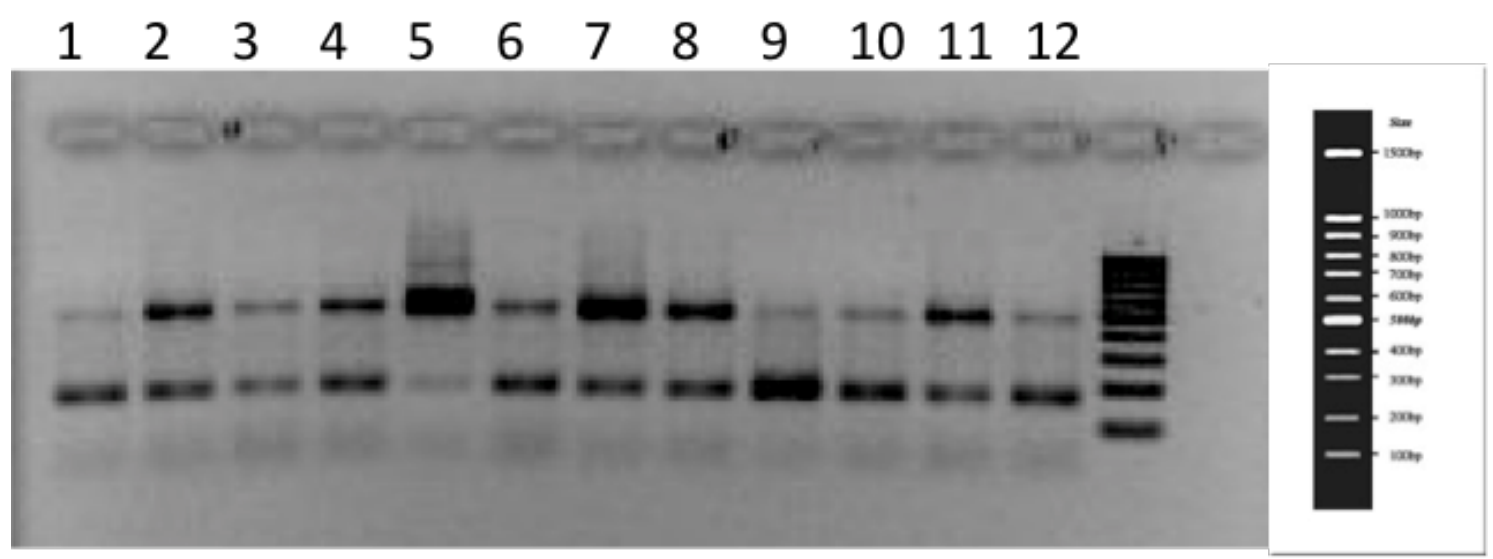

Abbildung 3: Gelbild für die Proben 1 bis 12

$\begin{array}{llllllllll}13 & 14 & 15 & 16 & 17 & 18 & 19 & 20 & 21 & 22 \\ \text { pos neg }\end{array}$

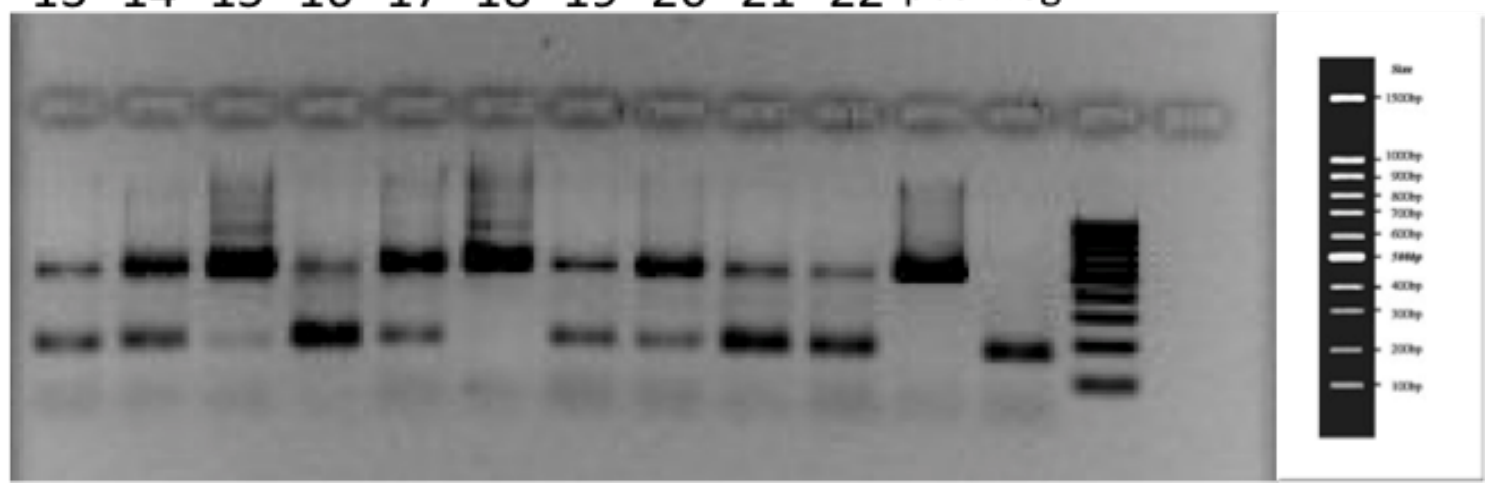

Abbildung 4: Gelbild für die Proben 13 bis 22, positiv und negativ

$\begin{array}{llllllllllll}23 & 24 & 25 & 26 & 27 & 28 & 29 & 30 & 31 & 32 & 33 & 34\end{array}$

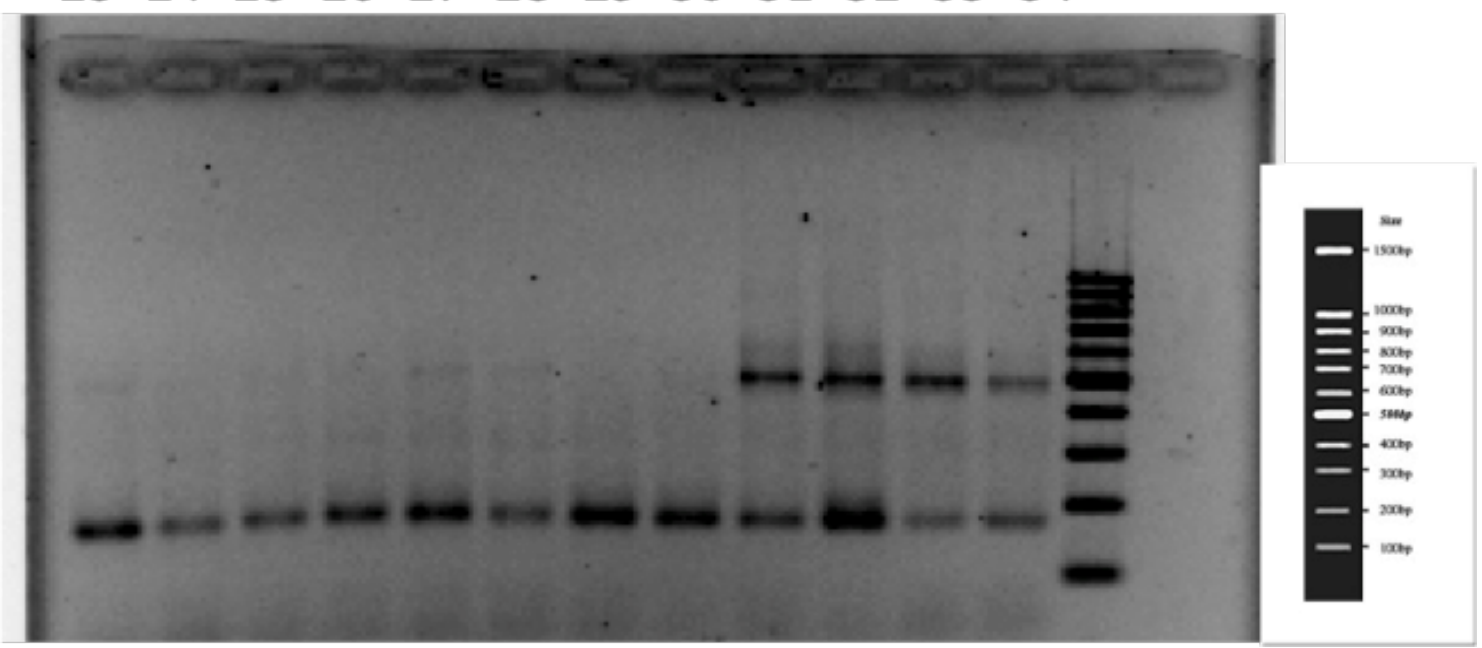

Abbildung 5: Gelbild für die Proben 23 bis 34 


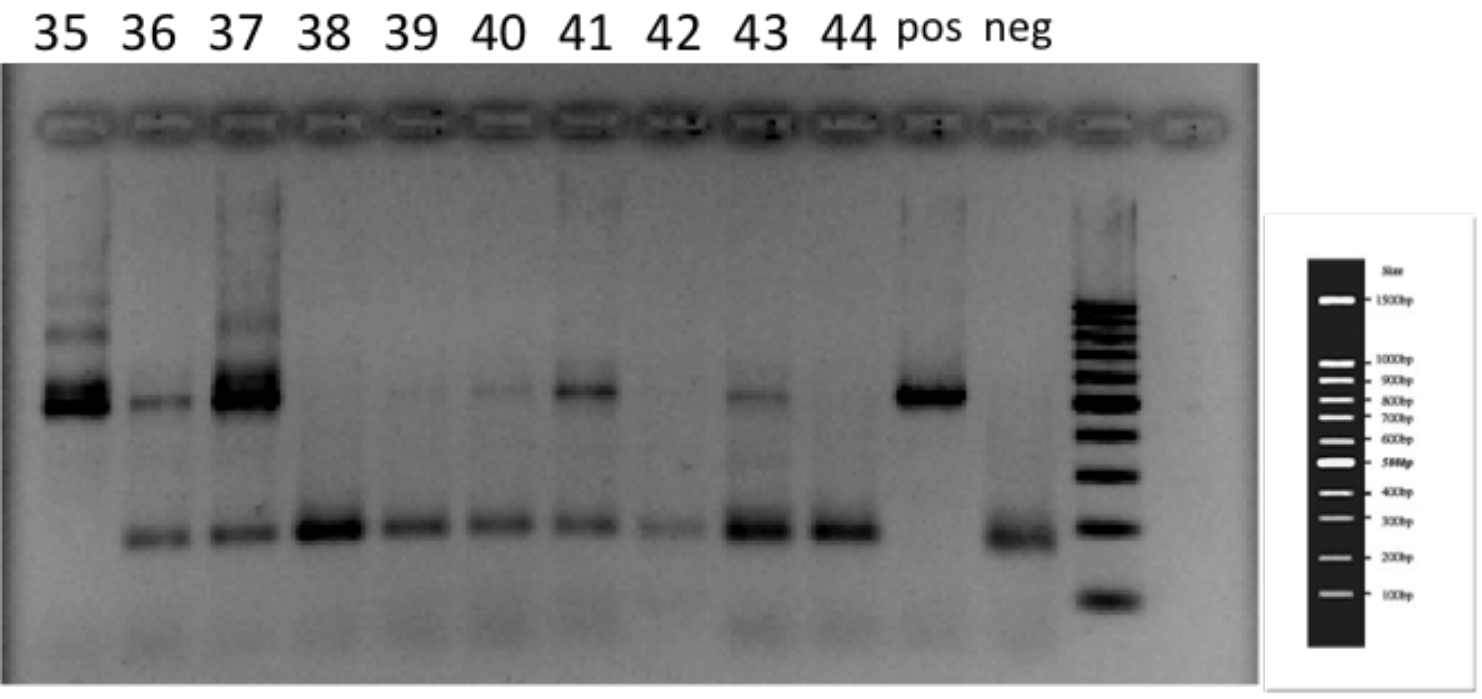

Abbildung 6: Gelbild für die Proben 35 bis 44, positiv und negativ

\section{$\begin{array}{llllllllllll}45 & 46 & 47 & 48 & 49 & 50 & 51 & 52 & 53 & 54 & 55 & 56\end{array}$}

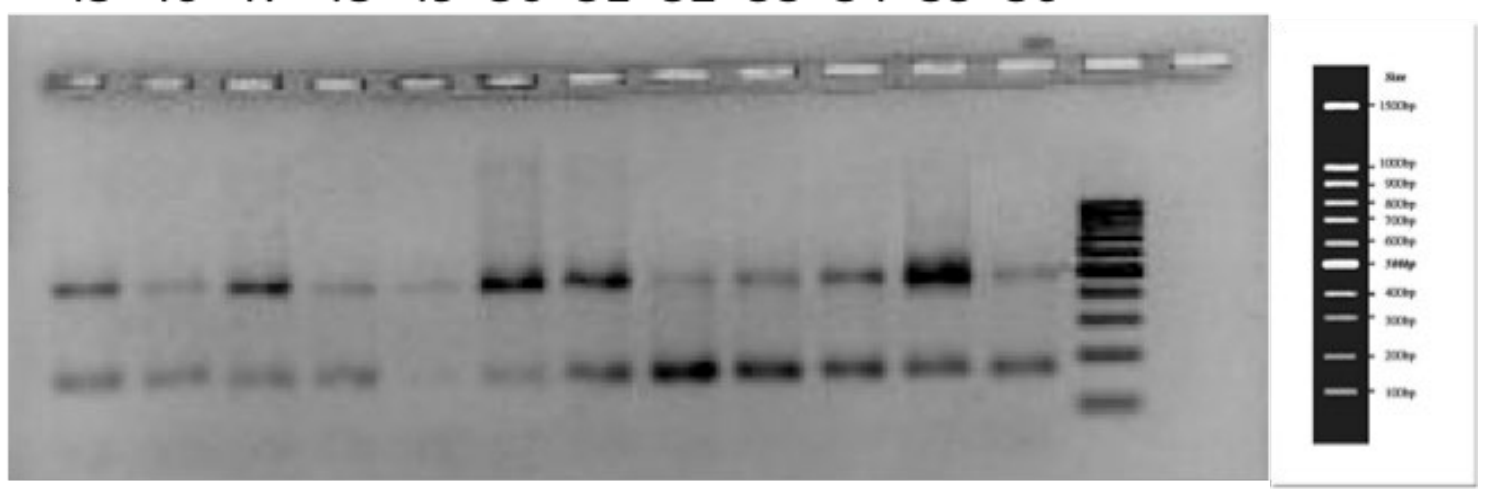

Abbildung 7: Gelbild für die Proben 45 bis 56

57585960 pos neg

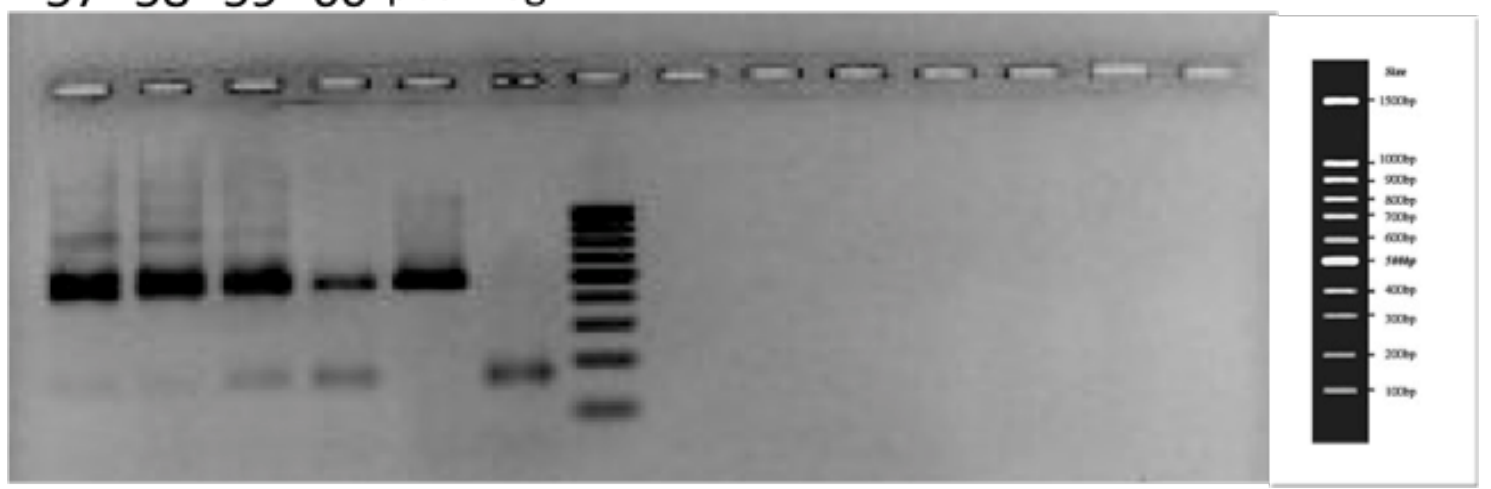

Abbildung 8: Gelbild für die Proben 57 bis 60, positiv und negativ 
Es waren an nahezu allen Gelen zwei Banden sichtbar. Proben, an denen keine Banden sichtbar waren, wurden erneut bearbeitet (PCR). Mithilfe des Markers konnte die obere Bande bei ca. 500 bp identifiziert werden, welches dem gewollten PCR-Produkt entspricht. Die zweite Bande bildete sich bei ca. $230 \mathrm{bp}$ ab. Hierbei handelt es sich um Primer-Dimere aus der 2. und 3. PCR. Dass Primer-Dimere entstehen, lässt sich dadurch erklären, dass die DNA-Menge der Proben relativ gering war und somit überschüssige Primer, die nicht verbraucht wurden, Dimere gebildet haben. Da nur die DNA der oberen Bande für die weiteren Schritte verwendet werden sollte, wurde das komplette PCR-Produkt der 3. PCR auf Gele mit vergrößerten Kammern aufgetragen und jeweils die obere Bande über dem UV-Gerät mit einem Skalpell ausgeschnitten. Als nächstes wurden die Gelstücke mit DNA aufgereinigt (Gel Extraction Kit, Qiagen, Hilden, Deutschland), wofür verschiedene Puffer und Isopropanol verwendet wurden. Zu Beginn wurde auf das Gelstück im Eppendorfgefäß QG-Puffer gegeben, um den $\mathrm{pH}-$ Wert stabil zu halten und mit Wärme $\left(55^{\circ} \mathrm{C}\right)$ das Gelstück aufzulösen. Danach wurde Isopropanol verwendet, um mehr DNA aus der Lösung herauszulösen. Das gesamte Volumen wurde in mehreren Schritten auf eine Säule gegeben und mit PE-Puffer versetzt, welcher die Ladungsverbindung zwischen Silikamembran und DNA löst und die Salze herauswäscht. Zuletzt wurde EB-Puffer (Elution Buffer) auf die Säule gegeben und die DNA darin gelöst.

\subsubsection{DNA-Konzentrationsmessung}

Von dem aufgereinigten PCR-Produkt (Amplikon) konnte anschließend die Konzentrationsmessung erfolgen. Diese wurde mithilfe von Picogreen (Thermofisher) durchgeführt. Picogreen ist ein fluoreszierender Stoff, der sich in die DNA einlagert. Je mehr DNA vorhanden ist, desto mehr Picogreen lagert sich ein und umso größer ist die Fluoreszenz, die anschließend gemessen werden kann. Zunächst wurde dazu der mitgelieferte 20x TE-Puffer zu 1x TE-Puffer verdünnt und somit $100 \mu \mathrm{l} 20 x$ TE-Puffer mit 19,9 ml sterilem $\mathrm{H}_{2} \mathrm{O}$ versetzt. Für 1 $\mu$ l Picogreen pro Probe wurden $199 \mu \mathrm{l}$ 1x TE-Puffer benötigt, sodass für 96 Proben pro Platte $96 \mu$ l Picogreen und 19,104 ml 1x TE-Puffer errechnet wurden. Auf jede Platte wurden dauaufhin $190 \mu$ Picogreen in 1x TE-Puffer und $10 \mu \mathrm{l}$ Probe gemischt, wobei jede Probe doppelt aufgetragen wurde. Anhand einer Standard-DNA mit der bekannten Konzentration von $100 \mathrm{ng} / \mu \mathrm{l}$ wurde eine Verdünnungsreihe wie folgt erstellt: $0,1,2,3,4,5,6,7,8,9,10$ und 20 (alle Werte in $\mathrm{ng} / \mathrm{\mu l}$ ).

Nun wurde die Absorption mit einem Victor 3v (Perkin Elmer) bei $530 \mathrm{~nm}$ gemessen. Aus den Werten der Verdünnungsreihe konnte eine Kalibrierungskurve (Abbildung 10) erstellt werden, anhand welcher die DNA- 
Konzentration in allen restlichen Proben berechnet werden konnte. Daraus wiederum wurde ermittelt, welches Volumen jeder Probe eingesetzt werden muss, um $10 \mathrm{ng}$ DNA von jeder Probe zu erhalten. Dies ist notwendig, da beim Sequenzieren von jeder Probe die gleiche Masse an DNA von $10 \mathrm{ng}$ vorhanden sein soll, um vergleichbare Ergebnisse zu haben. Schließlich wurden alle Proben mit dem gleichen Index in den errechneten Volumina zusammen pipettiert.

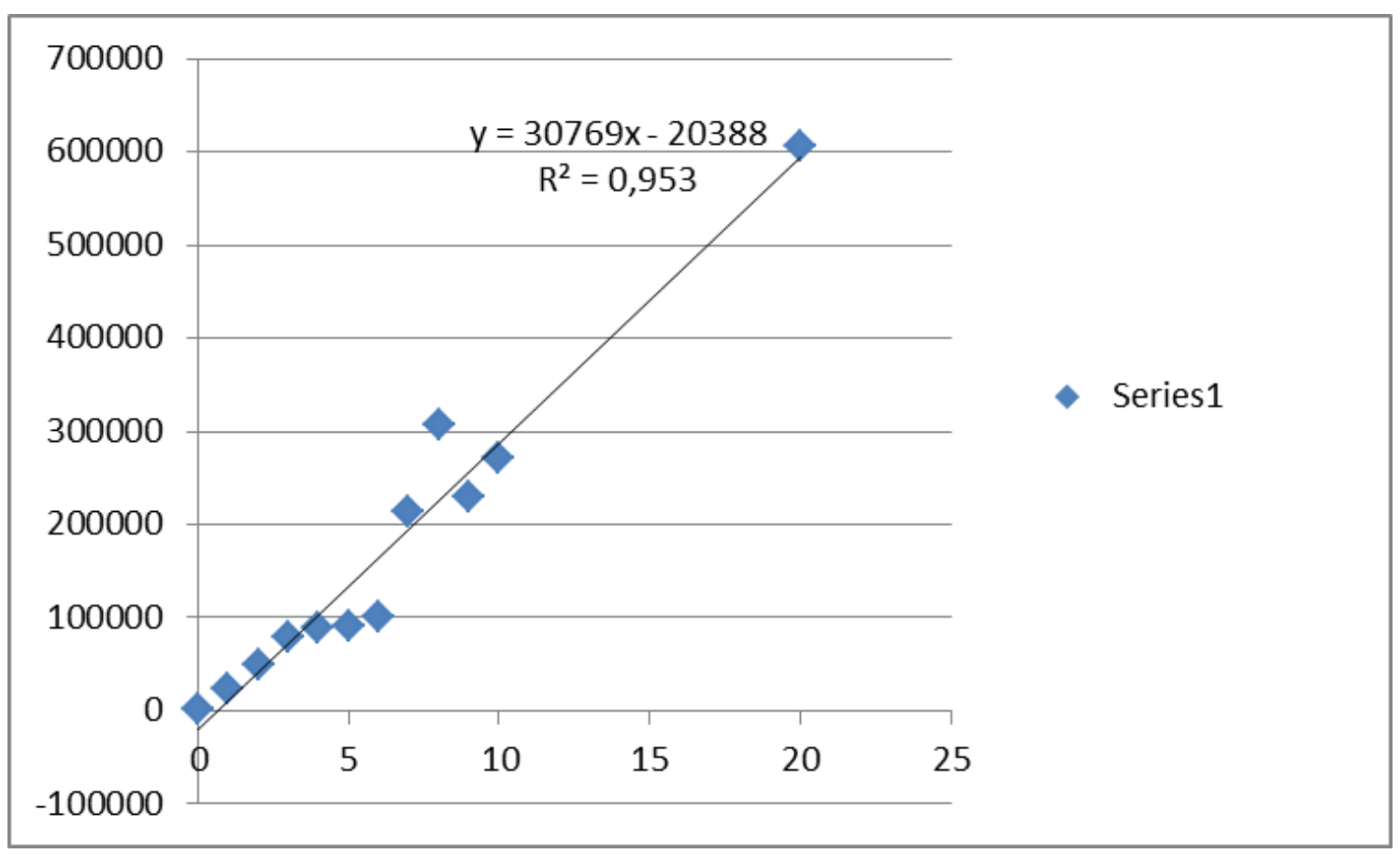

Abbildung 9: Kalibrierungskurve. Mithilfe der Kalibrierungskurve wurde die DNAKonzentration der einzelnen Proben bestimmt.

Die zusammen pipettierten Proben mit gleichen Indizes wurden erneut aufgereinigt und in EB-Puffer verdünnt. Anschließend wurde erneut eine Probe von $2 \mu \mathrm{l}$ auf ein Gel aufgetragen, um festzustellen, ob DNA in der Probe vorhanden ist. 


\subsection{Sequenzierung und Datenauswertung}

Alle Proben wurden auf einem MiSeq-Sequenziergerät von Illumina sequenziert. Insgesamt wurden 2.623.546 reads für 60 Proben produziert. Im Anschluss wurden die reads mit 97 \% Ähnlichkeit zu Operational Taxonomic Units (OTU, im Folgenden vereinfacht als Sequenz bezeichnet) zusammengefasst, alle Singletons (ein read pro Sequenz) und Doubletons (zwei reads pro Sequenz) entfernt. Ebenso wurden alle Sequenzen, die weniger als $0,01 \%$ reads pro Probe aufwiesen (im Vergleich zu der gesamten Readzahl), entfernt.

Nach der bioinformatischen Datenreinigung blieben 913 OTUs übrig, die für die weitere Analyse verwendet wurden. Im Folgenden wurden die OTUs gegen die Human Oral Microbiome Database (HOMD) geblasted (Abgleich der Sequenzen). Als Kriterium für die Artbestimmung wurde hier die 99-prozentige Ähnlichkeit verwendet. Bei einer nicht-eindeutigen Zuordnung einer Sequenz wurde die nächsthöhere Ebene (Genus) ausgewählt. Alle Sequenzen, die nicht zugeordnet werden konnten, wurden erneut gegen die Ribosomal Database Classifier-Datenbank geblasted. Hier wurde als Kriterium eine 95-prozentige Ähnlichkeit ausgewählt. Das Prozedere des Sequenzabgleiches ist in Abbildung 11 zu sehen.

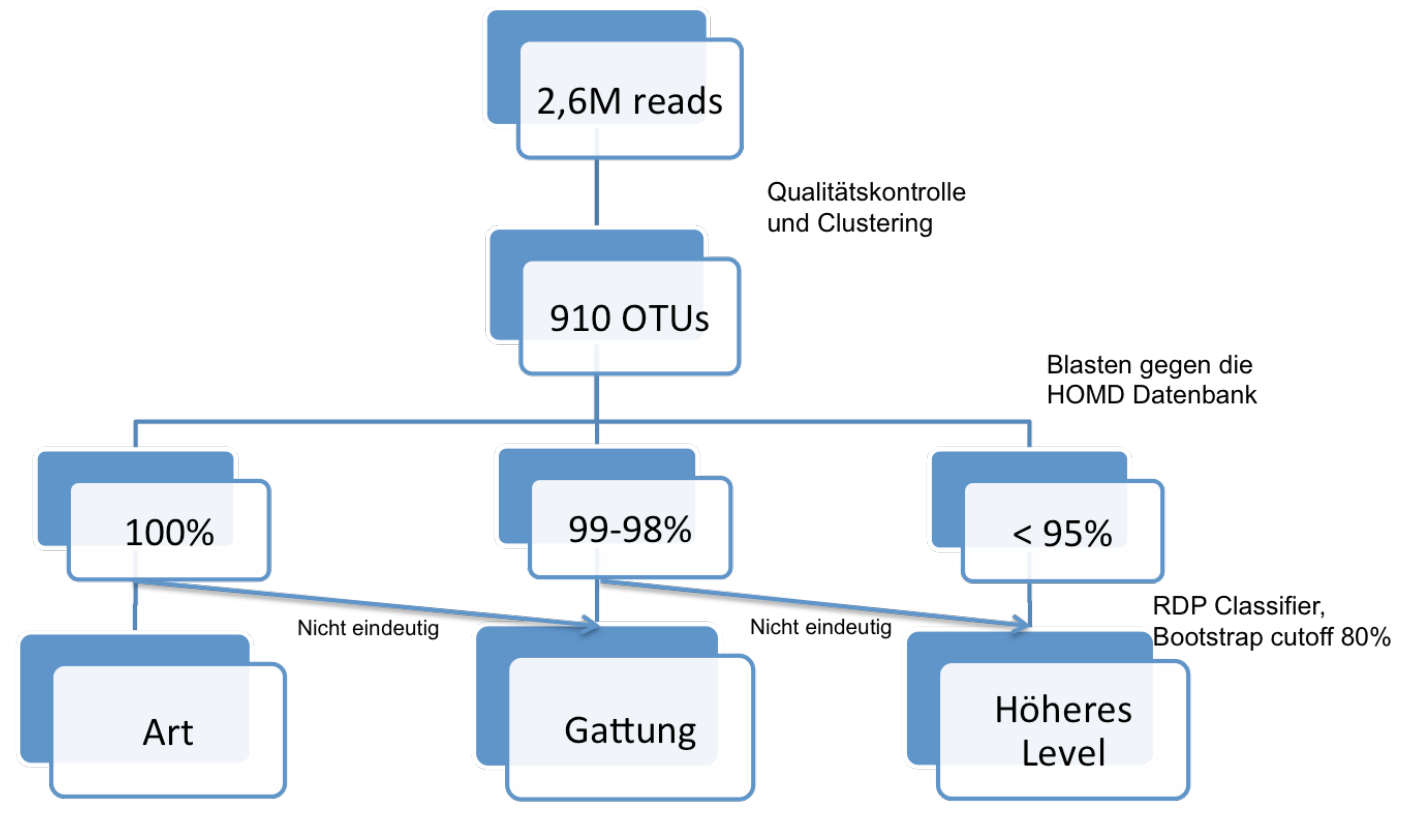

Abbildung 10: Sequenzabgleich. Die Abbildung zeigt schematisch den Prozess des Sequenzabgleiches. 


\subsection{Statistische Analyse}

Für die statistische Analyse wurden sowohl Microsoft Excel als auch das Ökologische Statistikprogramm Primer6 (Version 6.1.16)/Permanova (Version 1.0.6) (Primer e, Auckland, Neuseeland) verwendet. Die Rarefaction-Kurven wurden mithilfe des Open-Source-Statistikprogrammes R (Version 3.3.1) erstellt. Neben den Standardpaketen wurde hier noch zusätzlich das Paket "vegan“ verwendet.

Die Biomarkeranalyse erfolgte mit dem Onlinetool Lefse (http://huttenhower.org/galaxy/). Die Kriterien für die Identifizierung wurden standardmäßig verwendet: Als wichtigstes Kriterium gilt hierbei der sogenannte LDA-Score, dieser beträgt standardmäßig 2.0. 


\section{$3 \quad$ Ergebnisse}

\subsection{Probandendaten}

Die Geschlechterverteilung der Probanden war nahezu gleichmäßig. Es nahmen 14 Mädchen und 16 Jungen an der Studie teil. Das Alter der Kinder betrug zwischen einem und sechs Jahren. Der Großteil der Kinder war zwischen zwei und vier Jahre alt. Nur ein Kind hatte bereits das Alter von sechs Jahren erreicht. Der ECC-Status der Kinder war ungleichmäßig verteilt. Bei sieben Kindern wurde der ECC-Typ 1 festgestellt, bei 22 Kindern wurde der ECC-Typ 2 diagnostiziert und nur ein Kind konnte dem ECC-Typ 3 zugeordnet werden. 


\subsection{Mikrobiologische Daten}

\subsubsection{Qualität der Proben}

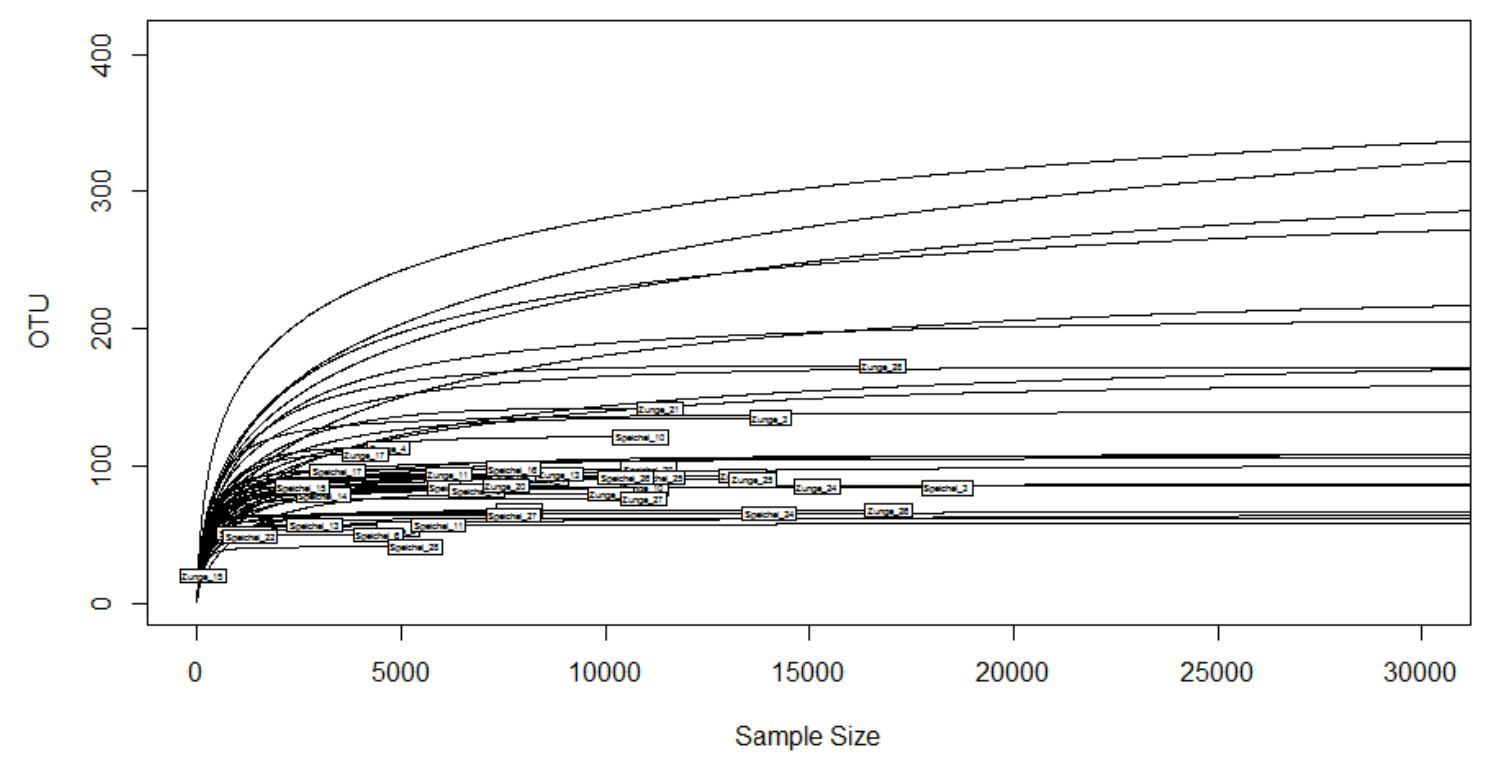

Abbildung 12: Rarefaction-Kurve aller Proben (Cutoff bei 30.000 reads pro Probe).

Durch die Rarefaction-Kurve wurde die Qualität der Proben festgestellt. Für jede Probe wurde eine Kurve ermittelt, welche zunächst einen steileren Anstieg hat und meist in einem Plateau endet. Bei einigen Proben hörten die Kurven bereits im Anstiegsbereich auf und erreichten kein Plateau. Alle Proben, die weniger als 4.000 reads hatten, wurden für die weitere Analyse ausgeschlossen. Dies betraf 3 Proben: Zunge15, Speichel21 und Speichel22. Für die weitere Analyse wurden somit alle Proben mit mehr als 4.000 reads verwendet. Von insgesamt 60 Proben hatten somit 57 Proben eine ausreichende Qualität, um weiter analysiert zu werden (Abbildung 12). 


\subsubsection{Taxonomie}

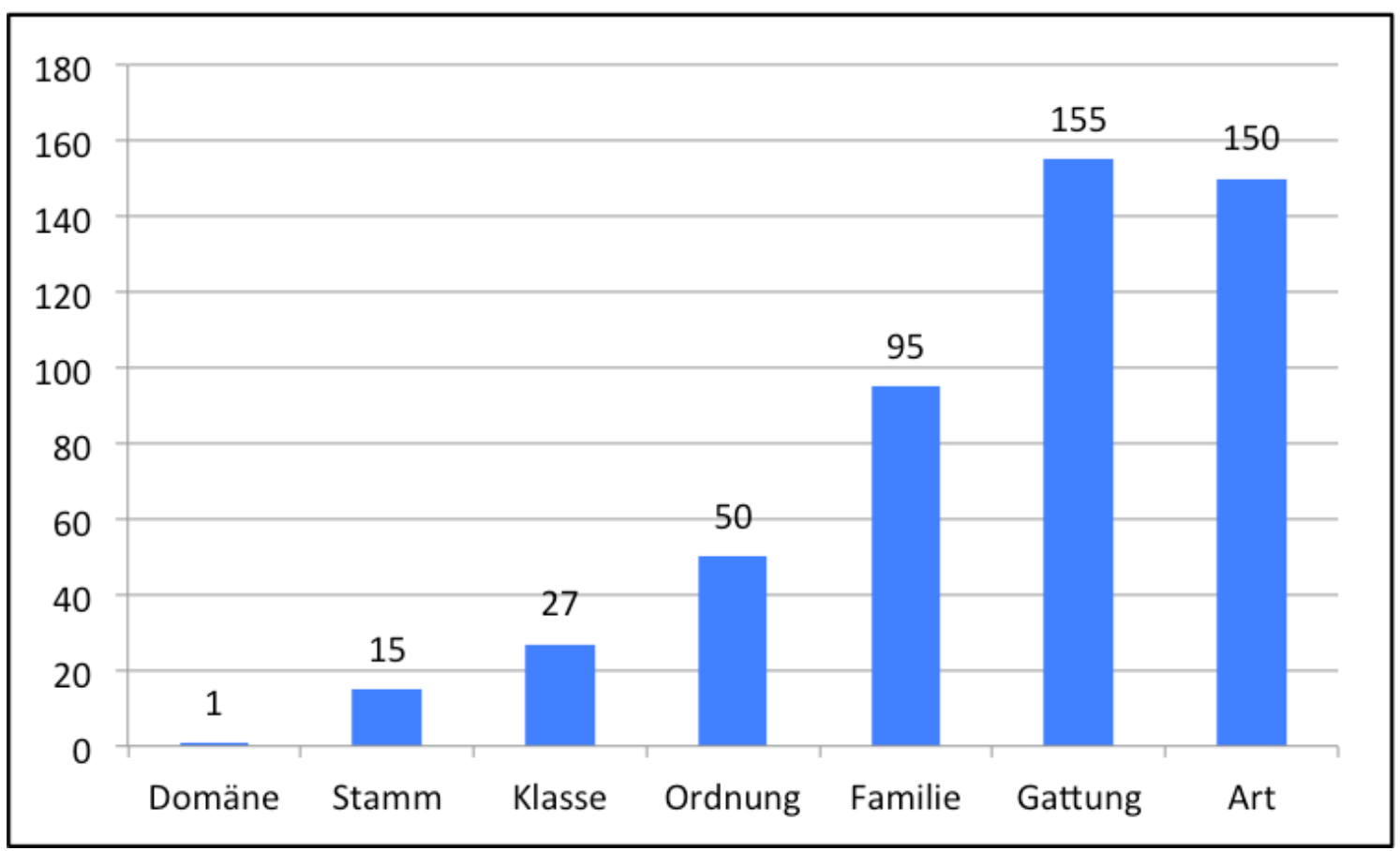

Abbildung 13: Taxonomische Diversität. Die Abbildung zeigt, wie viele Arten, Gattungen, Familien, Ordnungen, Klassen, Stämme und Domänen identifiziert werden konnten.

Es konnten 15 verschiedene Stämme, 27 Klassen, 50 Ordnungen, 95 Familien, 155 Gattungen und 150 verschiedene Arten identifiziert werden (Abbildung 13).

$\mathrm{Zu}$ den vorherrschenden Stämmen, die in großer Anzahl vertreten waren, gehören Firmicutes, Bacteroidetes, Proteobacteria, Actinobacteria und Fusobacteria. Andere Stämme, die nur in geringer Anzahl vorkamen, sind Spirochaetes, Saccheribacteria, Acidobacteria, SR1, Cynaobacteria, Verucomicrobia, Deinococcus-Thermes, Parulbacteria, Gemmatimonadetes und Tenericutes. Gattungen, die am häufigsten detektiert wurden, waren Streptokokken, Prevotella, Granulicatella, Haemophilus und Leptotrichia. Zu den Arten, die insgesamt am meisten gefunden wurden, gehören $G$. haemolysans, $S$. sobrinus und S. mutans (Tabelle 8). 
Tabelle 8: Top 5 Arten, Top 5 Gattungen, Top 5 Stämme, die in allen Proben gefunden werden konnten.

\begin{tabular}{|l|l|l|}
\hline Top 5 Arten & Top $\mathbf{5}$ Gattungen & Top $\mathbf{5}$ Stämme \\
\hline Gemella haemolysans & Streptokokken & Firmicutes \\
\hline Streptococcus sobrinus & Prevotella & Bacteroidetes \\
\hline Streptococcus mutans & Granulicatella & Proteobacteria \\
\hline Haemophilus parainfluenza & Haemophilus & Actinobacteria \\
\hline Porphyromonas sp. & Leptotrichia & Fusobacteria \\
\hline
\end{tabular}

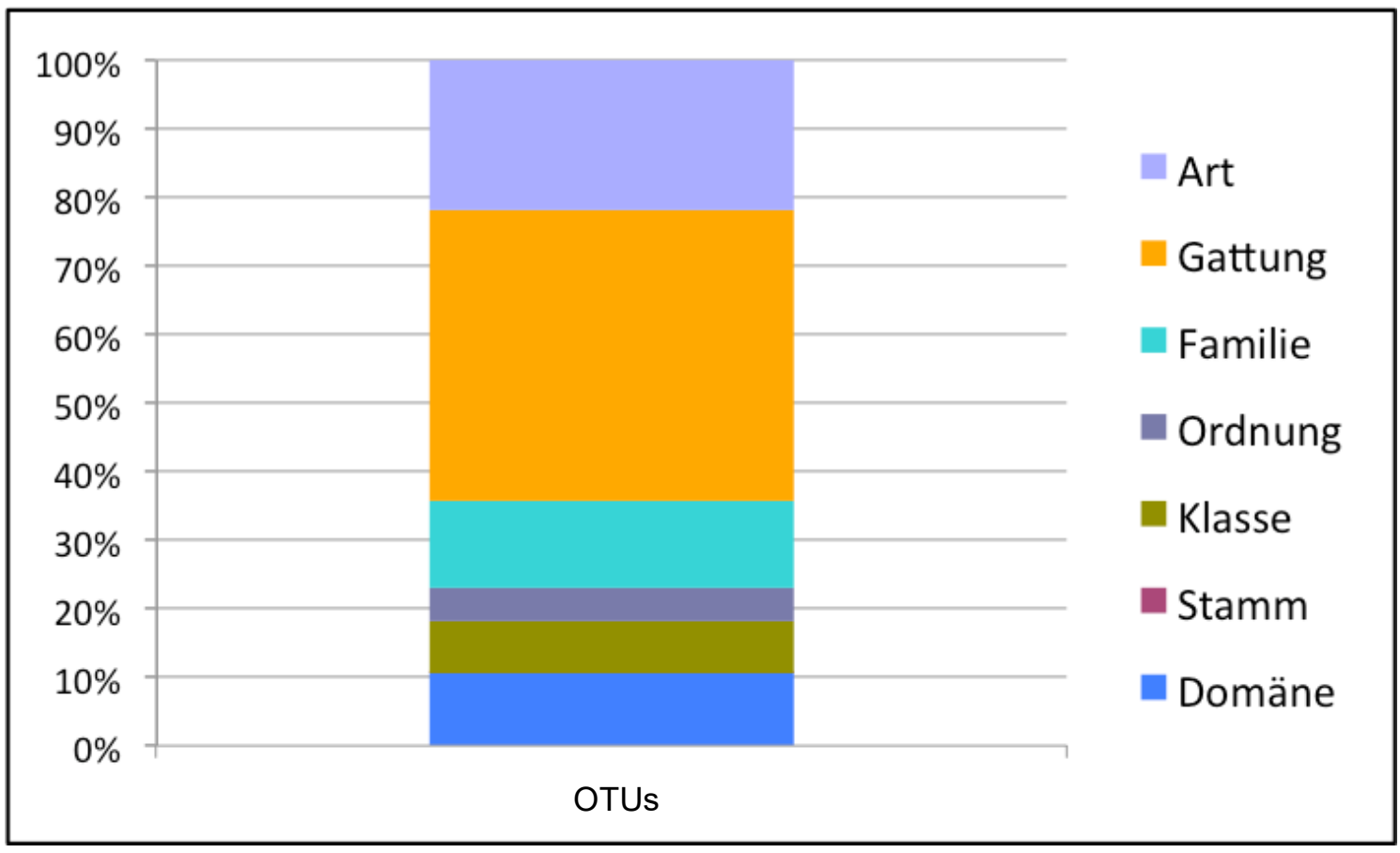

Abbildung 14: Taxonomische Zuordnung der OTUs. Die Abbildung zeigt prozentual, bis zu welcher Ebene die insgesamt 910 OTUs bestimmt werden konnten.

Von den insgesamt 910 OTUs konnten $22 \%$ bis auf Artebene bestimmt werden, $42 \%$ bis zur Ebene Gattung, $13 \%$ bis zur Familie, $5 \%$ bis zur Ordnung, $7 \%$ bis zur Klasse, $0,1 \%$ bis zum Stamm und $11 \%$ bis zur Domäne (Abbildung 14). 


\subsubsection{Vergleichende Analyse der Proben}

Die folgenden Abbildungen zeigen Hauptkomponentenanalysen (Principle Coordinate Analysis), welche nach verschiedenen Indikatoren und Faktoren erstellt werden konnten. Ziel dieser Abbildungen war es, verschiedene Cluster zu identifizieren und somit Ähnlichkeiten bestimmter Proben festzustellen. Die Zahlen an den Achsen beschreiben die Varianz, die durch die jeweilige Hauptkomponente beschrieben werden kann. Bei Addition beider Werte ergibt sich hier knapp $45 \%$, welches ein ordentlicher Wert ist und als Qualitätskriterium angesehen werden kann.

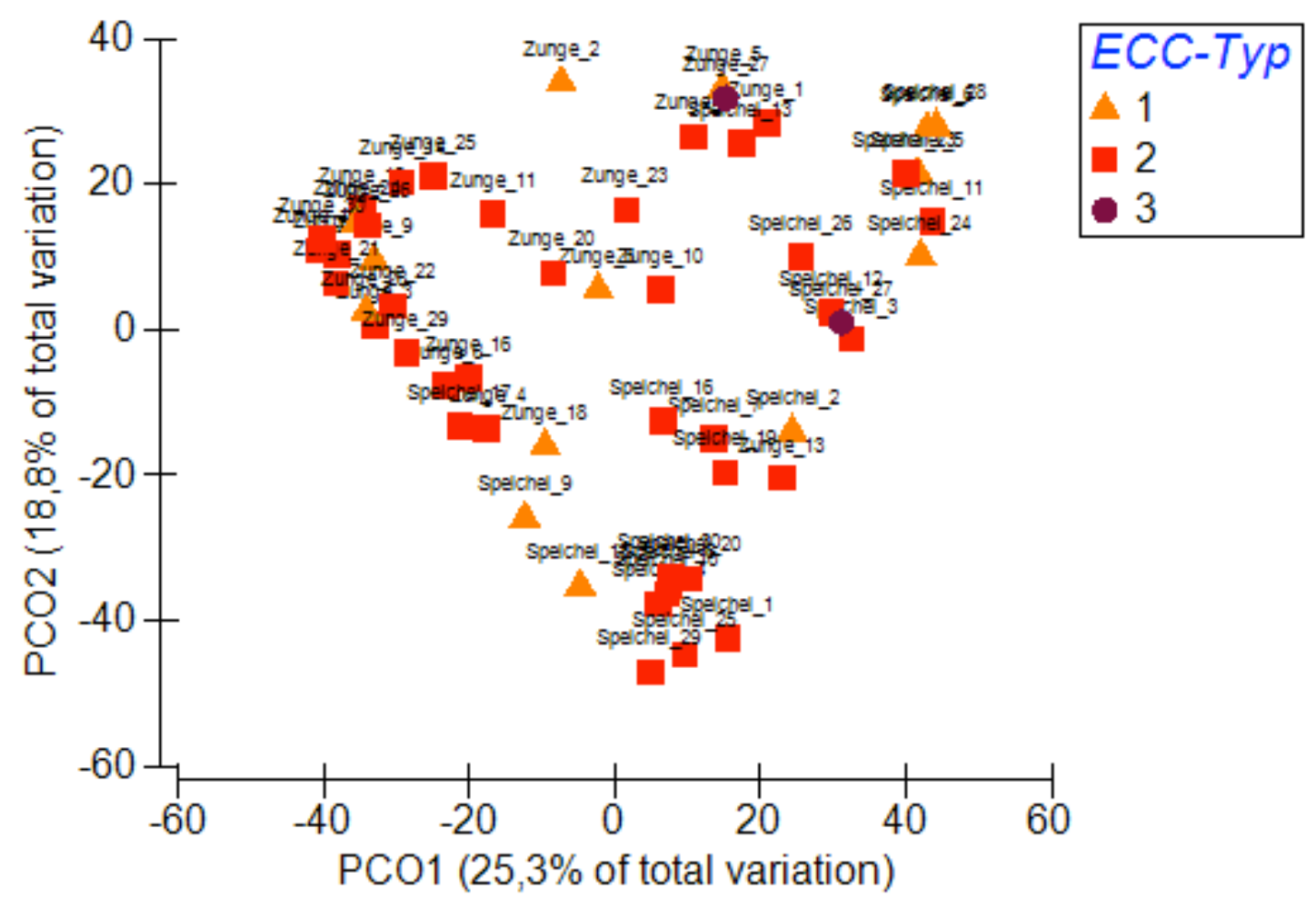

Abbildung 15: Hauptkomponentenanalyse der verschiedenen ECC-Typen.

Der Vergleich der ECC-Typen zeigte eine unwillkürliche Anordnung der verschiedenen ECC-Typen. Jeder ECC-Typ konnte an fast jeder Stelle gefunden werden. Es waren keine deutlichen Gruppen zu erkennen, in denen sich ein bestimmter ECC-Typ vermehrt befand (Abbildung 15). 


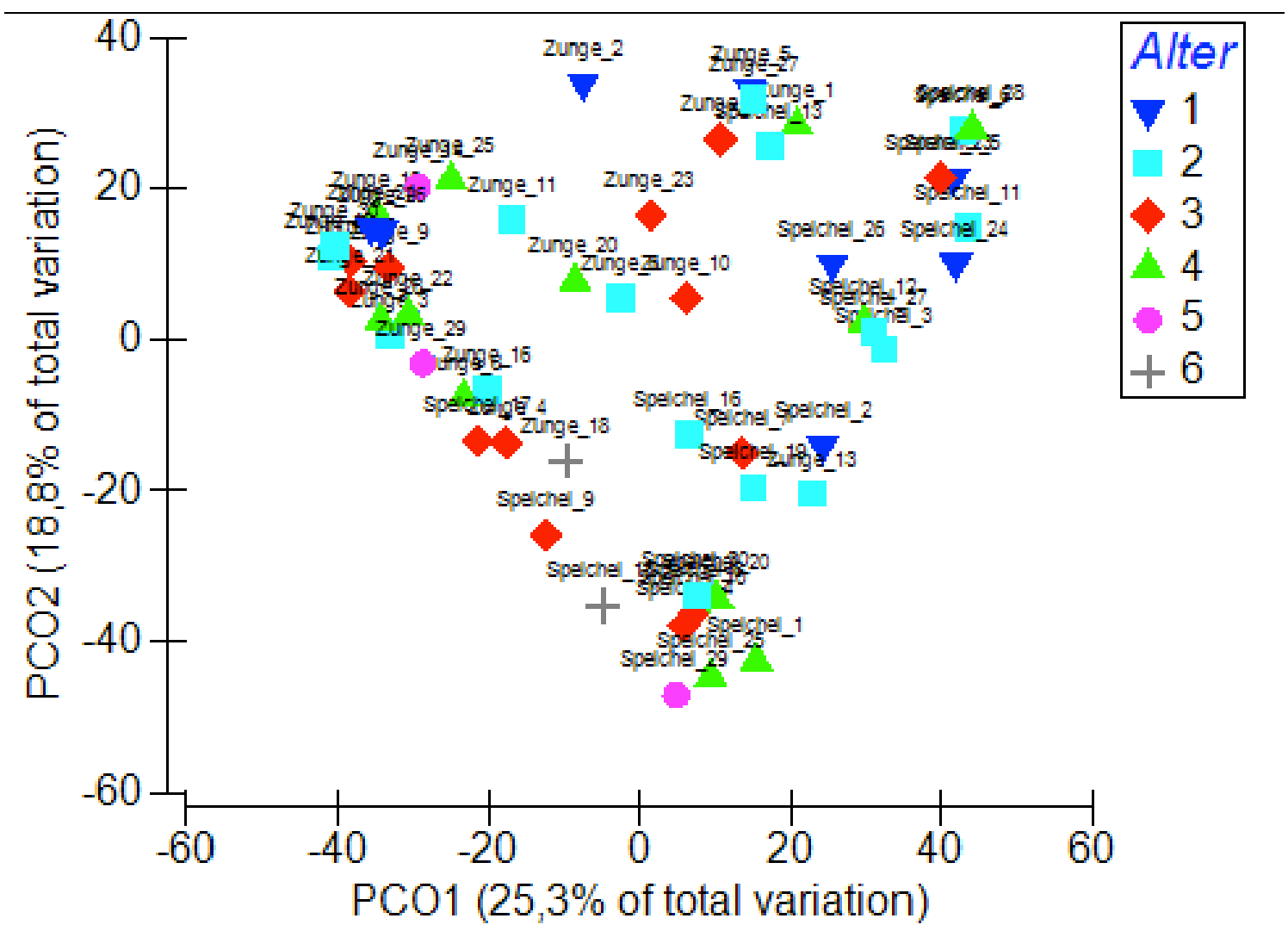

Abbildung 16: Hauptkomponentenanalyse der Proben nach Alter

Der Altersvergleich zeigte ebenfalls keine bestimmten Auffälligkeiten. Auch hier war festzustellen, dass es keine Cluster für bestimmte Altersgruppen gab (Abbildung 16). 


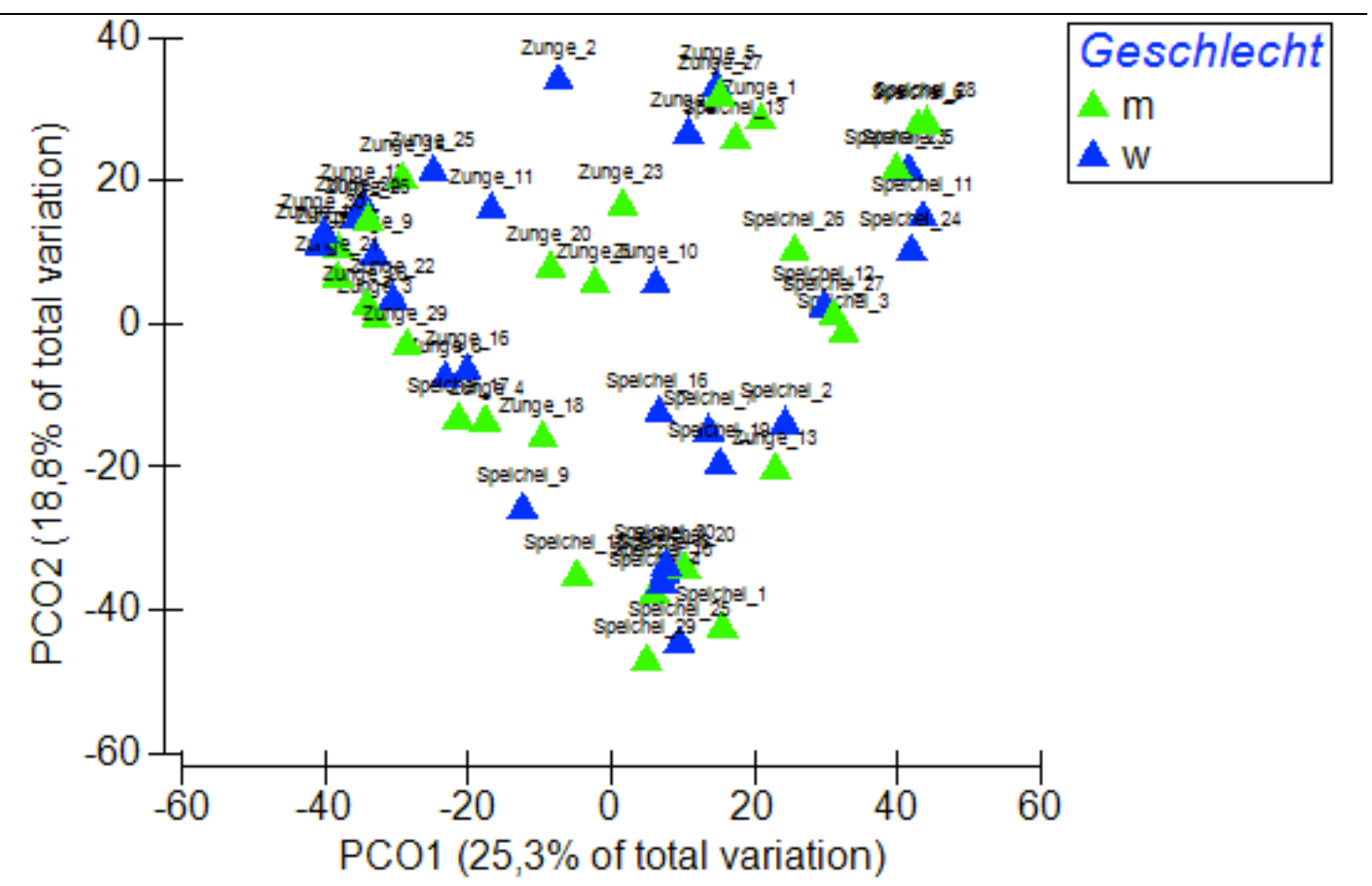

Abbildung 17: Hauptkomponentenanalyse der Proben nach Geschlecht

Beim Vergleich der Geschlechter ergab sich ebenfalls eine deutliche Durchmischung der Proben. Auch hier war festzustellen, dass es keine deutlichen Gruppen für männliche oder weibliche Proben gab (Abbildung 17). 


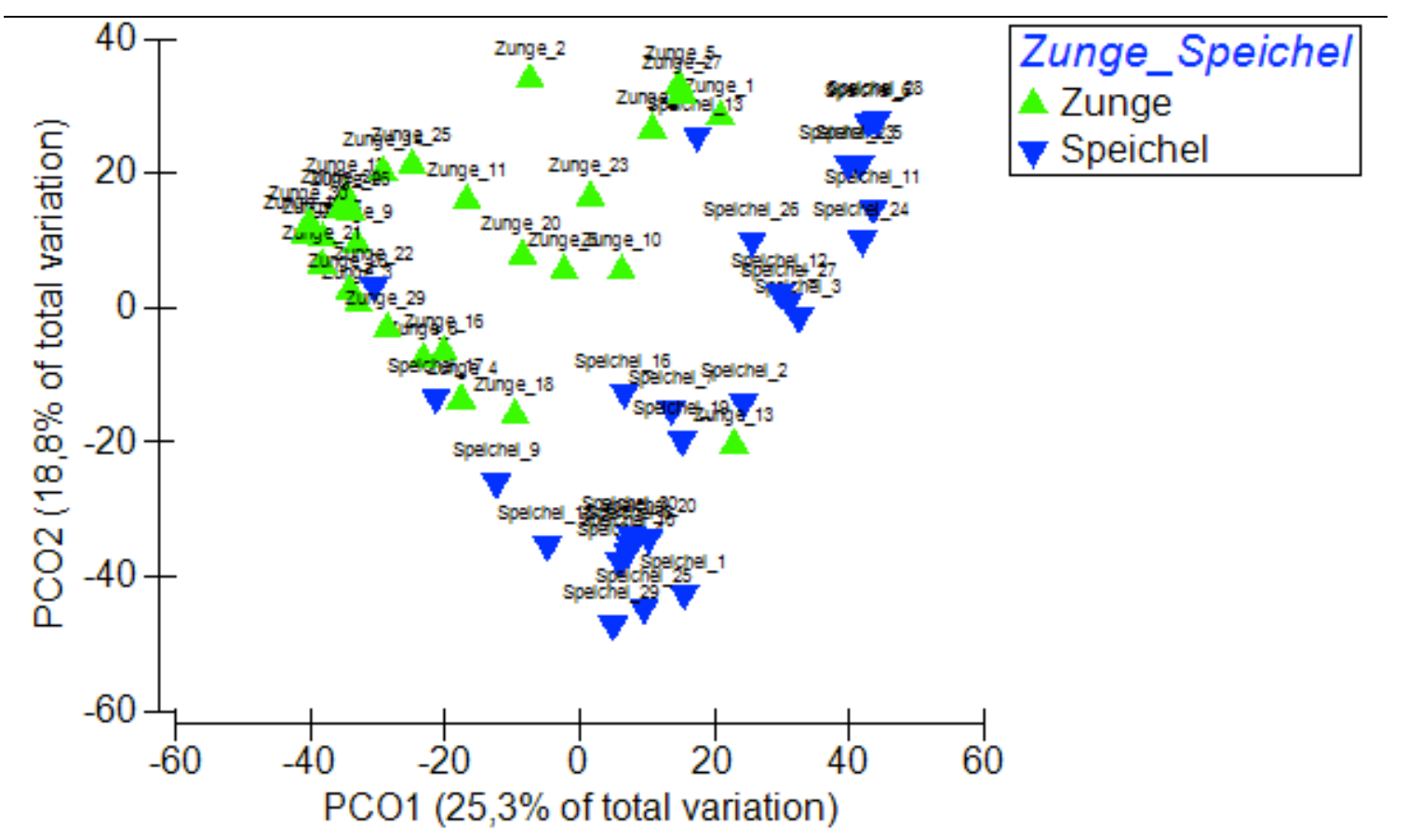

Abbildung 18: Hauptkomponentenanalyse der Zungen- und Speichelproben

Beim Vergleich der Zungen- und Speichelproben wurden Unterschiede sichtbar. Es fand eine deutliche Clusterung der Zungen- und Speichelproben statt. Es ergab sich eine klare Trennung, wobei sich oben links die Zungenproben sammelten und auf der rechten Seite die Speichelproben. Wenige Ausnahmen befanden sich auf beiden Seiten im jeweils anderen Cluster (Abbildung 18). 


\subsubsection{Biomarkeranalyse}

\section{Speichel Zunge}

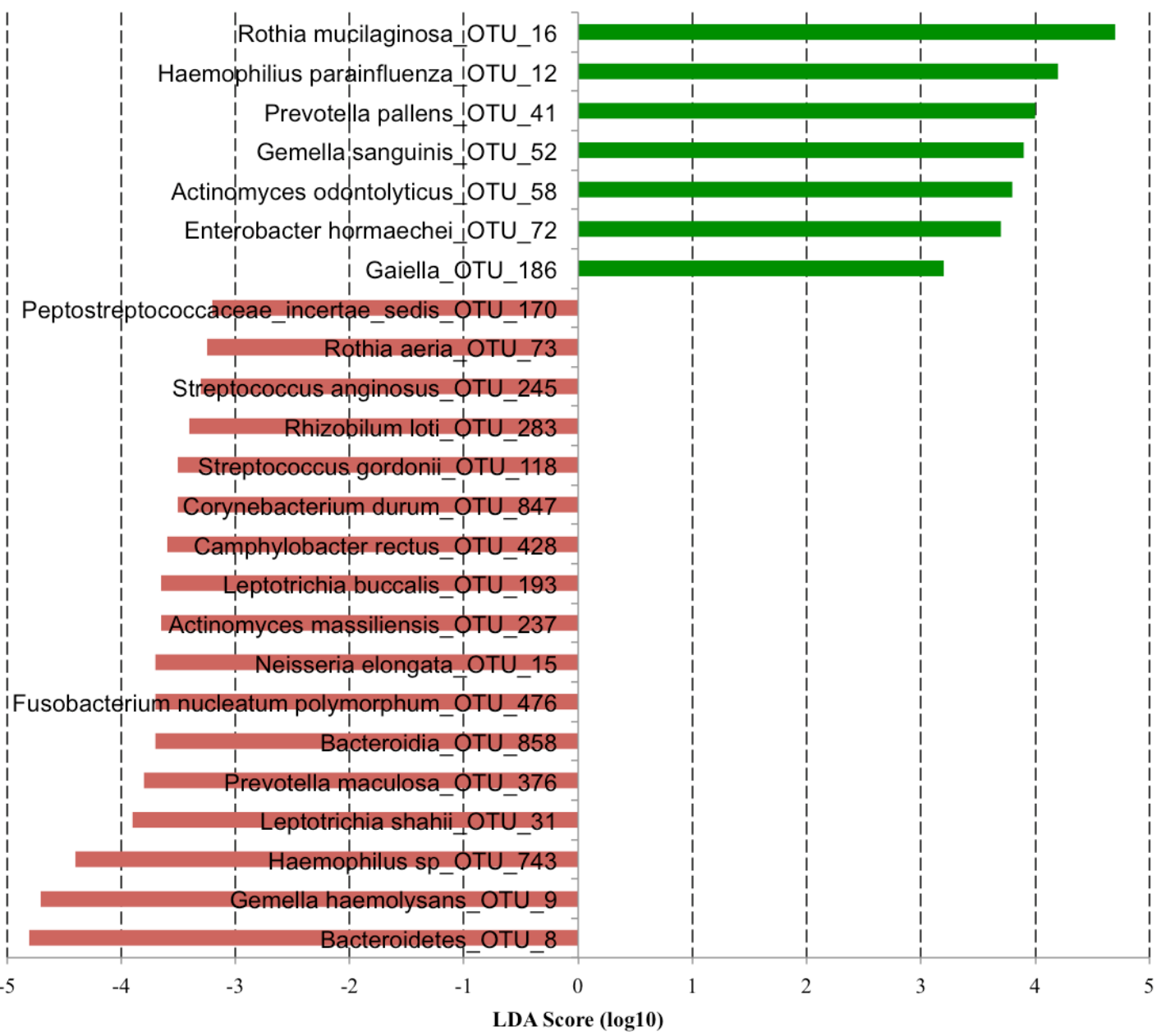

Abbildung 19: Lefse-Biomarkeranalyse. Es sind deutliche Unterschiede in der bakteriellen Zusammensetzung auf der Art- und Gattungsebene zwischen den Proben aus Speichel und von der Zunge zu erkennen.

Anhand der Biomarkeranalyse wurde ermittelt, in welchen OTUs sich die Zungen- und Speichelproben voneinander unterschieden. Die OTUs, die in den Zungenproben am häufigsten gefunden wurden, waren Rothia mucilaginosa, Haemophilus parainfluenzae und Prevotella pallens. Im Gegensatz dazu wurden in den Speichelproben am meisten OTU8 (nur bis auf Stammebene Bacteroidetes bestimmbar), Gemella haemolysans und Heamophilus sp. entdeckt (Abbildung 19). 


\subsubsection{Shannon-Diversität}

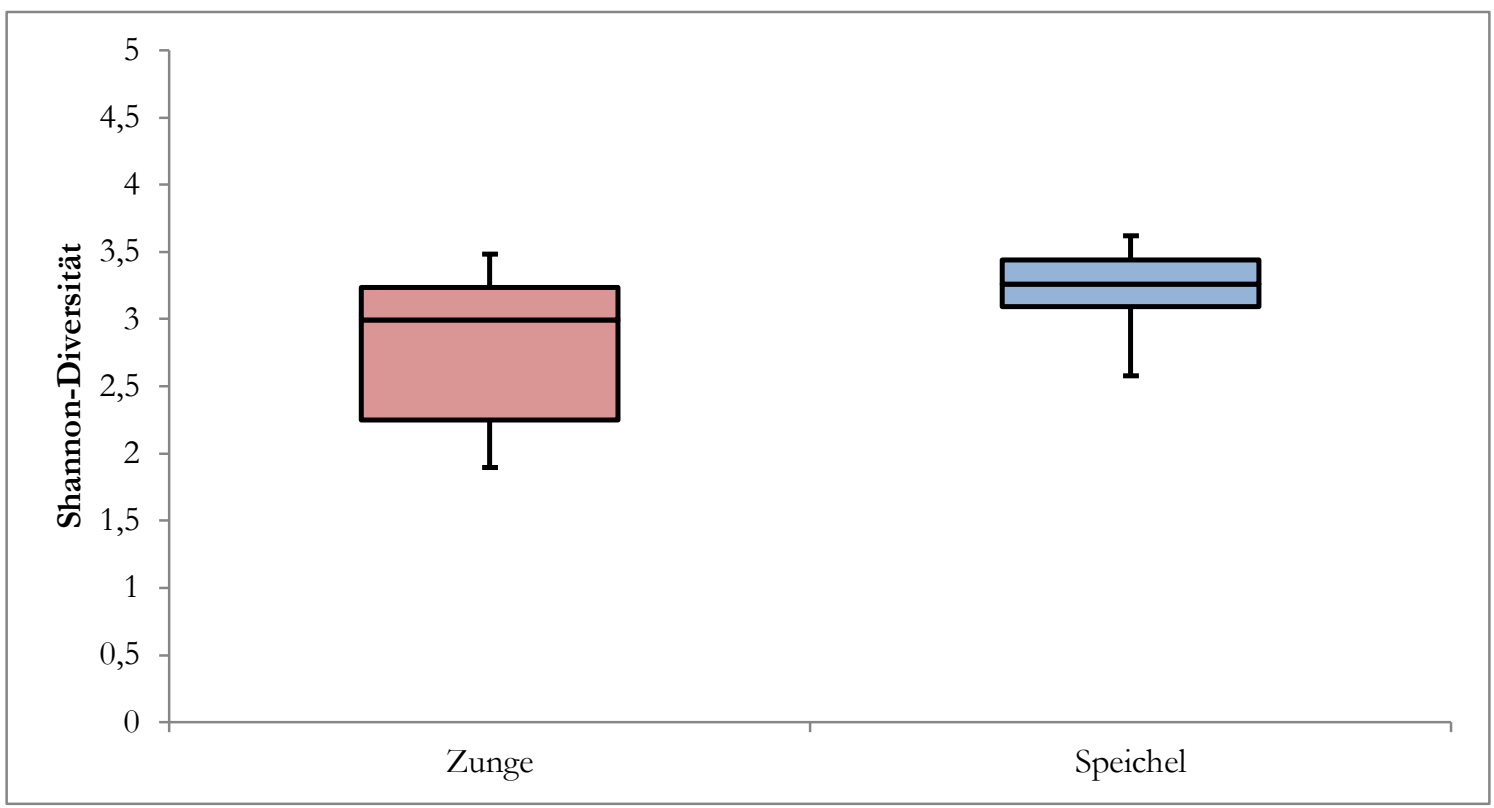

Abbildung 20: Shannon-Diversität. Auf der Zunge ist die bakterielle Diversität tendenziell höher, statistisch aber nicht signifikant.

Die Shannon-Diversität zeigt, wie hoch die Diversität innerhalb der Zungen- und Speichelproben ist. Es war zu sehen, dass die Zungenproben eine höhere Diversität als die Speichelproben aufwiesen. Die verschiedenen Speichelproben waren sich untereinander ähnlicher als die Zungenproben untereinander (Abbildung 20). 


\section{Diskussion}

In der vorliegenden Arbeit wurde die mikrobielle Zusammensetzung in Speichelproben und Zungenabstrichen bei ein- bis sechsjährigen Kindern untersucht, die an ECC erkrankt sind. Ziel dabei war es herauszufinden, ob es potentielle Unterschiedene zwischen den ECC-Typen in Bezug auf die mikrobielle Zusammensetzung der Zungen- und Speichelflora gibt. Darüber hinaus wurde untersucht, ob es Unterschiede zwischen den mikrobiellen Gemeinschaften des Speichels und der Zunge gibt und worin genau sich diese unterscheiden.

Von insgesamt 60 Proben hatten 57 Proben mehr als 4.000 reads und somit eine ausreichende Qualität, um weiter analysiert zu werden. Dies ergab sich daraus, dass die Rarefaction-Kurve bei 4.000 reads ein Plateau ergab und auch die OTUAnzahl ausreichend war. Zu den vorherrschenden Stämmen, die in großer Anzahl vertreten waren, gehören Firmicutes, Bacteroidetes, Proteobacteria, Actinobacteria und Fusobacteria. Gattungen, die am häufigsten vorkamen, waren Streptococcus, Prevotella, Granulicatella, Haemophilus und Leptotrichia. Die Arten, die insgesamt am häufigsten gefunden wurden, waren Gemella haemolysans, S. sobrinus, S. mutans, $H$. parainfluenza und Porphyromonas sp. Von den insgesamt 910 OTUs konnten $22 \%$ bis auf Artebene bestimmt werden, $42 \%$ bis zur Ebene Gattung, $13 \%$ bis zur Familie, $5 \%$ bis zur Ordnung, $7 \%$ bis zur Klasse, 0,1\% bis zum Stamm und $11 \%$ bis zur Domäne.

Wenn man die Proben von Zunge und Speichel miteinander vergleicht, so lassen sich deutliche Unterschiede erkennen. Es gibt eine klare Gruppierung von sowohl Speichel- als auch Zungenproben. OTUs, die am häufigsten in den Zungenproben gefunden wurden, sind den Arten Rothia mucilaginosa, Haemophilus parainfluenzae und Prevotella pallens zuzuordnen. Im Gegensatz dazu wurden in den Speichelproben am häufigsten OTU8 (Zuordnung nur bis zur Stammebene Bacteroidetes möglich), Gemella haemolysans und Heamophilus $s p$. entdeckt. Die Zungenproben wiesen eine höhere Diversität auf.

Diese Studie zeichnet sich besonders durch die klinischen Proben aus, welche professionell und standardisiert entnommen wurden. Zudem wurden bisher keine Zungen- und Speichelproben von Kindern mit frühkindlicher Karies mit verschiedenem ECC-Status in Bezug auf die mikrobielle Zusammensetzung untersucht.

Für die Identifizierung der Bakterienarten wurde mithilfe von drei PCRs die V1/V2-Region vervielfältigt. Alternativ kann auch eine andere variable Region verwendet werden, z. B. die V5/V6-Region. Nach einer Studie von Szafranski aus 
dem Jahr 2015 wurden unter identischen Versuchsbedingungen mehr OTUs mit den V1/V2-Primern erhalten als mit den V5/V6-Primern. Darüber hinaus konnten mit den V1/V2-Primern deutlich mehr Arten identifiziert werden (Szafranski et al. 2015).

Der frühere Focus in der dentalen Forschung lag darin, eine kleine Gruppe des oralen Mikrobioms, sogenannte opportunistische Pathogene, zu untersuchen. Durch NGS (Next Generation Sequencing)-Technologien können mikrobielle Proben sehr genau analysiert werden. Es wird hier von Sequenziertiefe gesprochen, was nichts Anderes bedeutet als eine hochauflösende Darstellung der mikrobiellen Zusammensetzung. Die Hauptvorteile sind der hohe Durchlauf und die Tatsache, dass die spezifischen Taxa nicht zielgerichtet sein müssen. Des Weiteren hat NGS eine hohe Auflösung und Sequenziertiefe. Zudem kommen die verhältnismäßig geringen Kosten und gute Verfügbarkeit als weitere Vorteile der Methode hinzu (Zaura 2012).

16S rRNA-Analysen bergen jedoch immer einen Bias, da nur gesehen wird, welche Bakterien vorhanden sind oder es mal waren und nicht, wie die Aktivität ist. Bei der hier angewendeten Methode der Bakterienidentifizierung werden sowohl aktive als auch inaktive und tote Bakterien berücksichtigt. Um festzustellen, welche Bakterienarten wirklich aktiver geworden sind, ist eine Metatranskriptom-Analyse notwendig. Dadurch kann die Aktivität der Bakterien bestimmt werden.

Ein weiteres Problem der angewendeten Methode sind die drei hintereinander ablaufenden PCRs, da drei PCR-Schritte das Verhältnis verzerren können und auch die Fehlerrate dadurch erhöht wird. Viele PCR-Schritte können somit zu einem Bias führen. Das PCR-Programm sollte dahingehend verbessert werden, dass möglichst wenige Schritte durchgeführt werden müssen und nur eine PCR notwendig ist.

Ein großer Nachteil der Studie ist, dass die Verteilung der ECC-Typen sehr ungleichmäßig ist. Der ECC-Typ 1 ist siebenmal vorhanden, ECC-Typ 2 kommt 22-mal vor und ECC-Typ 3 nur einmal. Beim Vergleich der verschiedenen ECCTypen konnten keine deutlichen Tendenzen festgestellt werden. Es muss hierbei jedoch die inhomogene Zusammensetzung der untersuchten Kohorte beachtet werden. Da ECC-Typ 3 nur einmal vertreten war, lässt sich keine Aussage über mögliche mikrobielle Unterschiede zu den anderen ECC-Typen treffen. Auch Typ 1 und 2 kamen in deutlich unterschiedlicher Anzahl vor, sodass auch hier keine eindeutige Aussage getroffen werden kann. Es ist in Bezug auf ECC-Typ 1 und 2 anzunehmen, dass sich die Zusammensetzung der bakteriellen Vielfalt nicht erheblich voneinander unterscheidet. Dies kann aber in dieser Studie aufgrund 
der inhomogenen Zusammensetzung nicht eindeutig bestätigt werden. In dieser Hinsicht hat die Studie ihr Ziel verfehlt, potentielle Unterschiede zwischen den ECC-Gruppen herauszufinden. In Bezug auf das Alter konnten ebenfalls keine Tendenzen bei der bakteriellen Zusammensetzung festgestellt werden. Da aber auch die Altersverteilung inhomogen war, sollte an dieser Stelle keine Aussage über potenzielle altersabhängige Unterschiede getroffen werden. In Bezug auf das Geschlecht, bei welchem eine gleichmäßige Verteilung vorlag, wurden keine Unterschiede in der mikrobiellen Zusammensetzung sichtbar.

Es konnten für diese Studie keine gesunden Probanden als Vergleichsgruppe verwendet werden. Ein Grund dafür ist, dass die Proben in Vollnarkose entnommen wurden und bei gesunden Kindern keine vergleichbaren Versuchsbedingungen geschaffen werden können. Andererseits gibt es bereits viele Studien, in denen die mikrobielle Zusammensetzung bei gesunden Kindern und bei Kindern mit ECC verglichen wird. Je nachdem, wo die Probenentnahme erfolgte, zeigen die Studien verschiedene Ergebnisse. Proben, die direkt von den kariösen Zähnen (Plaque- und Dentinproben) entnommen wurden, zeigen eine andere mikrobielle Zusammensetzung als Zahnabstriche bei gesunden Kindern (Ling et al. 2010; Xu et al. 2014). Beim Vergleich von Speichelproben bei gesunden und an ECC erkrankten Kindern unterscheiden sich die Ergebnisse verschiedener Studien. Einige Studien zeigen keine Unterschiede in der mikrobiellen Zusammensetzung. Ling und sein Team fanden keine signifikanten Unterschiede zwischen kariesaktiven und kariesfreien Speichelproben (Ling et al. 2010). Nach einer Studie von Jiang und Kollegen konnte kein signifikanter Unterschied in der Diversität von Speichelproben bei Kindern mit und ohne ECC nachgewiesen werden (Jiang et al. 2016). Die Mehrzahl der Studien zeigt jedoch Unterschiede in den Speichelproben von Gesunden und Kranken. Bei gesunden Kindern wurden von Santigli und Kollegen die Stämme Firmicutes, Proteobacteria, Actinobacteria, Bacteroidetes und Fusobacteria am häufigsten gefunden (Santigli et al. 2017). Dieses Ergebnis deckt sich mit den Ergebnissen aus vielen anderen Studien, wo sowohl bei kariesfreien, als auch bei kariesaktiven Speichelproben die gleichen Stämme gefunden wurden. Unterschiede werden vor allem auf Gattungs- und Artebene sichtbar. Einige Studien fanden Veränderungen in der Anzahl an MS und Lactobacillus bei erkrankten Kindern heraus. Ledder und Kollegen fanden eine erhöhte Anzahl an Lactobacillus in Speichel- und in Plaqueproben (Ledder et al. 2018). In der Studie von Neves et al. wurden S. mutans und Lactobacillus spp. in den kariesaktiven Speichelproben vermehrt gefunden. Es konnten keine Unterschiede in Bezug auf die Candida-Spezies festgestellt werden (Neves et al. 2015). Viele Studien fanden in den kariesaktiven Speichelproben vermehrt mutans streptococci, 
Lactobacilli und darüber hinaus auch vermehrt Candida spp. (Hemadi et al. 2017). In einer weiteren Studie wurden die Gattungen Fusobacterium, Prevotella, Leptotrichia und Capnocytophaga mit Karies assoziiert, wobei die Anzahl an Fusobacterium, Leptotrichia und Capnocytophaga in den kariesaktiven Proben erhöht war, wohingegen Prevotella in geringerer Zahl vorkam (Zhu et al. 2018). Dzidic und Kollegen stellten Streptococcus cristatus als potentiellen Biomarker für ECC heraus (Dzidic et al. 2018). Hurley und Kollegen fanden die Gattungen Leptotrichia, Bifidobacterium, Corynebacterium, Alloprevotella, Cardiobacterium und Veillonella in signifikant höherer Menge in kariesfreien Speichelproben. Die kariesaktiven Speichelproben wurden von den Gattungen Neisseria, Porphyromonas, Streptococcus und Haemophilus dominiert, wohingegen die kariesfreien Speichelproben von Leptotrichia, Capnocytophaga, Neisseria, Haemophilus, Streptococcus und Porphyromonas dominiert wurden. Signifikante Unterschiede auf Artebene wurden bei Streptococcus mutans, Haemophilus parainfluenzae, Prevotella histolica, Leptotrichia buccalis, Veillonella dispar, Alloprevotella tannerae und Prevotella salivae gefunden, wobei Streptococcus mutans, Prevotella histicola und Veillonella dispar in den kariesaktiven Speichelproben häufiger vorkamen (Hurley et al. 2019).

In dieser Studie konnten 15 verschiedene Stämme, 27 Klassen, 50 Ordnungen, 95 Familien, 155 Gattungen und 150 verschiedene Arten identifiziert werden. In einer ähnlichen Studie von Jiang und Kollegen wurden Speichelproben von dreibis vierjährigen Kindern mit und ohne Karies untersucht. Dabei wurden 17 Stämme, 26 Klassen, 40 Ordnungen, 80 Familien, 151 Gattungen und 310 Arten entdeckt. Die Ergebnisse unterscheiden sich im Wesentlichen nur auf Artebene. Eine Erklärung dafür ist, dass Jiang und Kollegen bei ihrer Studie auf Artebene die 97\%ige Ähnlichkeit gewählt haben und in dieser Studie mit der 99\%igen Ähnlichkeit gearbeitet wurde. Jiang und Kollegen fanden keine signifikanten Unterschiede in der Diversität der Mikrobiome zwischen kariesfreien und Kindern mit Karies (Jiang et al. 2016). Ma und seine Mitarbeiter fanden in ihrer Studie mit 40 drei- und vierjährigen chinesischen Kindern insgesamt 379 verschiedene Arten. Es handelt sich dabei allerdings um Speichelproben und supragingivale Plaqueproben von gesunden Kindern und Kindern mit ECC (Ma et al. 2015).

$\mathrm{Zu}$ den vorherrschenden Stämmen, die in dieser Studie in großer Anzahl vertreten waren, gehören Firmicutes, Bacteroidetes, Proteobacteria, Actinobacteria und Fusobacteria. Andere Stämme, die nur in geringer Anzahl vorkamen, sind Spirochaetes, Saccheribacteria, Acidobacteria, SR1, Cynaobacteria, Verucomicrobia, Deinococcus-Thermes, Parulbacteria, Gemmatimonadetes und Tenericutes. Dieses Ergebnis deckt sich mit den Ergebnissen aus anderen Studien. Ling und sein Team fanden in ihrer Studie aus 
dem Jahr 2010 mit Speichel- und Plaqueproben von Kindern zwischen drei und sechs Jahren mit und ohne Karies acht Hauptstämme: Bacteroidetes, Firmicutes, Proteobacteria, Actinobacteria, Fusobacteria, Spirochaetes, TM7 und SR1 (Ling et al., 2010). Auch in vielen anderen Studien werden Firmicutes, Bacteroidetes, Proteobacteria, Actinobacteria und Fusobacteria als häufigste Stämme unabhängig von einem kariesaktiven oder kariesfreien Zustand der Kinder gefunden (Santigli et al. 2017; Hurley et al. 2019). Gattungen, die in dieser Studie am häufigsten vorkamen, waren Streptococcus, Prevotella, Granulicatella, Haemophilus und Leptotrichia. In einer anderen Studie wurden Neisseria, Streptococcus, Prevotella, Haemophilus und Rothia als häufigste Gattungen gefunden (Zhu et al. 2018). Hurley und Kollegen fanden als häufigste Gattungen Neisseria, Porphyromonas, Streptococcus und Haemophilus in den kariesaktiven Speichelproben (Hurley et al. 2019). Unterschiede fallen hier bei der Gattung Neisseria auf, welche in dieser Studie nicht zu den häufigsten Gattungen zählt, in den anderen Studien jedoch am häufigsten gefunden wurde. Die Arten, die insgesamt am häufigsten gefunden wurden, waren Gemella haemolysans, S. sobrinus, S. mutans, $H$. parainfluenza und Porphyromonas sp. Auch in anderen Studien gehörte unter anderen S. mutans zu den am häufigsten gefundenen Arten. Darüber hinaus wurden die Arten Prevotella histicola, Prevotella melaninogenica, Porphyromonas catoniae und Prevotella salivae am häufigsten in den kariesaktiven Speichelproben gefunden (Hurley et al. 2019).

Beim Vergleich der Proben von Zunge und Speichel miteinander lassen sich deutliche Unterschiede erkennen. Es gibt eine klare Gruppierung von sowohl Speichel- als auch Zungenproben. Dies entspricht den Ergebnissen einer anderen Studie, die zeigt, dass verschiedene orale Nischen bevorzugt von bestimmten Bakterienarten besiedelt werden. Es ist bekannt, dass sich orale Bakterienarten oftmals auf bestimmten Oberflächen in der Mundhöhle festsetzen. Dies kommt durch spezifische Adhäsine auf der bakteriellen Oberfläche, welche an komplementären spezifischen Rezeptoren an einer bestimmten Oberfläche binden können (Gibbons 1989). OTUs, die hier am häufigsten in den Zungenproben gefunden wurden, waren Rothia mucilaginosa, Haemophilus parainfluenzae und Prevotella pallens zuzuordnen. Im Gegensatz dazu wurden in den Speichelproben am häufigsten OTU8 (Bacteroidetes), Gemella haemolysans und Heamophilus sp. entdeckt. Die Zungenproben wiesen eine deutlich höhere Diversität auf. Simon-Soro und ihre Mitarbeiter fanden 2013 in einer Studie mit zwei gesunden erwachsenen Probanden heraus, dass Speichelund Zungenproben eine erheblich höhere Anzahl an OTUs enthielten als Zahnund Gingivasulkusproben. Des Weiteren enthielten die Speichelproben eine höhere Diversität im Vergleich zu Zahn- und Gingivalproben. Eine weitere 
Beobachtung war, dass es eine beachtliche Ähnlichkeit zwischen den Zungenproben und Proben mit stimuliertem Speichel gab (Simon-Soro et al. 2013). Diese Beobachtung konnte in dieser Studie nicht bestätigt werden, da hier die Zungen- und Speichelproben deutliche Unterschiede zeigten. Es ist allerdings zu bedenken, dass man bei den Kindern in Vollnarkose Ruhespeichel entnommen hat und sich Ruhespeichel und stimulierter Speichel ebenfalls unterscheiden können.

Insgesamt lässt sich herausstellen, dass diese Studie erstmalig einen Vergleich zwischen dem Zungen- und Speichelmikrobiom in Bezug auf die Zusammensetzung der mikrobiellen Gemeinschaft bei verschiedenen ECCTypen darstellt. Es konnten 150 verschiedene Arten identifiziert werden. Außerdem wurden deutliche Unterschiede in Bezug auf die Zusammensetzung der Zungen- und Speichelproben festgestellt. Eine unterschiedliche Zusammensetzung der mikrobiellen Flora konnte bei verschiedenen ECC-Typen aufgrund der inhomogenen Zusammensetzung der untersuchten Kohorte nicht nachgewiesen werden. Für zukünftige weiterführende Untersuchungen wären eine größere Anzahl an Probanden mit gleichmäßiger Verteilung der drei ECCTypen und mit gesunden Probanden als Vergleichsgruppe sinnvoll. Zudem könnte anhand einer Metatranskriptom-Analyse herausgefunden werden, welche Bakterienarten wirklich aktiv sind. 


\section{Zusammenfassung}

Frühkindliche Karies ist nach wie vor ein weltweites Problem, welches sowohl Kinder in Entwicklungsländern als auch Kinder in Industrienationen wie Deutschland betrifft. Es handelt sich um eine multifaktorielle Erkrankung, wobei die Hauptfaktoren Substrat, Wirt, Mikroorganismen und Zeit von Bedeutung sind. Eine wichtige Rolle spielen darüber hinaus auch persönliche Faktoren, wie z. B. die Mundhygiene und Essgewohnheiten sowie orale Umweltfaktoren, bei denen genetische Faktoren und Speicheleigenschaften zu nennen sind. Karies ist eine polymikrobielle Erkrankung, bei welcher zahlreiche verschiedene Mikroorganismen vorhanden sind. Auch im gesunden Zustand treten dieselben Mikroorganismen auf, jedoch in anderer Zusammensetzung.

Insgesamt wurden für diese Studie von 30 Kindern zwischen einem und sechs Jahren mit frühkindlicher Karies jeweils ein Zungenabstrich von der Zungenoberseite und eine Speichelprobe aus dem Sublingualraum entnommen. Aus diesen Proben wurde die DNA der Mikroorganismen extrahiert und die variable Region 1-2 der ribosomalen 16S rRNA amplifiziert und sequenziert (MiSeq, Illumina). Nach der bioinformatischen Datenreinigung blieben 913 OTUs, die für die weitere Analyse verwendet wurden. Im Folgenden wurden dann die OTUs gegen die Human Oral Microbiome Database (HOMD) abgeglichen. Als Kriterium für die Artbestimmung wurde hier die 99\%-ige Ähnlichkeit verwendet. Konnte eine Sequenz nicht eindeutig zugeordnet werden, wurde für die Zuordnung die nächsthöhere Ebene ausgewählt. Alle Sequenzen mit einer Zuordnungsgenauigkeit kleiner als 95 \% wurden erneut gegen die Ribosomal Database Classifier-Datenbank geblasted.

Von insgesamt 60 Proben hatten 57 Proben eine ausreichende Qualität, um weiter analysiert zu werden. Es konnten dabei 15 verschiedene Stämme, 27 Klassen, 50 Ordnungen, 95 Familien, 155 Gattungen und 150 verschiedene Arten identifiziert werden. Zu den vorherrschenden Stämmen, die in großer Anzahl vertreten waren, gehören Firmicutes, Bacteroidetes, Proteobacteria, Actinobacteria und Fusobacteria. Zu den Arten, die insgesamt am häufigsten detektiert wurden, gehören Gemella haemolysans, Streptococcus sobrinus und Streptococcus mutans.

Als Ergebnis dieser Untersuchung konnten beim Vergleich der Mikrobiome bei den verschiedenen ECC-Typen keine Unterschiede festgestellt werden. Die Ausgangshypothese, dass es potenzielle Unterschiede in der bakteriellen Zusammensetzung bei verschiedenen ECC-Typen gibt, konnte nicht bestätigt werden. Durch die inhomogene Zusammensetzung der untersuchten Kohorte war es in dieser Hinsicht nicht möglich, ein aussagekräftiges Ergebnis zu 
erhalten. In Bezug auf das Alter und Geschlecht der Kinder konnten ebenfalls keine eindeutigen Tendenzen in der bakteriellen Zusammensetzung festgestellt werden.

Deutliche Unterschiede ließen sich jedoch bei dem Vergleich der Mikrobiome der Zungen- und der Speichelproben erkennen, wobei die Zungenproben eine andere mikrobielle Zusammensetzung aufwiesen als die Speichelproben. Dieser Sachverhalt entspricht damit der anfänglich aufgestellten Vermutung, dass die Zungen- und die Speichelmikrobiome sich unterschiedlich bakteriell zusammensetzen. OTUs, die am häufigsten in den Zungenproben gefunden wurden, konnten Rothia mucilaginosa, Haemophilus parainfluenzae und Prevotella pallens zugeordnet werden. Im Gegensatz dazu konnten in den Speichelproben am häufigsten OTU8 (Bacteroidetes), Gemella haemolysans und Heamophilus sp. nachgewiesen werden. Dabei wiesen die Zungenproben eine höhere Diversität auf als die Speichelproben.

Im Rahmen dieser Arbeit wurde erstmalig die Zusammensetzung der mikrobiellen Gemeinschaft in Zungen- und Speichelproben bei verschiedenen ECC-Typen untersucht. Dabei konnten deutliche Unterschiede in Bezug auf die mikrobielle Zusammensetzung der Zungen- und Speichelproben festgestellt werden. Eine unterschiedliche Zusammensetzung der mikrobiellen Flora konnte bei den verschiedenen ECC-Typen jedoch aufgrund der inhomogenen Zusammensetzung der untersuchten Kohorte nicht nachgewiesen werden.

Für zukünftige weiterführende Untersuchungen wären eine größere Anzahl an Probanden mit gleichmäßiger Verteilung der drei ECC-Typen und ein Vergleich mit einer Kontrollgruppe (gesunde Probanden) zu empfehlen. 


\section{$6 \quad$ Anhang}
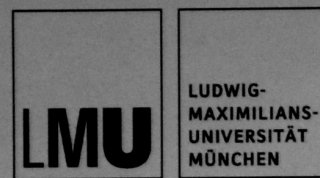
MONNCHEN

Ethikkommission ·Pettenkoferstr. $8 \cdot 80336$ München

Herrn

PD Dr. Jahn Kühnisch

Poliklinik für Kieferorthopädie

Goethestr. 70

80336 München

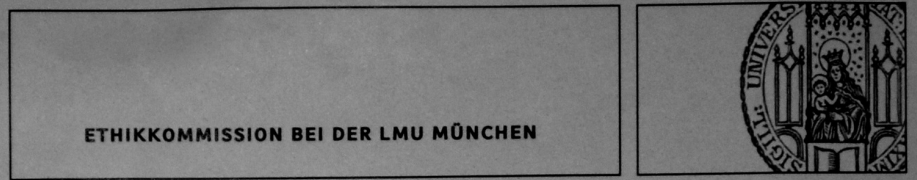

Vorsitzender: Prof. Dr. W. Eisenmenger Telefon+49 (0)89440055191 elefax $+49(0) 69440055192$ thikkommission@ med.uni-muenchen.de www.ethikkommission.med.un -muenchen de

Anschrift:

Pettenkoferstr. $8 \mathrm{a}$

D-80336 München

München, 15.12.2014 Hb/ck

Unser Zeichen: 554-14 (bitte bei Schriftwechsel angeben)

\section{Beratung nach geltendem Fakultätsrecht}

Titel: $\quad$ Analyse des Transkriptoms aus kavitierten, kariösen Läsionen unter besonderer Berücksichtigung der interakion zwischen Streptccoccus mutans und Candida albicans

Antragsteller: PD Dr. Jahn Kühnisch, Poliklinlik fìr Kieisrorthopädie, Goethestr. 70,80336 München

Sehr geehrter Herr Dr. Kühnisch,

die Ethikkommission hat lihren Antrag vom 08.12.2014 zur 0.g. Studie auf der Basis der vorgelegten Unterlagen und informationen geprüft.

Die Ethikkommission (EK) erhebt keine Einwände gegen das Forschungsprojekt /gegen die Durchführung der Studie. Allerdings bittet die EK darzulegen, dass sich das "Labor" in Braunschweig und nicht an der LMU befindet.

Bitte achten Sie darauf, dass in den geänderten Unterlagen alle Änderungen (Streichungen, Änderungen / Ergänzungen) optisch kenntlich gemacht werden. Bitte nutzen Sie nach Möglichkeit die in gängigen Textbearbeitungsprogrammen verfügbare Funktion, Änderungen nachverfolgen:

Allgemeine Hinweise:

- Änderungen im Verlauf der Studie sind der EK zur erneuten Prüfung vorzulegen.

- Schwerwiegende unerwartete Ereignisse im Rahmen der Studie sind der EK mitzuteilen.

- Das Ende der Studie ist anzuzeigen und das Ergebnis vorzulegen.

- Die ärztliche und juristische Verantwortung bei der Durchführung der Studie verbleibt uneingeschränkt bei Ihnen und Ihren Mitarbeitern.

Mit freundlichen Grüßen

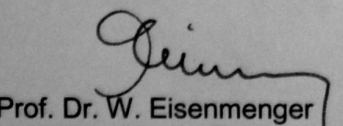

Vorsitzender der Ethikkommission 


\section{Literaturverzeichnis}

Aas JA, Paster BJ, Stokes LN, Olsen I., Dewhirst FE (2005): Defining the normal bacterial flora of the oral cavity. J Clin Microbiol $\underline{43}, 5721-5732$

Aas JA, Griffen AL, Dardis SR, Lee AM, Olsen I, Dewhirst FE, Leys EJ, Paster BJ (2008): Bacteria of dental caries in primary and permanent teeth in children and young adults. J Clin Microbiol $\underline{46}, 1407-1417$

Anderson M (2002): Risk assessment and epidemiology of dental caries: review of the literature. Pediatr Dent 24, 377-385

Arendorf TM, WALKER DM (1979): Oral candidal populations in health and disease. Br Dent J 147, 267-272

Axelsson P: Diagnosis and risk prediction of dental caries. Quintessence Pub Co, Chicago 2000

Berkowitz RJ (2003): Acquisition and transmission of mutans streptococci. J Calif Dent Assoc 31, 135-138

Bissar A, Schiller P, Wolff A, Niekusch U, Schulte AG (2014): Factors contributing to severe early childhood caries in south-west Germany. Clin Oral Investig. $\underline{18}, 1411-8$

Borutta A, Wagner M, Kneist S (2010): Early Childhood Caries: A Multi-Factorial Disease. OHDMBSC $\underline{9}, 32-38$

Bowden GH, Hardie JM, Slack GL (1975): Microbial variations in approximal dental plaque. Caries Res $\underline{9}$, 253-277

Buhl S, Wetzel WE, Bodeker RH (1989): Studies on the incidence of caries in 6to 48-month old infants. Dtsch Zahnarztl Z $\underline{44}$, 673-677

Camarinha-Silva A, Jauregui R, Chaves-Moreno D, Oxley AP, Schaumburg F, Becker K, Wos-Oxley ML, Pieper DH (2014): Comparing the anterior nare bacterial community of two discrete human populations using Illumina amplicon sequencing. Environ Microbiol 16, 2939-2952

Caufield PW, Childers NK, Allen DN, Hansen JB (1985): Distinct bacteriocin groups correlate with different groups of Streptococcus mutans plasmids. Infect Immun 48, 51-56

Caufield PW, Cutter GR, Dasanayake AP (1993): Initial acquisition of mutans streptococci by infants: evidence for a discrete window of infectivity. J Dent Res $\underline{72}, 37-45$

Caufield PW, Griffen AL (2000): Dental caries. An infectious and transmissible disease. Pediatr Clin North Am 47, 1001-1019

Colak H, Dulgergil CT, Dalli M, Hamidi MM (2013): Early childhood caries update: A review of causes, diagnoses, and treatments. J Nat Sci Biol Med $\underline{4}, 29-$ 38

DAJ (2016): Epidemiologische Begleituntersuchungen zur Gruppenprophylaxe. Deutsche Arbeitsgemeinschaft für Jugendzahnpflege e.V., Bonn 2016 
Davey AL, Rogers AH (1984): Multiple types of the bacterium Streptococcus mutans in the human mouth and their intra-family transmission. Arch Oral Biol $\underline{29}, 453-460$

DGZMK-Leitlinie 2013: Fluoridierungsmaßnahmen zur Kariesprophylaxe.

Dige I, Raarup MK, Nyengaard JR, Kilian M, Nyvad B (2009): Actinomyces naeslundii in initial dental biofilm formation. Microbiology $\underline{155}$, 2116-2126

Douglass JM, Tinanoff N, Tang JM, Altman DS (2001): Dental caries patterns and oral health behaviors in Arizona infants and toddlers. Community Dent Oral Epidemiol $\underline{29}$, 14-22

Duangthip D, Gao SS, Lo EC, Chu CH (2017): Early childhood caries among 5to 6-year-old children in Southeast Asia. Int Dent J 67, 98-106

Dulgergil CT, Soyman M, Civelek A (2005): Atraumatic restorative treatment with resin-modified glass ionomer material: short-term results of a pilot study. Med Princ Pract 14, 277-280

Dye BA, Hsu KL, Afful J (2015): Prevalence and measurement of dental caries in young children. Pediatr Dent 37, 200-2016

Dzidic M, Collado MC, Abrahamsson T, Artacho A, Stensson M, Jenmalm MC, Mira A (2018): Oral microbiome development during childhood: an ecological succession influenced by postnatal factors and associated with tooth decay. ISME J 12, 2292-2306

EAPD-Leitlinie 2008: Prevention of Early Childhood Caries: An EAPD Policy Document. o. Verf., Dublin 2008

EFSA (2005): European Food Safety Authority (EFSA). Opinion of the Panel on dietic products, nutrition and allergies (NDA) on a request from the Commission related to the tolerable upper intake level of fluoride. EFSA Journal 2005 192, 1-65

Ercan E, Dulgergil CT, Yildirim I, Dalli M (2007) Prevention of maternal bacterial transmission on children's dental-caries-development: 4-year results of a pilot study in a rural-child population. Arch Oral Biol $\underline{52}, 748-752$

Fakhruddin KS, Ngo HC, Samaranayake LP (2018): Cariogenic microbiome and microbiota of the early primary dentition: A contemporary overview. Oral Dis $\underline{25}, 982-995$

FDI (2015): The Challenge of Oral Disease - A call for global action. The Oral Health Atlas 2, 16-17

Featherstone JD (2000): The science and practice of caries prevention. J Am Dent Assoc 131, 887-899

Featherstone JD (2004): The continuum of dental caries--evidence for a dynamic disease process. J Dent Res, $\underline{83}, 39-42$

Fejerskov $O$ (2004): Changing paradigms in concepts on dental caries: consequences for oral health care. Caries Res $\underline{38}, 182-191$

Fox PC (2004): Salivary enhancement therapies. Caries Res $\underline{38}$, 241-246

Ghannoum MA, Jurevic RJ, Mukherjee PK, Cui F, Sikaroodi M, Naqvi A, Gillevet PM (2010): Characterization of the oral fungal microbiome (mycobiome) in healthy individuals. PLoS Pathog $\underline{6}$, e1000713 
Gibbons RJ (1989): Bacterial adhesion to oral tissues: a model for infectious diseases. J Dent Res $\underline{68}$, 750-760

Gomez A, Espinoza JL, Harkins DM, Leong P, Saffery R, Bockmann M, Torralba M, Kuelbs C, Kodukula R, Inman J (2017): Host Genetic Control of the Oral Microbiome in Health and Disease. Cell Host Microbe 22, 269-278

Grund K, Goddon I, Schüler IM, Lehmann T, Heinrich-Weltzien R (2015): Clinical consequences of untreated dental caries in German 5- and 8-year-olds. BMC Oral Health $\underline{15}, 140$

Hallett KB, O'Rourke PK (2002): Early childhood caries and infant feeding practice. Community Dent Health $\underline{19}$, 237-242

Hamada S, Slade HD (1980): Biology, immunology, and cariogenicity of Streptococcus mutans. Microbiol Rev $\underline{44}, 331-384$

Harel-Raviv M, Laskaris M, Chu KS (1996): Dental caries and sugar consumption into the 21st century. Am J Dent $\underline{9}, 184-190$

Harris R, Nicoll AD, Adair PM (2004): Risk factors for dental caries in young children: a systematic review of the literature. Community Dent Health $\underline{21}$, 71-85

Hassell TM, Harris EL (1995): Genetic influences in caries and periodontal diseases. Crit Rev Oral Biol Med $\underline{6}, 319-342$

Hausen H (1997): Caries prediction--state of the art. Community Dent Oral Epidemiol 25, 87-96

Hemadi AS, Huang R, Zhou Y, Zou J (2017): Salivary proteins and microbiota as biomarkers for early childhood caries risk assessment. Int J Oral Sci $\underline{9}$, e1

Holgerson P, Öhman C, Rönnlund A, Johansson I (2015): Maturation of Oral Microbiota in Children with or without Dental Caries. PLoS One $\underline{10}$, e0128534

Hu DY, Hong X, Li X (2011): Oral health in China - trends and challenges. Int J Oral Sci $\underline{3}, 7-12$

Hung WC, Tsai JC, Hsueh PR, Chia JS, Teng LJ (2005): Species identification of mutans streptococci by groESL gene sequence. J Med Microbiol $\underline{54}$, 857-862

Hurley E, Barrett MPJ, Kinirons M, Whelton H, Ryan CA, Stanton C, Harris HMB, O'Toole PW (2019): Comparison of the salivary and dentinal microbiome of children with severe-early childhood caries to the salivary microbiome of caries-free children. BMC Oral Health $\underline{19}, 13$

Jensen ME (1999): Diet and dental caries. Dent Clin North Am 43, 615-633

Jiang S, Gao X, Jin L, Lo EC (2016): Salivary Microbiome Diversity in CariesFree and Caries-Affected Children. Int J Mol Sci 17, 1978

Jose B, King NM (2003): Early childhood caries lesions in preschool children in Kerala, India. Pediatr Dent 25, 594-600

Kawamura Y, Hou XG, Sultana F, Miura H, Ezaki T (1995): Determination of $16 \mathrm{~S}$ rRNA sequences of Streptococcus mitis and Streptococcus gordonii and phylogenetic relationships among members of the genus Streptococcus. Int J Syst Bacteriol $\underline{45}$, 406-408 
Kellesarian SV, Malignaggi VR, De Freitas P, Ahmed HB, Javed F (2017) Association between prenatal maternal cigarette smoking and early childhood caries. A systematic review. J Clin Exp Dent $\underline{9}$, 1141-1146

Keyes $P$ (1962): Recent advances in dental caries research. IDJ 12, 443-464

Kidd EA, Fejerskov O (2004): What constitutes dental caries? Histopathology of carious enamel and dentin related to the action of cariogenic biofilms. J Dent Res, 83 Spec No C, 35-38

Kidd EA, Joyston-Bechal (1997): Essentials of dental caries: The disease and its management. Oxford University Press, New York 1997

Kim D, Sengupta A, Niepa TH, Lee BH, Weljie A, Freitas-Blanco VS, Murata RM, Stebe KJ, Lee D, Koo H (2017): Candida albicans stimulates Streptococcus mutans microcolony development via cross-kingdom biofilm-derived metabolites. Sci Rep ㄱ, 41332

Kindelan SA, Day P, Nichol R, Willmott N, Fayle SA, British Society Of Paediatric Dentistry (2008): UK National Clinical Guidelines in Paediatric Dentistry: stainless steel preformed crowns for primary molars. Int J Paediatr Dent 18, 20-28

Kiwanuka SN, Astrom AN, Trovik TA (2004): Dental caries experience and its relationship to social and behavioural factors among 3-5-year-old children in Uganda. Int J Paediatr Dent 14, 336-346

König K: Karies und Kariesprophylaxe. Wilhelm Goldmann Verlag, München 1971

Kramer MS, Kakuma R (2012): Optimal duration of exclusive breastfeeding. Cochrane Database Syst Rev $\underline{8}, \mathrm{CD} 003517$.

Krol DM (2003): Dental caries, oral health, and pediatricians. Curr Probl Pediatr Adolesc Health Care $\underline{33}$, 253-270

Kumaraswamy KL, Vidhya M (2011): Human papilloma virus and oral infections: an update. J Cancer Res Ther $\underline{7}, 120-127$

Ledder RG, Kampoo K, Teanpaisan R, McBain AJ (2018): Oral Microbiota in Severe Early Childhood Caries in Thai Children and Their Families: A Pilot Study. Front Microbiol $\underline{9}, 2420$

Leitlinie Prevention of Early Childhood Caries: An EAPD Policy Document s. EAPD-Leitlinie 2008.

Leitlinie Fluoridierungsmaßnahmen zur Kariesprophylaxe s. DGZMK-Leitlinie 2013

Lepp PW, Brinig MM, Ouverney CC, Palm K, Armitage GC, Relman DA (2004): Methanogenic Archaea and human periodontal disease. Proc Natl Acad Sci U S A $101,6176-6181$

Ling Z, Kong J, Jia P, Wei C, Wang Y, Pan Z, Huang W, Li L, Chen H, Xiang C (2010): Analysis of oral microbiota in children with dental caries by PCRDGGE and barcoded pyrosequencing. Microb Ecol 무, 677-690

Livny A, Assali R, Sgan-Cohen HD (2007): Early Childhood Caries among a Bedouin community residing in the eastern outskirts of Jerusalem. BMC Public Health $\underline{7}, 167$ 
Loesche WJ, Eklund S, Earnest R, Burt B (1984): Longitudinal investigation of bacteriology of human fissure decay: epidemiological studies in molars shortly after eruption. Infect Immun $\underline{46}, 765-772$

Loning T, Ikenberg H, Becker J, Gissmann L, Hoepfer I, Zur Hausen H (1985): Analysis of oral papillomas, leukoplakias, and invasive carcinomas for human papillomavirus type related DNA. J Invest Dermatol $\underline{84}, 417-420$

Luke GA, Gough H, Beeley JA, Geddes DA (1999): Human salivary sugar clearance after sugar rinses and intake of foodstuffs. Caries Res $\underline{33}, 123-$ 129

Ma C, Chen F, Zhang Y, Sun X, Tong P, Si Y, Zheng S (2015): Comparison of oral microbial profiles between children with severe early childhood caries and caries-free children using the human oral microbe identification microarray. PLoS One $\underline{10}$, e0122075

Mangla R, Kapur R, Dhindsa A, Madan M (2017): Prevalence and associated Risk Factors of Severe Early Childhood Caries in 12- to 36-month-old Children of Sirmaur District, Himashal Pradesh, India. Int J Clin Pediatr Dent 10, 183-187

Mantzourani M, Gilbert SC, Sulong HN, Sheehy EC, Tank S, Fenlon M, Beighton D (2009): The isolation of bifidobacteria from occlusal carious lesions in children and adults. Caries Res $\underline{43}, 308-313$

Marsh PD (1994): Microbial ecology of dental plaque and its significance in health and disease. Adv Dent Res $\underline{8}, 263-271$

Marsh PD (1999): Microbiologic aspects of dental plaque and dental caries. Dent Clin North Am $\underline{43}, 599-614$

Moore WJ (1983): The role of sugar in the aetiology of dental caries. 1. Sugar and the antiquity of dental caries. J Dent $\underline{11}, 189-190$

Matarazzo F, Ribeiro AC, Feres M, Faveri M, Mayer MP (2011): Diversity and quantitative analysis of Archaea in aggressive periodontitis and periodontally healthy subjects. J Clin Periodontol $\underline{38}$, 621-627

Meyer F, Karch A, Schlinkmann KM, Dreesman J, Horn J, Rübsamen N, Sudradjat H, Schubert R, Mikolajczyk R (2017): Sociodemographic determinants of spatial disparities in early childhood caries: An ecological analysis in Braunschweig, Germany. Community Dent Oral Epidemiol. $\underline{45}$, 442-448

Meyer-Lückel $H$, Paris S, Ekstrand KR: Karies. Wissenschaft und klinische Praxis. Georg Thieme Verlag, Stuttgart 2012

Micheelis W, Schiffner U: Vierte Deutsche Mundgesundheitsstudie (DMS IV). Deutscher Zahnärtze Verlag DÄV, Köln 2006

Milnes AR (1996): Description and epidemiology of nursing caries. J Public Health Dent $\underline{56}, 38-50$

Misra S, Tahmassebi JF, Brosnan M (2007): Early childhood caries--a review. Dent Update 34, 556-558, 561-562, 564 
Neves AB, Lobo LA, Pinto KC, Pires ES, Requejo M, Maia LC, Antonio AG (2015): Comparison between Clinical Aspects and Salivary Microbial Profile of Children with and without Early Childhood Caries: A Preliminary Study. J Clin Pediatr Dent 39, 209-14

Nurelhuda NM, Al-Haroni M, Trovik TA, Bakken V (2010): Caries experience and quantification of Streptococcus mutans and Streptococcus sobrinus in saliva of Sudanese schoolchildren. Caries Res 44, 402-407

Nyvad B (1993): Microbial colonization of human tooth surfaces. APMIS Suppl $\underline{32}, 1-45$

Nyvad B, Kilian M (1987): Microbiology of the early colonization of human enamel and root surfaces in vivo. Scand J Dent Res $\underline{95}, 369-380$

Nyvad B, Kilian M (1990): Comparison of the initial streptococcal microflora on dental enamel in caries-active and in caries-inactive individuals. Caries Res 24, 267-272

Nyvad B, Machiulskiene V, Baelum V (2003): Construct and predictive validity of clinical caries diagnostic criteria assessing lesion activity. J Dent Res $\underline{82}$, 117-122

Peressini S, Leake JL, Mayhall JT, Maar M, Trudeau R (2004): Prevalence of early childhood caries among First Nations children, District of Manitoulin, Ontario. Int J Paediatr Dent 14, 101-110

Peretz B, Bercovich R, Blumer S (2013): Using elements of hypnosis prior to or during pediatric dental treatment. Pediatr Dent $\underline{35}, 33-36$

Petersen PE (2009): Global policy for improvement of oral health in the 21st century--implications to oral health research of World Health Assembly 2007, World Health Organization. Community Dent Oral Epidemiol 37, 18

Rajab LD, Hamdan MA (2002): Early childhood caries and risk factors in Jordan. Community Dent Health $\underline{19}$, 224-229

Ramos-Gomez F, Crystal YO, Ng MW, Tinanoff N, Featherstone JD (2010): Caries risk assessment, prevention, and management in pediatric dental care. Gen Dent $\underline{58}, 505-519$

Ripa LW (1988): Nursing caries: a comprehensive review. Pediatr Dent $\underline{10}$, 268282

(RKI) Robert Koch-Institut (Hrsg.), Bundeszentrale für gesundheitliche Aufklärung (Hrsg): Erkennen- Bewerten- Handeln: Zur Gesundheit von Kindern und Jugendlichen in Deutschland. o. Verl., Berlin 2008

Rosenblatt A, Zarzar P (2002): The prevalence of early childhood caries in 12- to 36-month-old children in Recife, Brazil. ASDC J Dent Child 69, 319-324

Sansone C, Van Houte J, Joshipura K, Kent R, Margolis HC (1993): The association of mutans streptococci and non-mutans streptococci capable of acidogenesis at a low $\mathrm{pH}$ with dental caries on enamel and root surfaces. J Dent Res 므, 508-516

Santigli E, Koller M, Klug B (2017): Oral Biofilm Sampling for Microbiome Analysis in Healthy Children. J Vis Exp $\underline{130}$, e56320 
Schafer TE, Adair SM (2000): Prevention of dental disease. The role of the pediatrician. Pediatr Clin North Am 47, 1021-1042

Scheie AA, Petersen FC (2004): The Biofilm Concept: Consequences for Future Prophylaxis of Oral Diseases? Crit Rev Oral Biol Med 15, 4-12

Scott DA, Coulter WA, Lamey PJ (1997): Oral shedding of herpes simplex virus type 1: a review. J Oral Pathol Med 26, 441-447

Section On Pediatric Dentistry And Oral Health (2008): Preventive oral health intervention for pediatricians. Pediatrics $\underline{122}, 1387-1394$

Selwitz RH, Ismail AI, Pitts NB (2007): Dental caries. Lancet $\underline{369}$, 51-59

Sheiham A, Watt RG (2000): The common risk factor approach: a rational basis for promoting oral health. Community Dent Oral Epidemiol 28, 399-406

Simon-Soro A, Tomas I, Cabrera-Rubio R, Catalan MD, Nyvad B, Mira A (2013): Microbial geography of the oral cavity. J Dent Res $\underline{92}, 616-621$

Syed SA, Loesche WJ (1978): Bacteriology of human experimental gingivitis: effect of plaque age. Infect Immun 21, 821-829

Szafranski SP, Wos-Oxley ML, Vilchez-Vargas R, Jauregui R, Plumeier I, Klawonn F, Tomasch J, Meisinger C, Kuhnisch J, Sztajer H (2015): Highresolution taxonomic profiling of the subgingival microbiome for biomarker discovery and periodontitis diagnosis. Appl Environ Microbiol 81, 10471058

Szatko F, Wierzbicka M, Dybizbanska E, Struzycka I, Iwanicka-Frankowska E (2004): Oral health of Polish three-year-olds and mothers' oral healthrelated knowledge. Community Dent Health $\underline{21}$, 175-180

Takahashi N, Nyvad B (2008). Caries ecology revisited: microbial dynamics and the caries process. Caries Res $\underline{42}, 409-418$

Tang JM, Altman DS, Robertson DC, O'Sullivan DM, Douglass JM, Tinanoff N (1997): Dental caries prevalence and treatment levels in Arizona preschool children. Public Health Rep 112, 319-331

ten Cate JM, Featherstone DJ (1991): Mechanistic aspects of the interactions between fluoride and dental enamel. Crit Rev Oral Biol Med 2, 283-296

Thomas A, Mhambrey S, Chokshi K, Chokshi A, Jana S, Thakur S, Jose D, Bajpai G (2016): Association of Oral Candida albicans with Severe Early Childhood Caries - A Pilot Study. J Clin Diagn Res 10, 109-112

Tinanoff N, Douglass JM (2001): Clinical decision-making for caries management in primary teeth. J Dent Educ $\underline{65}, 1133-1142$

Tinanoff N, Baez RJ, Guillory CD, Donley KJ, Feldens CA, McGrath C, Phantumvanit P, Pitts NB, Seow WK, Sharkov N, Songpaisan Y (2019): Early childhood caries epidemiology, aetiology, risk assessment, societal burden, management, education, and policy: Global perspective. Int J Paediatr Dent 29, 238-248

Tsai Al, Chen CY, Li LA, Hsiang CL, Hsu KH (2006): Risk indicators for early childhood caries in Taiwan. Community Dent Oral Epidemiol 34, 437-445 
Vadiakas G (2008): Case definition, aetiology and risk assessment of early childhood caries (ECC): a revisited review. Eur Arch Paediatr Dent $\underline{9}, 114-$ 125

Vieira AR (2012): Genetics and caries: prospects. Braz Oral Res $\underline{26}$, 7-9

Wantland WW, Wantland EM, Remo JW, Winquist DL (1958): Studies on human mouth protozoa. J Dent Res $\underline{37}$, 949-950

Weinstein P, Domoto P, Koday M, Leroux B (1994): Results of a promising open trial to prevent baby bottle tooth decay: a fluoride varnish study. ASDC J Dent Child 61, 338-341

Wetzel WE (1981): Sweet tea caries: a new form of deciduous tooth caries in small children. Dtsch Zahnarztl Z $\underline{36}, 330-332$

World Health Organisation. Oral Health Surveys - Basic Methods. 4th edn. Geneva 1997

World Health Organisation (2003): Diet, nutrition and the prevention of chronic diseases. World Health Organ Tech Rep Ser $\underline{916}$, 1-149

Winn DM (2001): Tobacco use and oral disease. J Dent Educ $\underline{65}$, 306-312

Winter J, Bartsch B, Schütz C, Jablonski-Momeni A, Pieper K (2019): Implementation and evaluation of an interdisciplinary preventive program to prevent early childhood caries. Clin Oral Investig 23,187-197

Wyne AH (1999): Early childhood caries: nomenclature and case definition. Community Dent Oral Epidemiol 27, 313-315

Ximenez-Fyvie LA, Haffajee AD, Socransky SS (2000): Microbial composition of supra- and subgingival plaque in subjects with adult periodontitis. J Clin Periodontol 27, 722-732

Xu H, Hao W, Zhou Q, Wang W, Xia Z, Liu C, Chen X, Qin M, Chen F (2014): Plaque bacterial microbiome diversity in children younger than 30 months with or without caries prior to eruption of second primary molars. PLoS One $\underline{9}$, e89269

Yang F, Zeng X, Ning K, Liu KL, Lo CC, Wang W, Chen J, Wang D, Huang R, Chang $X$ (2012): Saliva microbiomes distinguish caries-active from healthy human populations. ISME J $\underline{6}, 1-10$

Zaura E (2012): Next-generation sequencing approaches to understanding the oral microbiome. Adv Dent Res $\underline{24}$, 81-85

Zeng X, Luo Y, Du M, Bedi R (2005): Dental caries experience of preschool children from different ethnic groups in Guangxi Province in China. Oral Health Prev Dent $\underline{3}, 25-31$

Zero DT (2004): Sugars - the arch criminal? Caries Res $\underline{38}, 277-285$

Zhu C, Yuan C, Ao S, Shi X, Chen F, Sun X, Zheng (2018): The Predictive Potentiality of Salivary Microbiome for the Recurrence of Early Childhood Caries. Front Cell Infect Microbiol $\underline{8}, 423$ 


\section{Danksagung}

Mein Dank geht in erster Linie an meinen Doktorvater Herrn Prof. Dr. med. Nicolai Miosge und an meine Ko-Betreuerin Frau Prof. Dr. med. dent. Anette Wiegand für die Unterstützung bei der Erstellung meiner Arbeit.

Darüber hinaus möchte ich Frau Prof. Dr. Irene Wagner-Döbler vom HelmholtzZentrum für Infektionsforschung in Braunschweig für die Möglichkeit danken, am $\mathrm{HZI}$ meine Arbeit beginnen zu dürfen. Ein besonderer Dank gilt dabei auch Frederic Meyer vom HZI für die Einarbeitung in die Methodik und die fachliche Unterstützung.

Zum Schluss möchte ich Herrn Prof. Dr. med. dent. Jan Kühnisch für die Entnahme und Bereitstellung der Proben danken. 


\section{Lebenslauf}

Am 25.09.1991 wurde ich in Braunschweig als Tochter der Realschullehrerin Astrid Landrath (geb. Leitow) und des Elektroingenieurs Prof. Dr.-Ing. Joachim Landrath geboren. Ich wuchs zusammen mit meinen beiden jüngeren Geschwistern Alexandra und Oliver in Braunschweig auf.

Im Jahr 1998 wurde ich an der Grundschule Edith Stein in Braunschweig eingeschult und besuchte diese bis zum Jahr 2002. Für die folgenden zwei Jahre (2002-2004) besuchte ich die Orientierungsstufe Leonhardstraße in Braunschweig. Ab dem Jahr 2004 war ich Schülerin des Wilhelm-Gymnasiums in Braunschweig. Im Jahr 2011 bestand ich das Abitur.

Mit dem Sommersemester 2012 begann ich das Studium der Zahnmedizin an der Georg-August-Universität Göttingen. Im September 2014 legte ich die Prüfungen zum 1. Staatsexamen ab.

Am 17.11.2017 bestand ich das Zahnärztliche Staatsexamen.

Seit Januar 2018 arbeite ich als Vorbereitungsassistentin in einer Zahnarztpraxis in Braunschweig. 